\title{
Modeling and Simulation of a Satellite Training Kit for Providing Space Systems Engineering Knowledge and Technological Development in STEAM
}

\author{
By \\ Tanjidul Islam Sanvi -16321001 \\ Md. Shoaib Islam -13321052 \\ Md. Jahid Hashan Talukder -16321005 \\ Md. Khairul Bashar Bhuiyan -16121046
}

A Thesis Submitted to the Department of Electrical and Electronic Engineering in partial fulfillment of the requirements for the degree of Bachelor of Science in Electrical and Electronic Engineering

Electrical and Electronic Engineering

BRAC University

January 2021

(C) 2021. Brac University

All rights reserved. 


\section{DECLARATION}

We hereby declare that research work titled "Modeling and Simulation of a Satellite Training Kit for Providing Space Systems Engineering Knowledge and Technological Development in STEAM" is our work. The thesis does not contain material that has been accepted or submitted, for any other degree or diploma at a university or other institution.

Signature of Supervisor

Dr. A. K. M. Abdul Malek Azad
Signature of Authors

Tanjidul Islam Sanvi

Md. Shoaib Islam

Md. Jahid Hashan Talukder

Md. Khairul Bashar Bhuiyan 


\title{
Approval
}

The thesis/project titled "Modeling and Simulation of a Satellite Training Kit for Providing Space Systems Engineering Knowledge and Technological Development in STEAM" submitted by

1.Tanjidul Islam Sanvi

16321001

2.Md. Shoaib Islam

13321052

3.Md. Jahid Hashan Talukder

16321005

4.Md. Khairul Bashar Bhuiyan

16121046

of Fall, 2020 has been accepted as satisfactory in partial fulfillment of the requirement for the degree of Bachelor of Science in Electrical \& Electronic Engineering and Bachelor of Science in Electrical \& Electronic Engineering on $13^{\text {th }}$ January 2021.

\section{Examining Committee:}

Supervisor:

(Member)

A.K.M Abdul Malek Azad, PhD

Professor, Department of Electrical and Electronic

Engineering

Brac University

Program Coordinator:

(Member)

\author{
Dr. Abu S.M. Mohsin \\ Assistant Professor, Department of \\ Electrical and Electronic Engineering \\ Brac University
}

Departmental Head:

(Chair)

Md. Mosaddequr Rahman, PhD

Professor, Department of Electrical and Electronic

Engineering

Brac University 


\section{ACKNOWLEDGEMENTS}

We are very grateful to our supervisor, Dr. A K M Abdul Malek Azad, Professor, Department of Electrical and Electronic Engineering (EEE), BRAC University for enabling us to work on an interesting topic. He has allowed us to explore the subject of our thesis by putting himself in the background and we could not have asked for more. We would also like to thank our co-supervisor, Raihana Shams Islam Antara, for helping us make this whole experience of the thesis relatively simpler and enjoyable and providing us with her precious time. We would also like to thank our friends whose support has kept us and every member of our team moving forward for having the dedication to work until the very end. 


\begin{abstract}
Aerospace Engineering is a flourishing branch of modern engineering nowadays. To introduce the topic to the students, many space programs have been taken lately at the graduate and post-graduate levels. As a result, space technological knowledge and research has been limited to graduate and doctorate students. However, undergraduate, college, and school students do not get proper access to space-related knowledge. Again, as big satellites are costly and too complex, nowadays small satellites are very popular for educational and technology demonstration purposes. However, for school and college students, it is very hard to understand the system and functions of small satellites due to the limitation of space system knowledge. Generally, there are few satellite training kits are available in the international market which is very much expensive. The complete simulator of such a satellite training kit with a proper curriculum guide can eradicate the limitation of the availability of space education and keep growing interest among the students about satellite technology. In this thesis project, a systematic architecture has been proposed that can provide the students with space systems engineering experience through simulation, assembly, integration, and operation of a satellite training kit. The whole architecture has four parts - 1) Simulation, 2) Mechanical, 3) Electrical, and 4) Software. In this thesis, to prove our whole concept we will complete the mechanical and electrical simulations of the satellite training kit.
\end{abstract}




\section{Table of Contents}

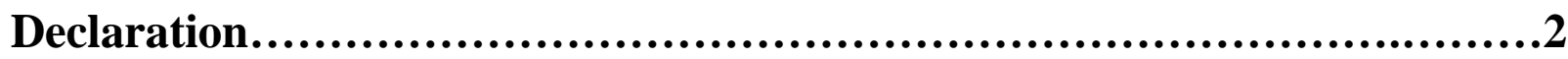

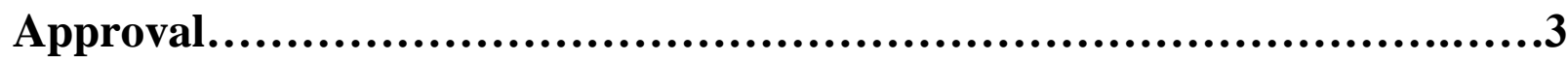

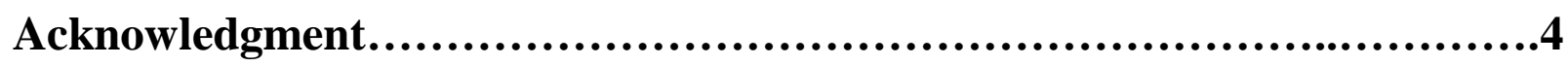

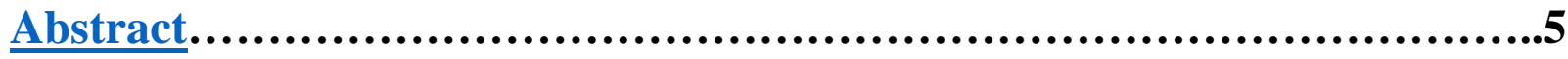

Table of Contents ......................................................................................................6

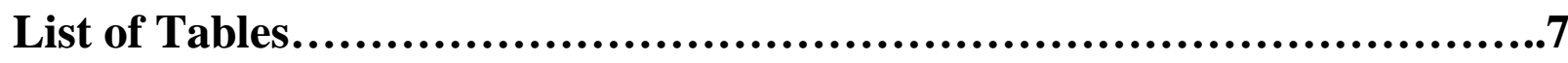

Table of Figures..................................................................8

List of Acronyms...........................................................9

1. Introduction

1.1Satellite Era of Bangladesh............................................... 12

1.2 Satellite Education Material............................................... 12

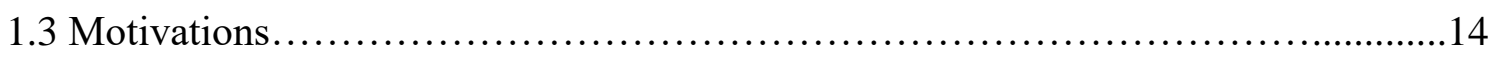

2. Overview of the Training kit

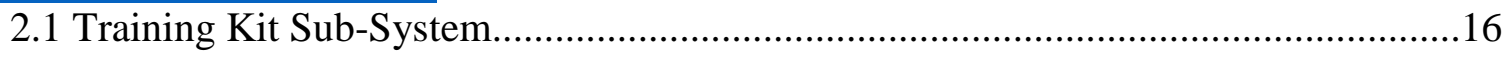

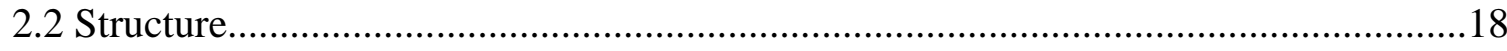

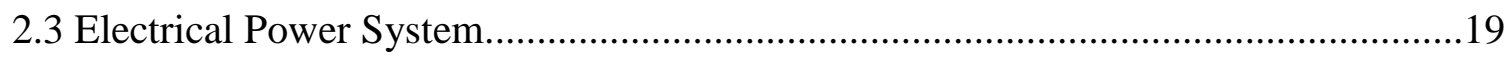

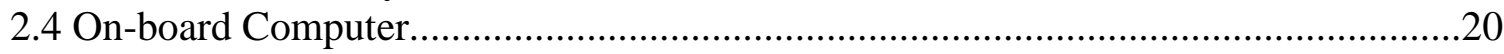

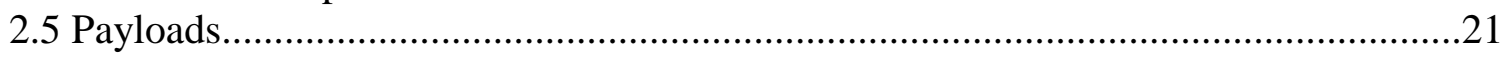

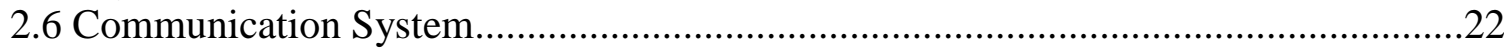

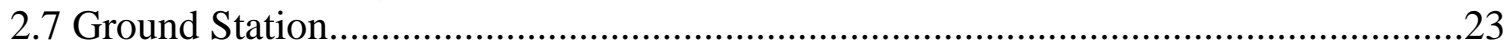

3.Mechanical Model and Electrical Simulation

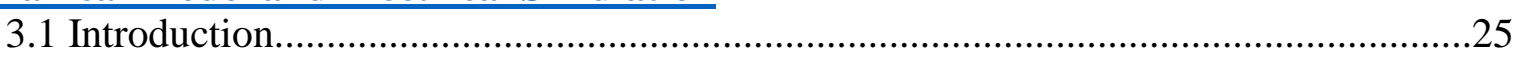

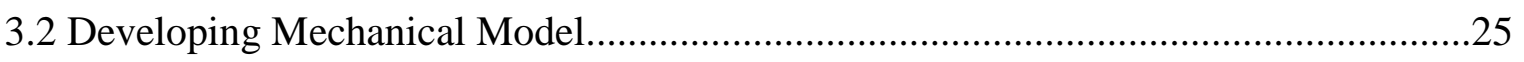

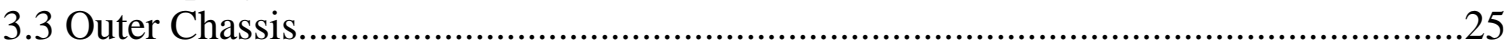

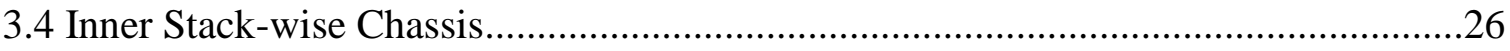

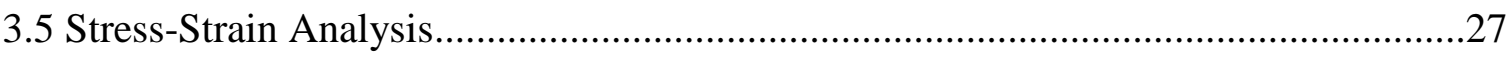




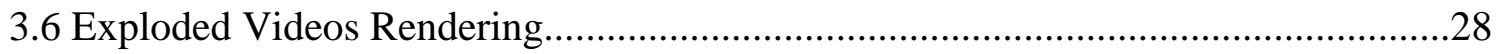

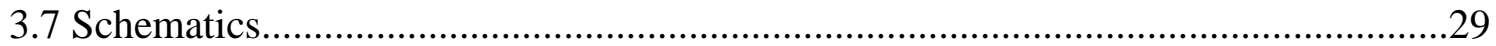

4. Design and Assemble of the Training kit

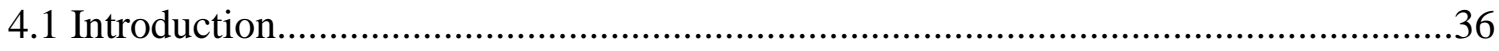

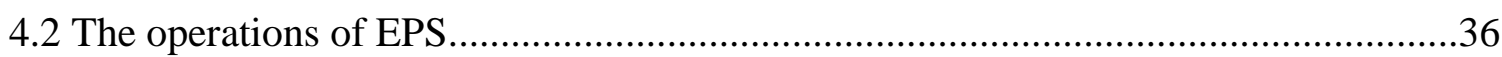

4.2.1 Connection Diagram of EPS..........................................................................

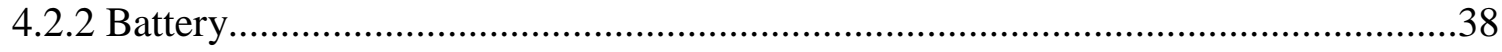

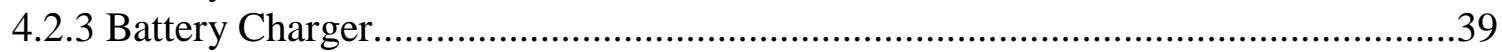

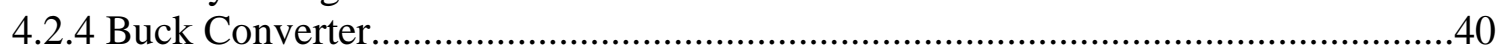

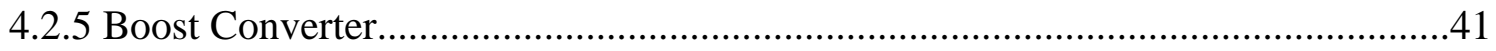

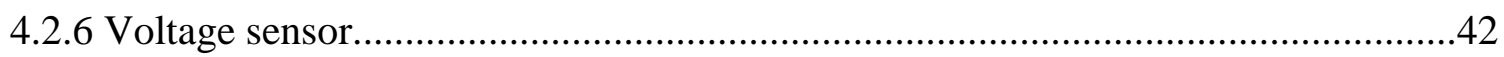

4.2.7 Power Requirements of Component...................................................................43

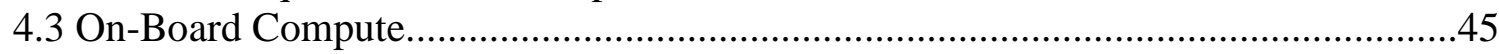

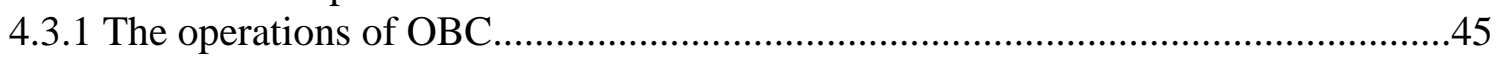

4.3.2 Block Diagram and sensor calibration...............................................................

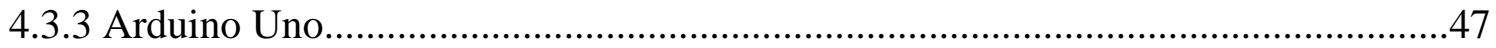

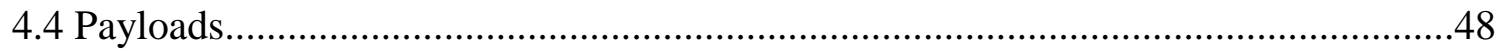

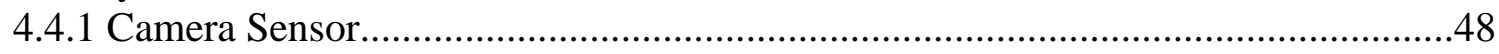

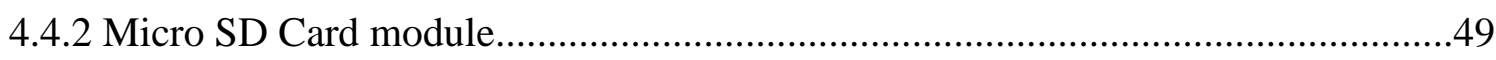

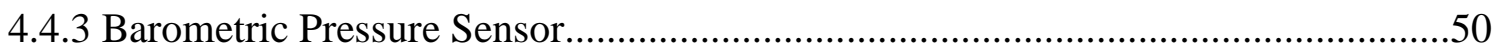

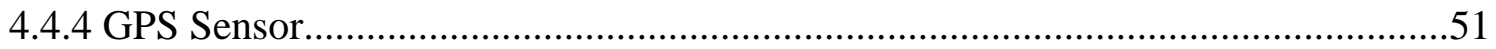

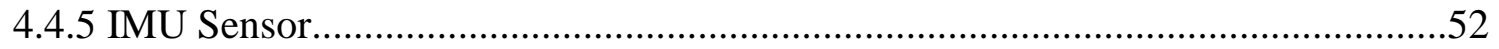

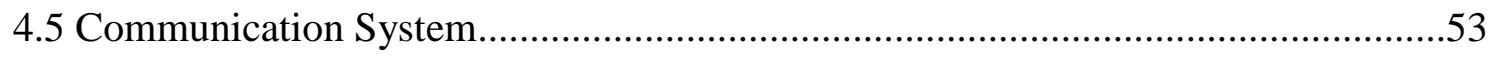

4.5.1. The operations of Communication System......................................................54

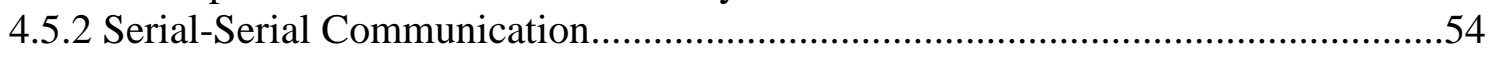

4.5.3 Choosing components for Communication System................................................55

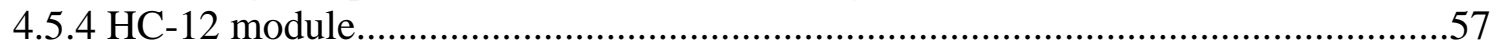

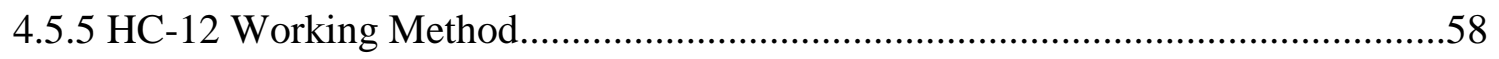

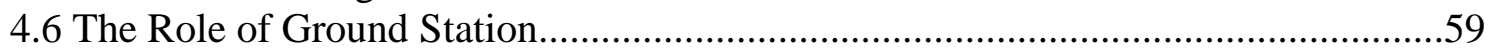

5. Field test of satellite training kit

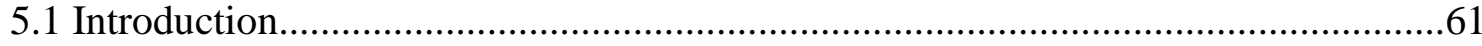

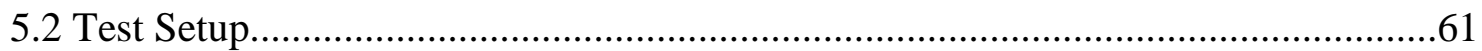

5.3 Field test for short-range.................................................................................61

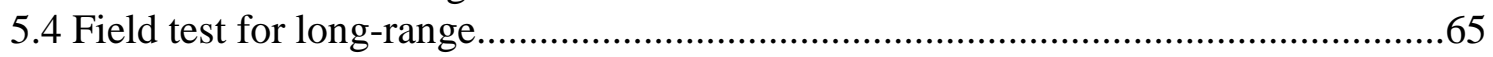

6. Conclusion

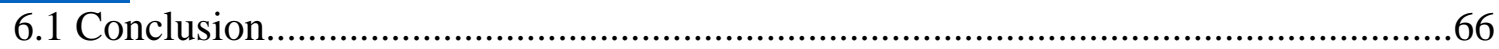

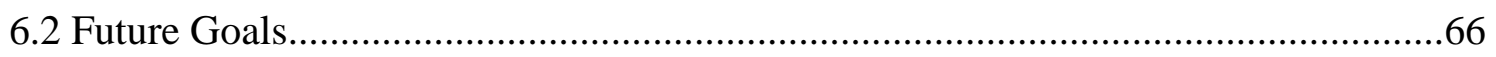

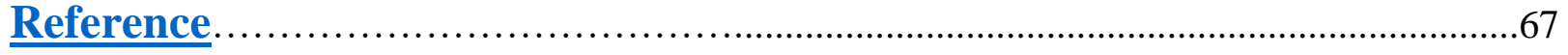

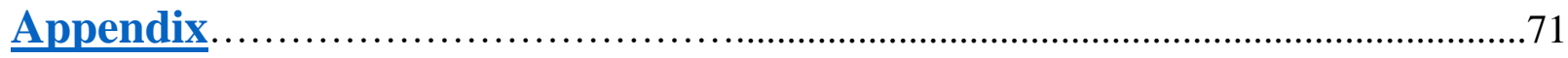

\section{List of Tables}

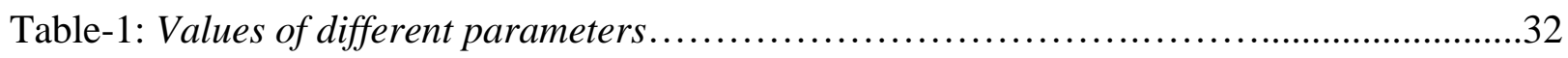

Table-2: The power requirements of components ........................................... 43 


\section{List of Figures}

Fig. 1.1 Statistics of Cube-Sat owners................................................................................ 13

Fig. 1.2 Price of different Satellite Training Kit.......................................................................... 14

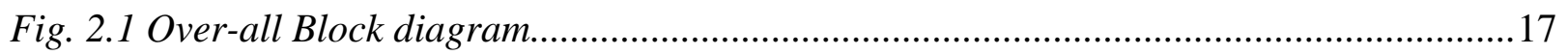

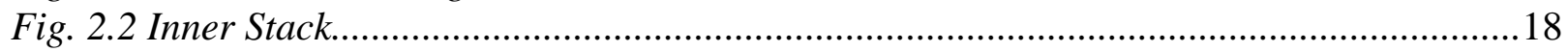

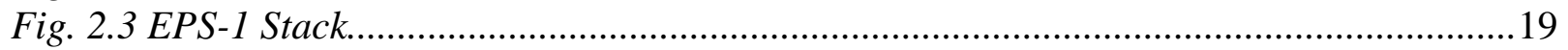

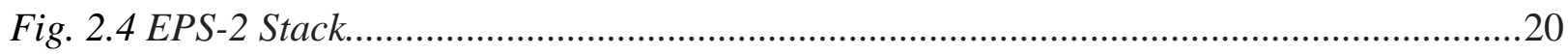

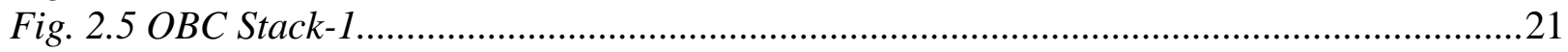

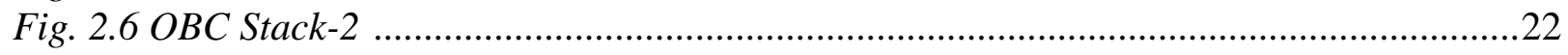

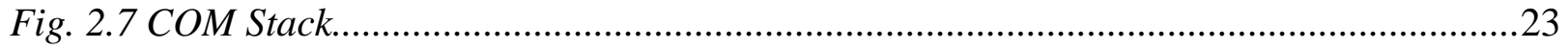

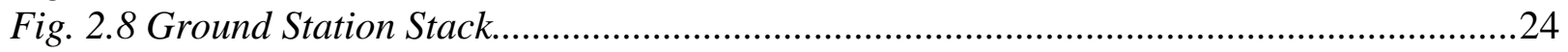

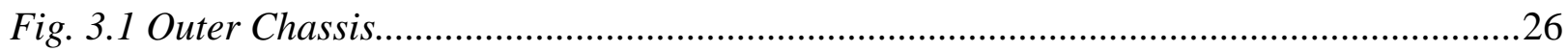

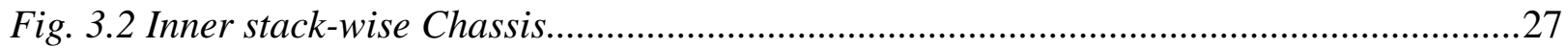

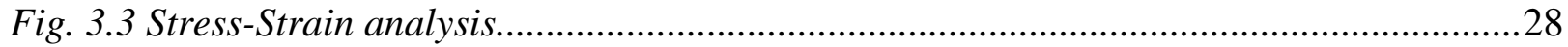

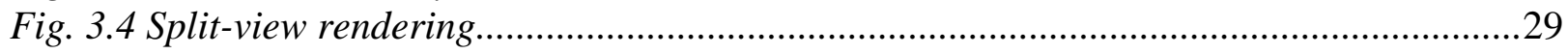

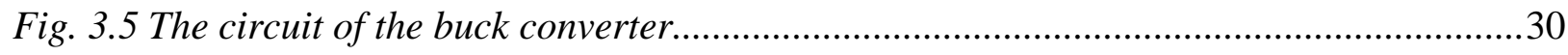

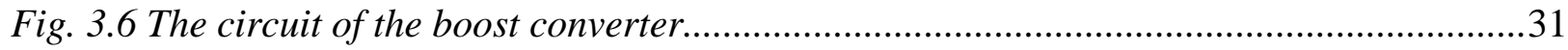

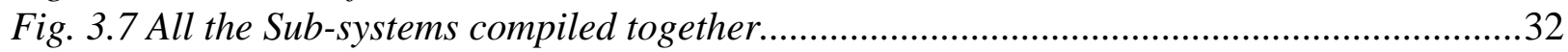

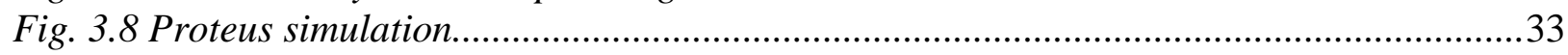

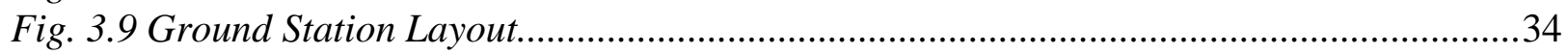

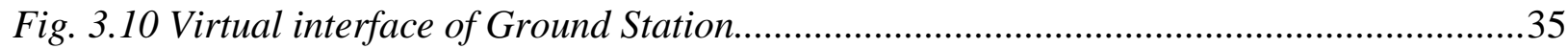

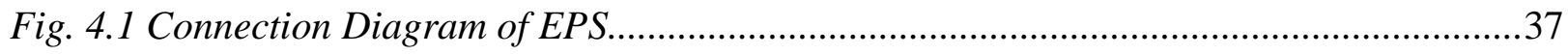

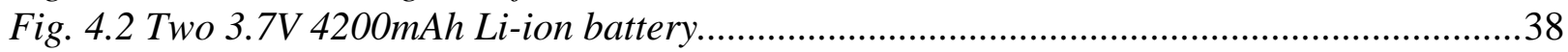

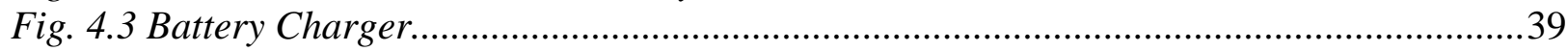


Fig. 4.4 LM2596 Buck converter .................................................................................40

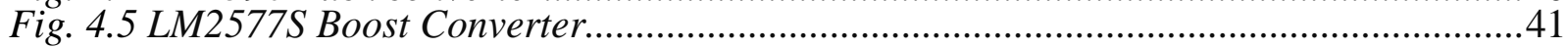

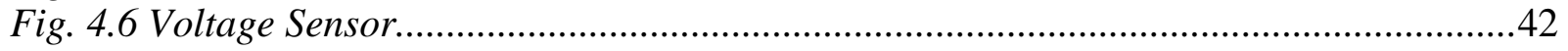

Fig. 4.7 Block Diagram of the On-Board Computer system...............................................46

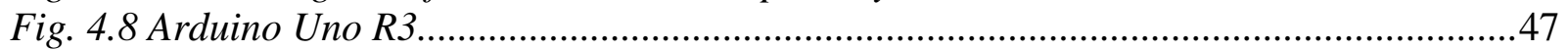

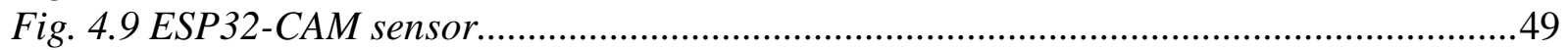

Fig. 4.10 Micro SD Card module .....................................................................................50

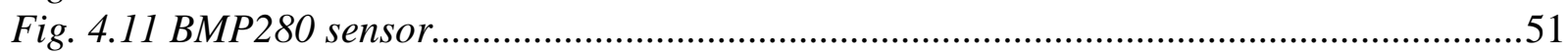

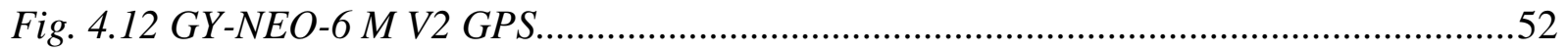

Fig. 4.13 IMU Sensor Module .......................................................................................5

Fig. 4.14 Block diagram of the Communication System......................................................55

Fig. 4.15 Zigbee Board......................................................................................................56

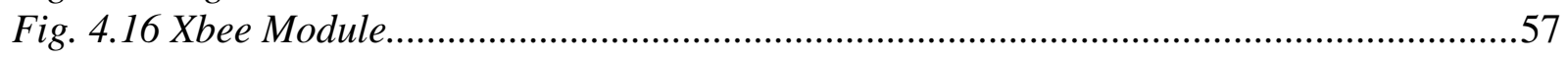

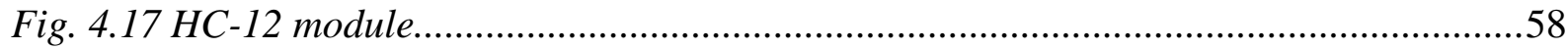

Fig. 4.18 HC12 wireless Serial port communication module...............................................59

Fig. 5.1 Field test result for short-range .........................................................................62

Fig. 5.2 IMU Sensor Data.........................................................................................62

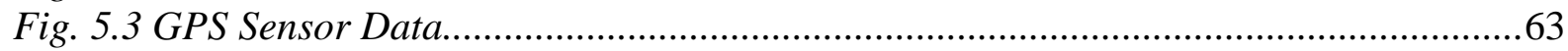

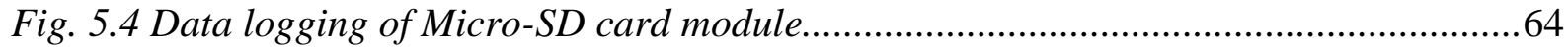

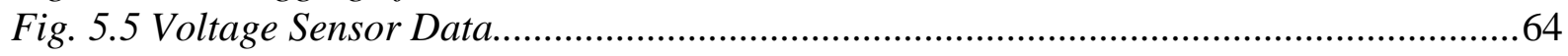

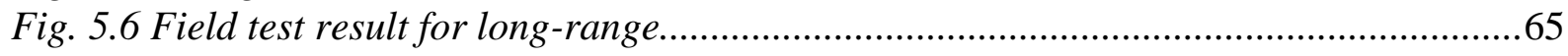




\section{List of Acronyms}

STEAM= Science, Technology, Engineering, Agriculture, and Mathematics EPS = Electrical Power System

OBC $=$ On-Board Computer

$\mathrm{COM}=$ Communication

GS $=$ Ground Station

UART $=$ Universal asynchronous receiver-transmitter

IMU = Inertial measurement unit

GPS $=$ Global Positioning System

HEPTA =Hands-on Education Program for Technical Advancement

SPI $=$ Serial Peripheral Interface

I2C= Inter-Integrated Circuit

PWM=Pulse Width Modulation

$\mathrm{ADC}=$ Analog-to-digital converter

$\mathrm{DAC}=$ Digital-to-analog converter

SMPS $=$ Switched-mode power supply

DC=Direct Current

MOSFET $=$ The metal-oxide-semiconductor field-effect transistor

EEPROM= Electrically erasable programmable read-only memory

ICSP $=$ In-system programming

SDHC $=$ Standard-capacity SD cards

SRAM $=$ Static random-access memory

MCU $=$ Microcontroller

ROM= Read-only memory

$\mathrm{MHz}=$ megahertz

$\mathrm{KHz}=$ kilohertz

$\mathrm{mHz}=$ miliherz

$\mathrm{mH}=$ mili Henry

$\mathrm{uF}=$ Micro Farad

$\mathrm{mW}=$ mili Watt

$\mathrm{mA}=$ mili Ampere

GND $=$ Ground

$\mathrm{RF}=$ Radio Frequency

$\mathrm{cm}=$ centi-Meter

$\mathrm{mm}=$ mili-Meter

USA=United States of America 


\section{Chapter 01}

\section{Introduction}

Aerospace Engineering knowledge is very limited and costly around the world. Space innovation and admittance to space have been slippery for developing nations in the course of the last fifty years, attributable to the absence of consciousness of strategy/chiefs about the job of room innovation in public turn of events. Space innovation was viewed as pricey and esteemed, implied uniquely for the major industrialized nations. The space knowledge has been limited to developed countries like the USA, Russia, UK, France etc. for decades. They have plenty of resources to invest in such ludicrous projects as space. For instance, Russia (then the Soviet Union) and the USA have been conducting space-research since late-70. They have been a pioneer for spacerelated research. They have kept the space technology sacred among themselves. On the contrary, the non-industrial developing nations were emphasizing building their public economy and giving food, cover and other social conveniences for their consistently developing populaces. They had hardly any spare resources to invest in such costly projects like space. As space-related knowledge is scarce, third-world countries could never get access to knowledge. For example, Bangladesh is mainly a developing agricultural country, therefore we never focused on aerospace engineering. In a developing country like Bangladesh, it is very unlikely to see any involvement in satelliterelated projects. In the most recent decade, the pattern has changed, with many non-industrial nations including Bangladesh holding onto space innovation as one of the significant methods of accomplishing practical turn of events. 


\subsection{Satellites Era of Bangladesh}

Our country used to depend on the satellites of Malaysia and Indonesia for telecommunication [1]. Besides, we used the Indian satellites for watching over the weather forecasting. However, the situation has changed at present. As a developing country, sending the artificial satellite into space brings prestige to Bangladesh on the world stage. Bangladesh is the 57 th country in the world to a satellite enters orbit [2]. Our country has two satellites al-together. The first-ever satellite of Bangladesh was BRAC Onnesha, a nanosatellite (CubeSat) [3]. It was launched from NASA's Kenedy Space Center by SpaceX on June 3, 2017, on a Falcon 9[3]. It was part of a program, backed by Japan, called The Joint Global Multi-Nation Birds Satellite Project (BIRDS) [3]. Hence, BRAC University is the first educational institution in Bangladesh to have its very own nanosatellite out there in space. This satellite completes one orbit once every 90 minutes and travels four to six times a day. Most notably, seven ground stations are a complete aid in monitoring the satellite without using any GPS. The second is the first geostationary communications satellite for Bangladesh, Bangabandhu Satellite-1[1]. Launched by a SpaceX Falcon 9 (Block 5 rocket) from Kenedy Space Center on May 11, 2018. It contributes to boosting our country's economy by providing all citizens with a wide range of uninterrupted telecommunications services such as direct-to-home TV, radio, telemedicine, education and internet access [2]. It was expected that Bangladesh will not only save much money in the future but will also earn profit by leasing the unused bandwidth to other countries [1]. For instance, the Philippines government is negotiating to rent out USD 1.5 million for $\mathrm{C}$ band bandwidth per month to the Philippines along with USD 1.0 million KU band per month. Nepal has also shown interest to use our satellite recently [1]. BRAC Onnesha and Bangabandhu Satellite-1 have brought our nation to the global innovation and growth stage [1]. Also, the success of these two satellites has inspired the nation to invest in satellite-related projects.

\subsection{Satellite Education Material}

Previously we mentioned the availability of the satellite training kit currently in the world. In this segment, and shortly compared the total price of some popular satellite training kit. For example, HEPTA-Sat is now used as a training kit for a wide circle of people who want to learn about space engineering and technology [4]. This kit has been a role model for others to make them enthusiastic about space technology. Generally, the weight of a nanosatellite or Nano-sat varies from $1 \mathrm{~kg}$ and $10 \mathrm{~kg}$ [5]. The Nano-sat has nearly all of the features including miniaturized components and subsystems of a standard satellite. Many developing countries concentrate mainly on making a powerful and low-cost nanosatellite that enables people to gather knowledge about space engineering within a short time. As of January 2020, more than 1200 nano-satellite was launched. 
And over 1100 were successfully deployed in orbit and over 80 were lost in launch failures. With 548 CubeSat, Japan is second with 23, and China is third with 18. In terms of the countries with the most CubeSat, the United States of America significantly leading the way. Then UK (11), Denmark (11), India (4) are following up on these [6]. The countries with the most CubeSat in space are shown in Fig. 1.1.

\section{Cubesatownership}

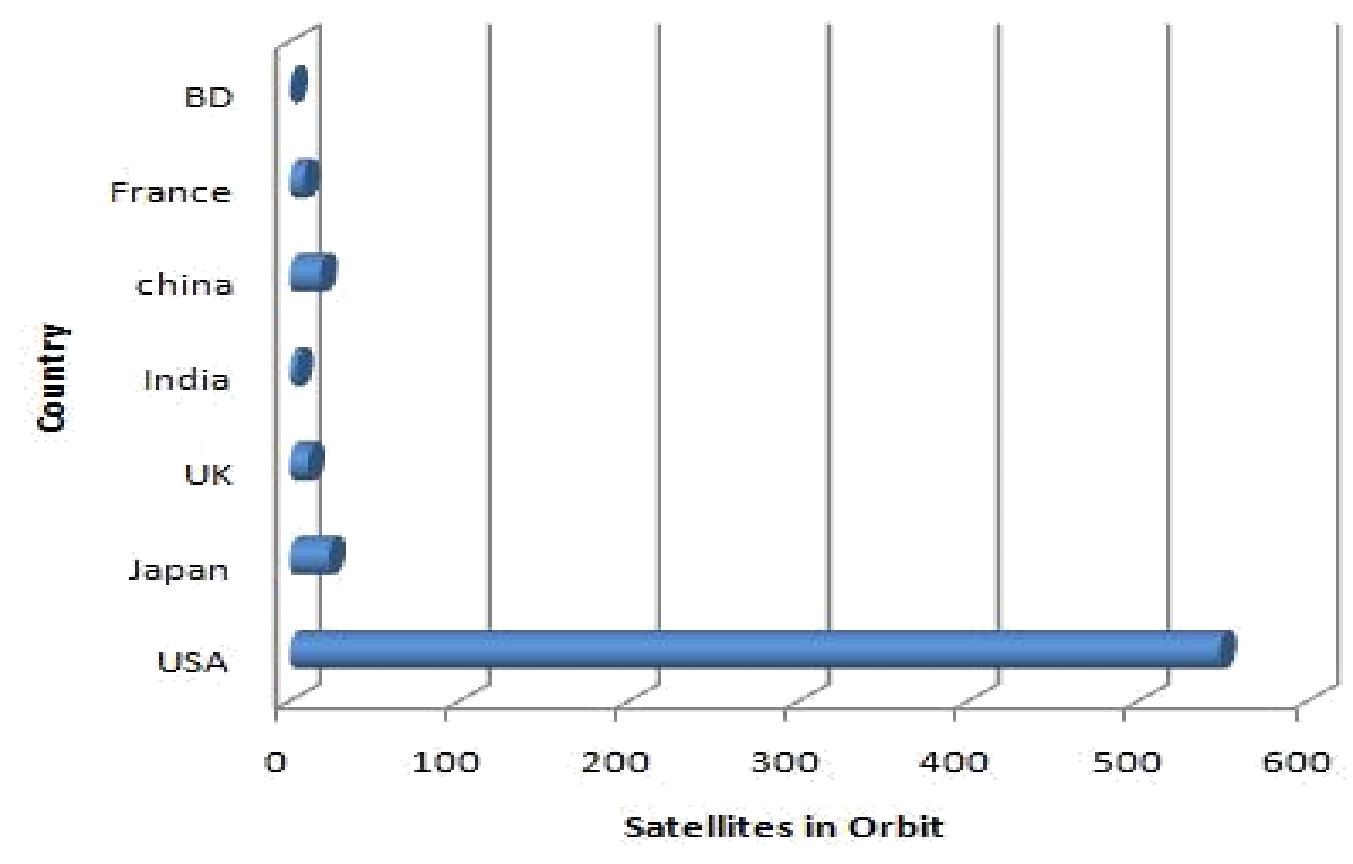

Fig. 1.1 Statistics of Cube-Sat owners

Nowadays, people are more interested in making small satellites. For example, the CubeSat kit is the cheapest standard technical satellite training kit on the planet. Previously, the CubeSat 1.0 was the cheapest satellite training kit around. However, the new CubeSat 2.0 satellite training package is simpler to develop and more advanced compared to CubeSat 1.0[7]. Every CubeSat is $0.75 \mathrm{~kg}$ that costs $\$ 6.200$ per unit [7]. EyasSat is known to be one of the most popular satellite training kits in the world [1]. It is a complete functional nanosatellite intended to teach in-class and laboratory in spacecraft systems engineering [8]. It was established in collaboration between the U.S. Air Force Academy and Colorado Satellite Services. The price of an EyasSat satellite classroom is $\$ 11500$ [9]. Besides, there are some other satellite trailing kits prices of which are given below in Fig 1.2. 


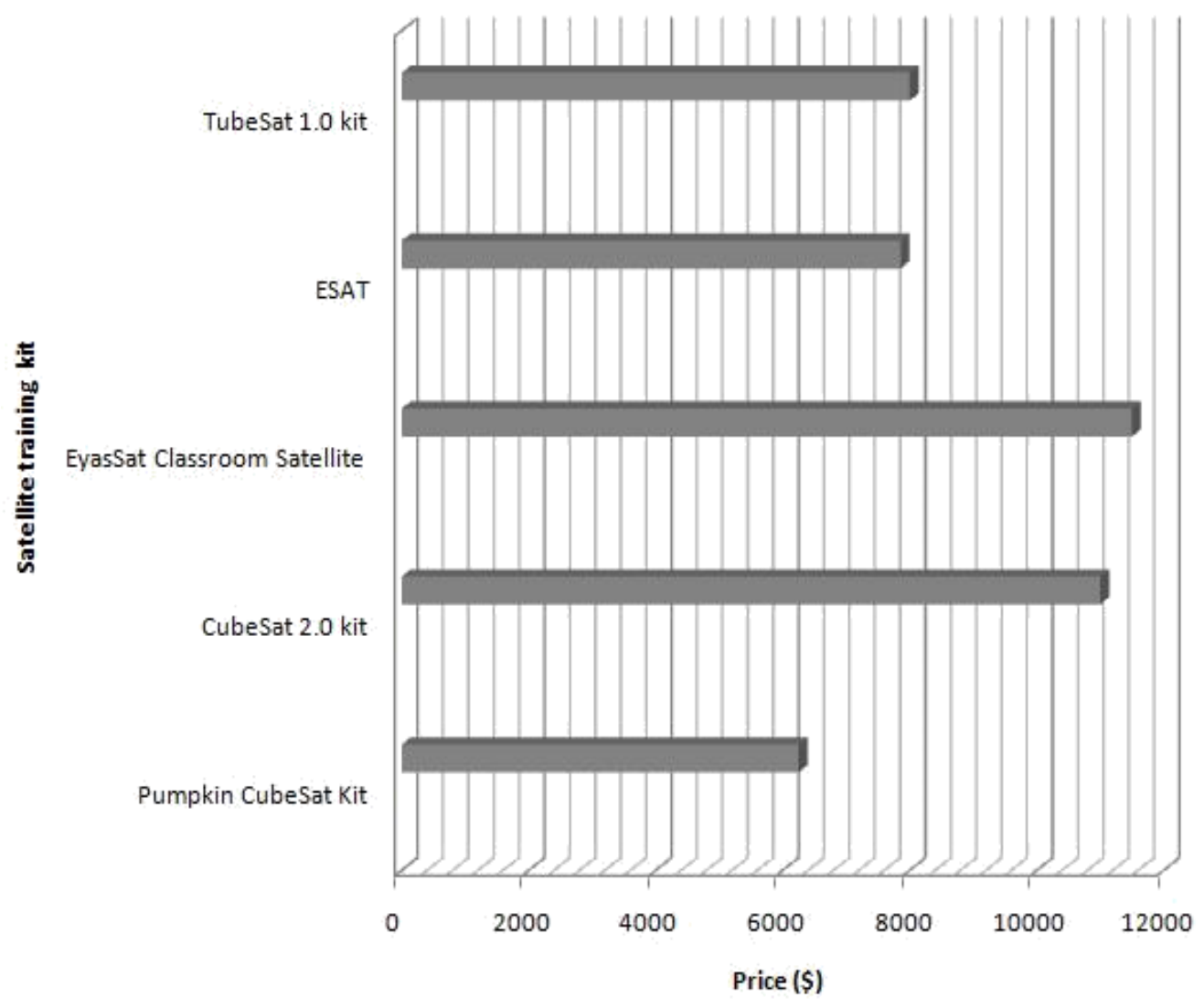

Fig.1.2 Price of different Satellite Training Kit

\subsection{Motivations}

The Soviet Union launched Sputnik-1, the world's first artificial satellite on October 4, 1957. Then, Sputnik 2 took a dog called Laika into orbit as the first live passenger on November 3, 1957[9]. However, the United States of America still holds the record in space, with most satellites. Our neighboring country such as India has launched 118 satellites so far [1]. Bangladesh is the world's 57th country to enter orbit and so far, we've launched two satellites that make us truly proud [10]. As a developing country, we do not have adequate knowledge, capital, and access to space technology. Moreover, our neighboring nations like India, Pakistan, and Bhutan are well ahead in space technology compared to us. We know satellite configurations are both very complicated and expensive. Therefore, we have been inspired to make a satellite training kit based on the low-cost component available in the local market so that any students or general people can get the basic idea of a satellite from our satellite training kit. 
The main purpose of this training kit is to grow curiosity about space technology among students and general people. The satellite training kit can help the students to learn about different subsystems of a basic satellite, how to assemble the different sub-systems into a fully functional system and how to test or debug it once it is incorporated. However, our proposed training kit is fitted with six sub-systems. We will use our satellite training kit for educational purposes. Every student will have a good understanding of how the satellite operates. Our satellite training kit will not be launched into space. However, our training kit will help anyone to get the basic idea of satellite and its sub-systems. We take it as a challenge because this sort of satellite training kit is still very scarce in the world. We believe that this project will grow the interest of both students and the general people in space engineering and related fields. This is our main purpose for making the satellite training kit. 


\section{Chapter 02}

\section{Overview of the Training kit}

In this chapter, we introduced our satellite training kit and described the whole sub-systems of our training kit in brief. We discussed the subsystems we selected for the training kit.

\subsection{Training Kit Sub-System}

$>$ Structure

$>$ Electrical Power System (EPS)

$>$ On-Board Computer (OBC)

$>$ Payload System

$>$ Communication System (COM)

$>$ Ground Station (GS)

A general overview of the project is presented in Fig. 2.1 below. 


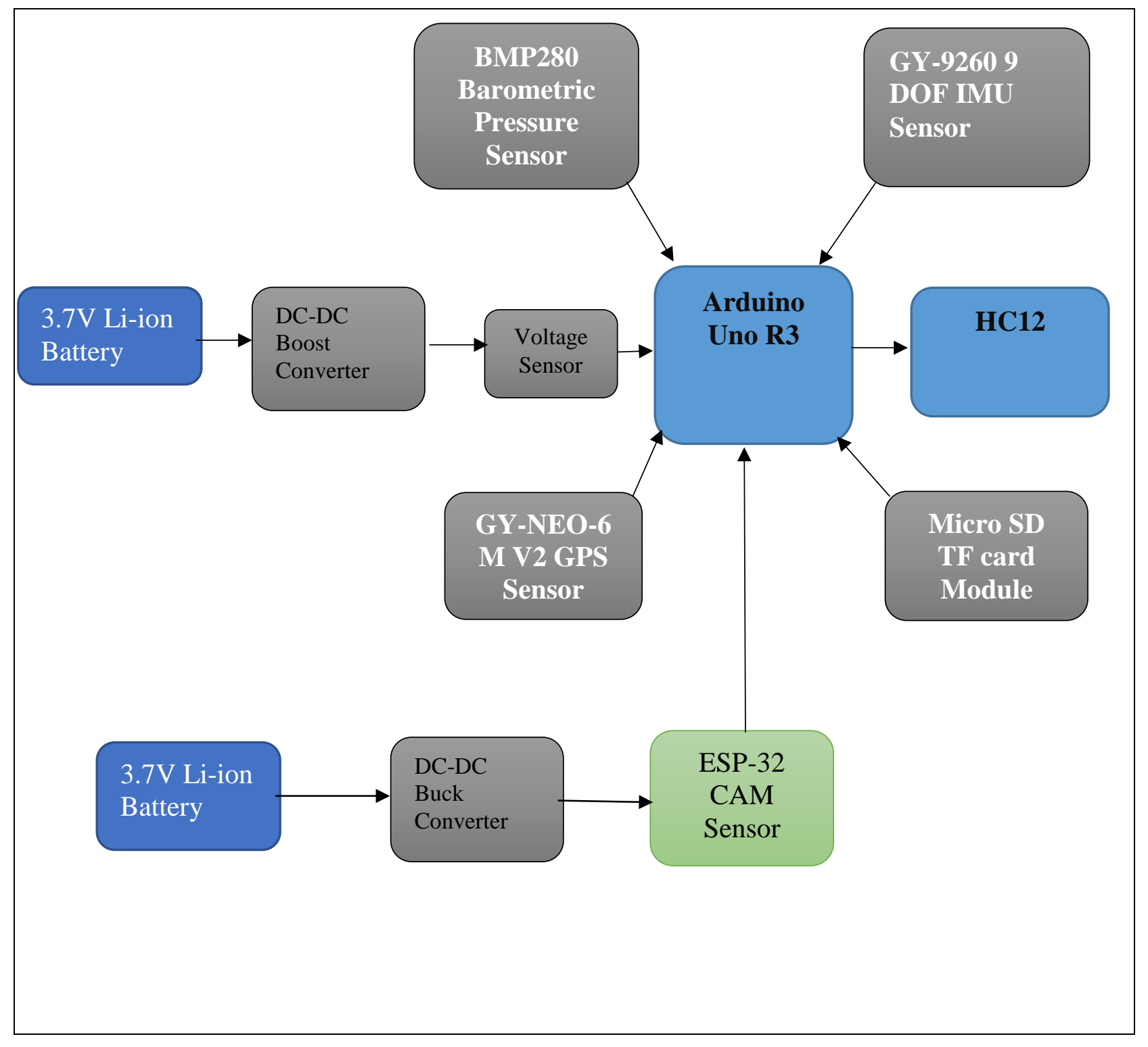

Fig. 2.1 Over-all Block diagram 


\subsection{Structure}

Our structure scheme for the satellite training kit is divided into two main parts: the outer chassis and the stack-wise or inner chassis. Firstly, the outer frame is $10 \mathrm{~cm}$ tall and $10 \mathrm{~cm}$ wide. We chose the tubular design to give the structure more strength in each plane. It has a separate solid plane at the bottom and a separate tubular plane at the top. The outer chassis is rectangular in size. Secondly, each sub-system has its internal chassis constructed with individual stack-boards. The stacks are assembled to form the base of the main interior. The inner structure is about $10 \mathrm{~cm}$ wide and about $10 \mathrm{~cm}$ tall. The topmost chassis is the communication stack, OBC stack boards are the next two stacks and the last two stacks are for the EPS. Finally, the main ESP-32 CAM Sensor is mounted in the second stack to allow the camera access to the full wide-angle. Here, Fig. 2.2 shows the inner stack of our training kit.

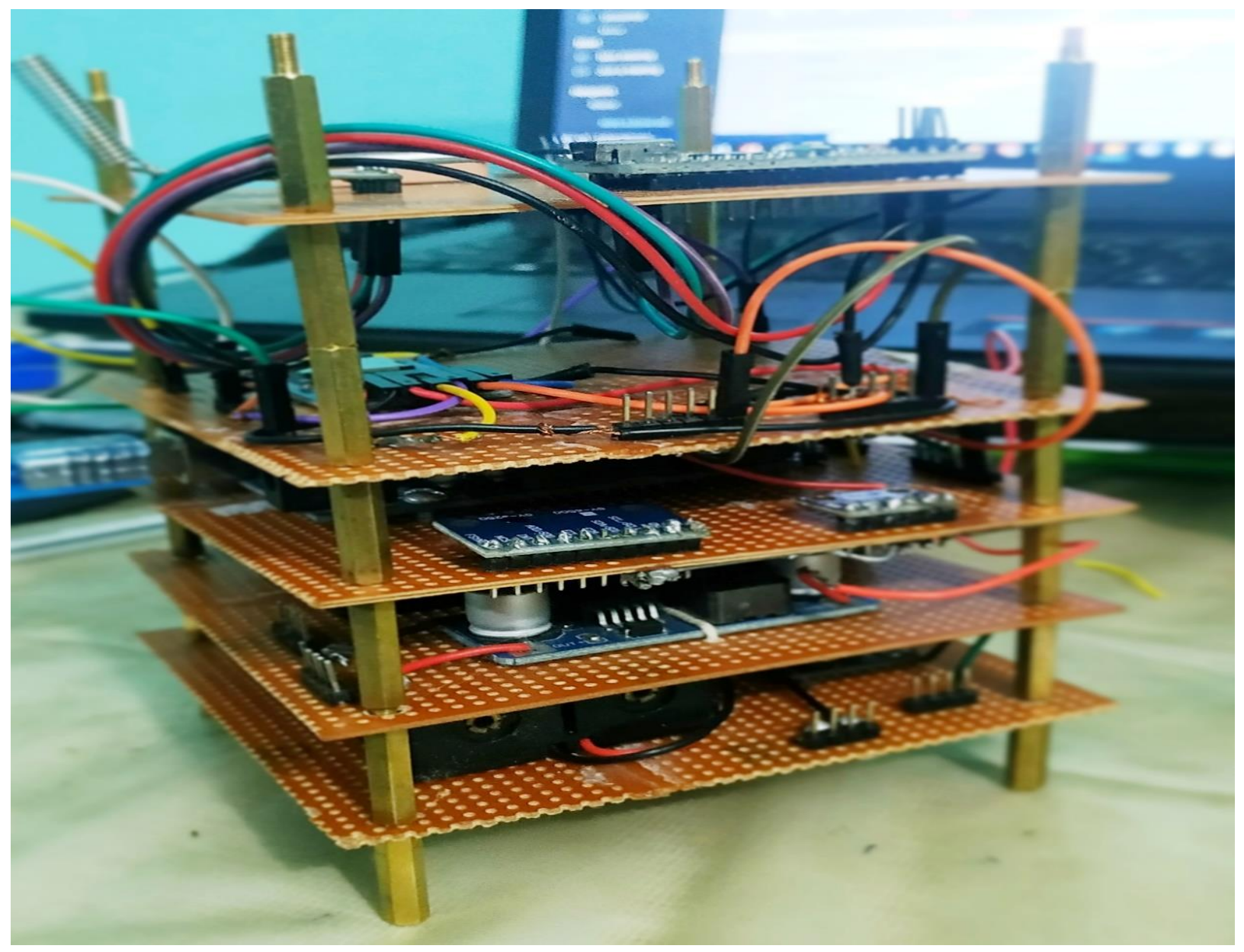

Fig. 2.2 Inner Stack 


\subsection{Electrical Power System}

The Electrical Power System (EPS) is designed to generate the power, store and distribute total power to the whole satellite [5]. Every satellite training kit requires some type of EPS that can maintain the flow of power continuously within the whole sub-system [11]. The great challenge for an electrical power system is to supply enough power to all the sensors so that they can run and provide us the right data [5]. Electrical power is the product of two quantities - current and voltage. There are one or two sources of electricity for all power systems [12]. In our project, we have used four 3.7V Li-ion rechargeable batteries for their good specification. A proper design of an electrical power system for a satellite training kit must have the ability to provide power from a set of rechargeable batteries. We have used LM2596 Buck Converter to step down the output voltage and LM2577s Boost Converter to step up the output voltage. Moreover, we have used two voltage sensors which can help us to calculate and track the voltage level of the system. In chapter 3 , a general overview of the electrical power system is described. EPS-1 and EPS-2 stacks are shown below in Fig. 2.3 and Fig. 2.4.

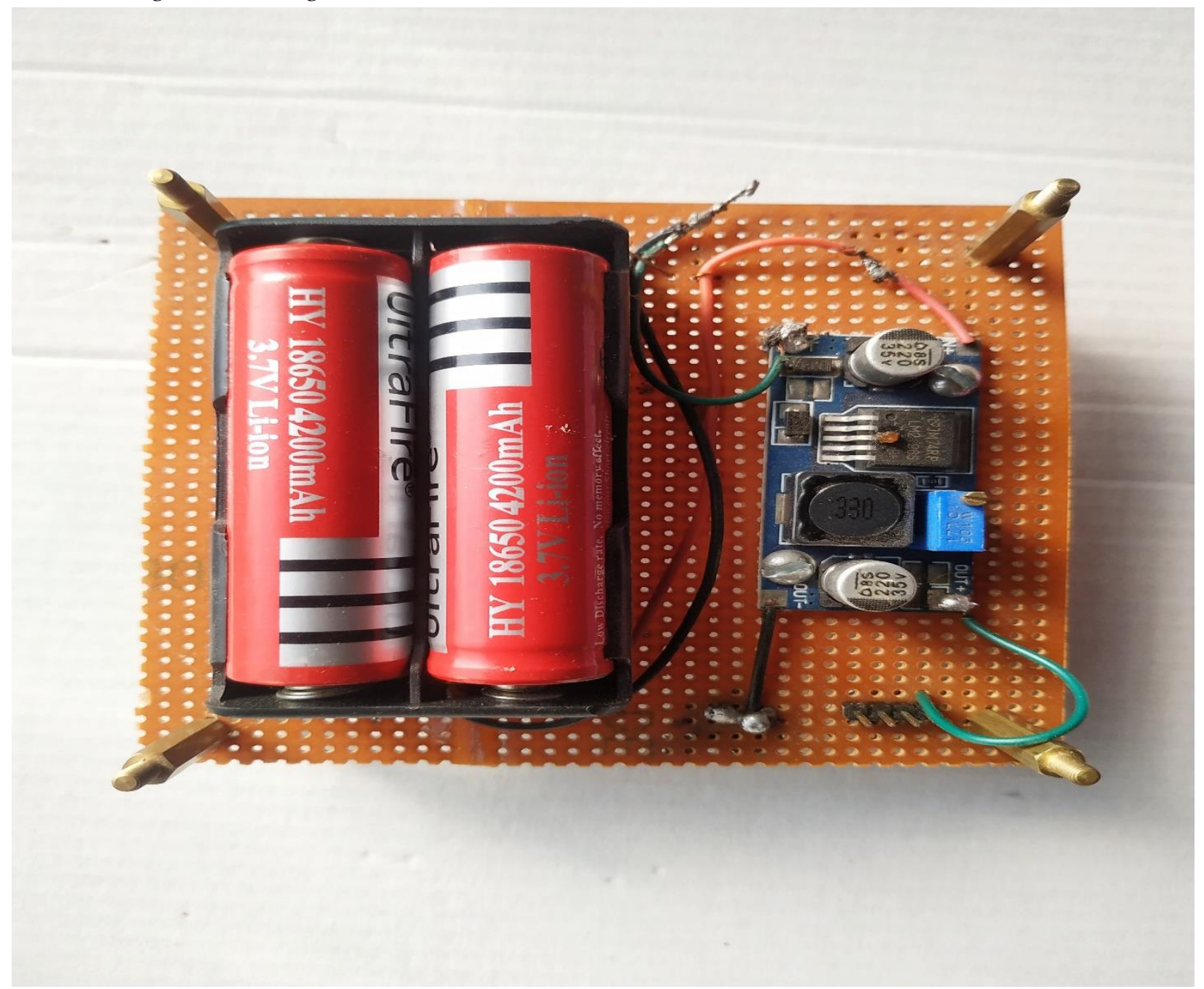

Fig. 2.3 EPS-1 Stack 


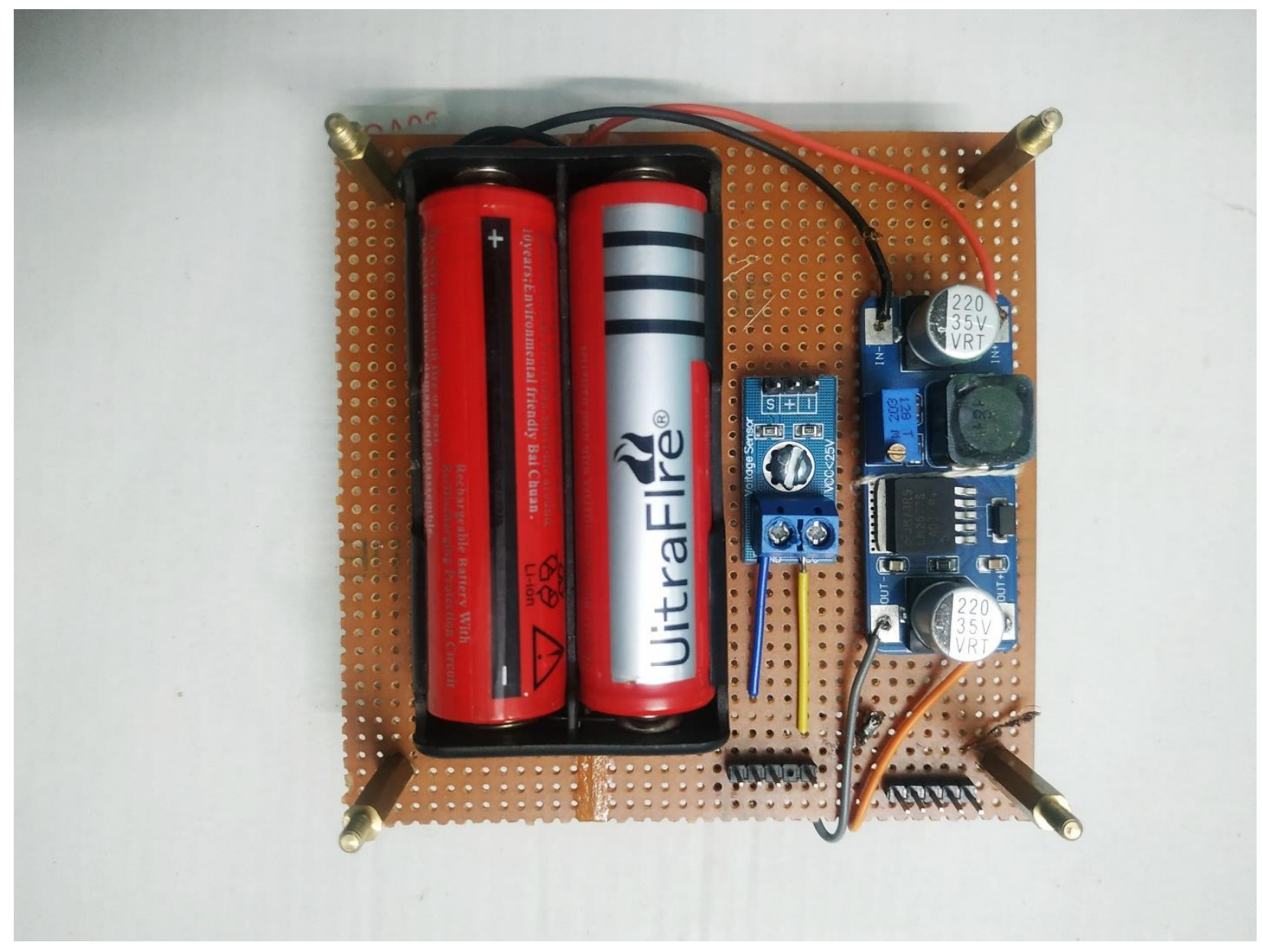

Fig. 2.4 EPS-2 Stack

\subsection{On-board computer}

The primary role of an onboard computer (OBC) is to control all the sub-systems of the satellite. The on-board computer (OBC) is said to be like the brain of a satellite [13]. There are some different roles that the $\mathrm{OBC}$ performs. Collecting the key data, editing, and encoding the data for transmission to the ground station are the most critical tasks [13]. Moreover, OBC analyzes the data and takes appropriate decisions when it is required. In our onboard computer (OBC) part, we used Arduino Uno as our motherboard, ESP-32 CAM Sensor as our main payload sensor. Besides, we used BME280 as our temperature, pressure and humidity sensor. Next, we have GY-9260 9 DOF Module as our IMU Sensor. We have also used the GY-NEO$6 \mathrm{M} \mathrm{V} 2$ module as our GPS sensor. These all the sensors are calibrated with the Arduino Uno. Finally, this whole concept and framework of OBC are presented in chapter 4. Here, the OBC1 stack is shown below in Fig. 2.5. 


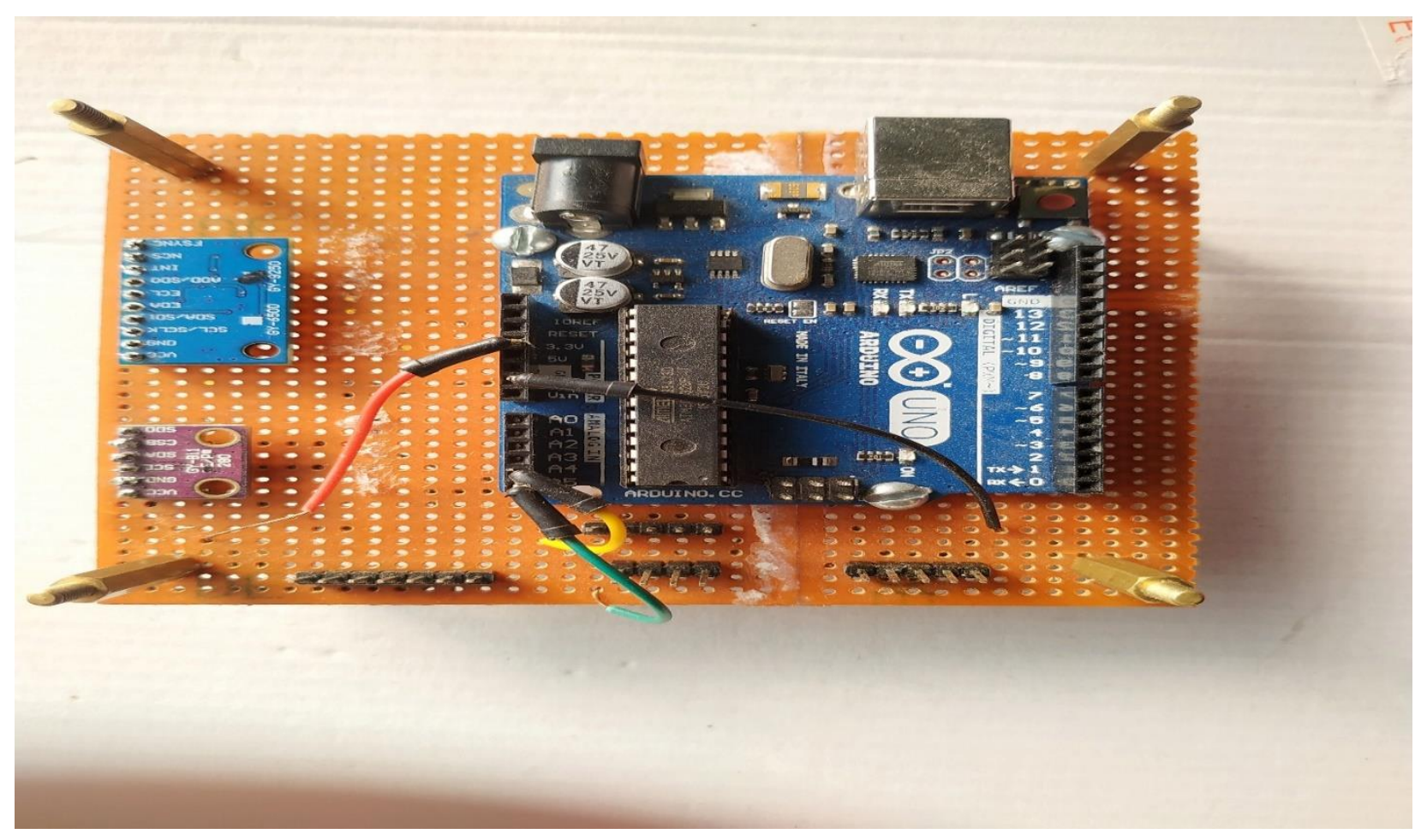

Fig. 2.5 OBC Stack-1

\subsection{Payloads}

In computer networking, it comprises both a header and the actual data to be transmitted when a transmission device is sent from the source to the destination. The actual charging data is called payload. We used three payload sensors in our satellite training kit: the ESP-32 CAM Sensor, the temperature, pressure and humidity sensor BME280 and the GY-NEO-6 M V2 GPS Sensor. ESP32 CAM sensor is our key payload sensor. It has a UART HCI with high speeds of up to 4Mbps [14]. We chose this sensor because it is popular and available in our local market and we can capture the image from different angles or coordinates. With the aid of the BME280 sensor, we can calculate temperature, pressure and humidity. Then, GY-9260 9 DOF IMU sensor module will help us to measure the inertial stats [15]. Our GY-NEO-6 M V2 module will navigate our satellite's position and will navigate our CAM sensor's coordinates as ordered from the ground station [15]. Finally, there is a simple overview of our payload system in chapter 4 . The main payload sensor, ESP32 CAM is shown in Fig. 2.6. 


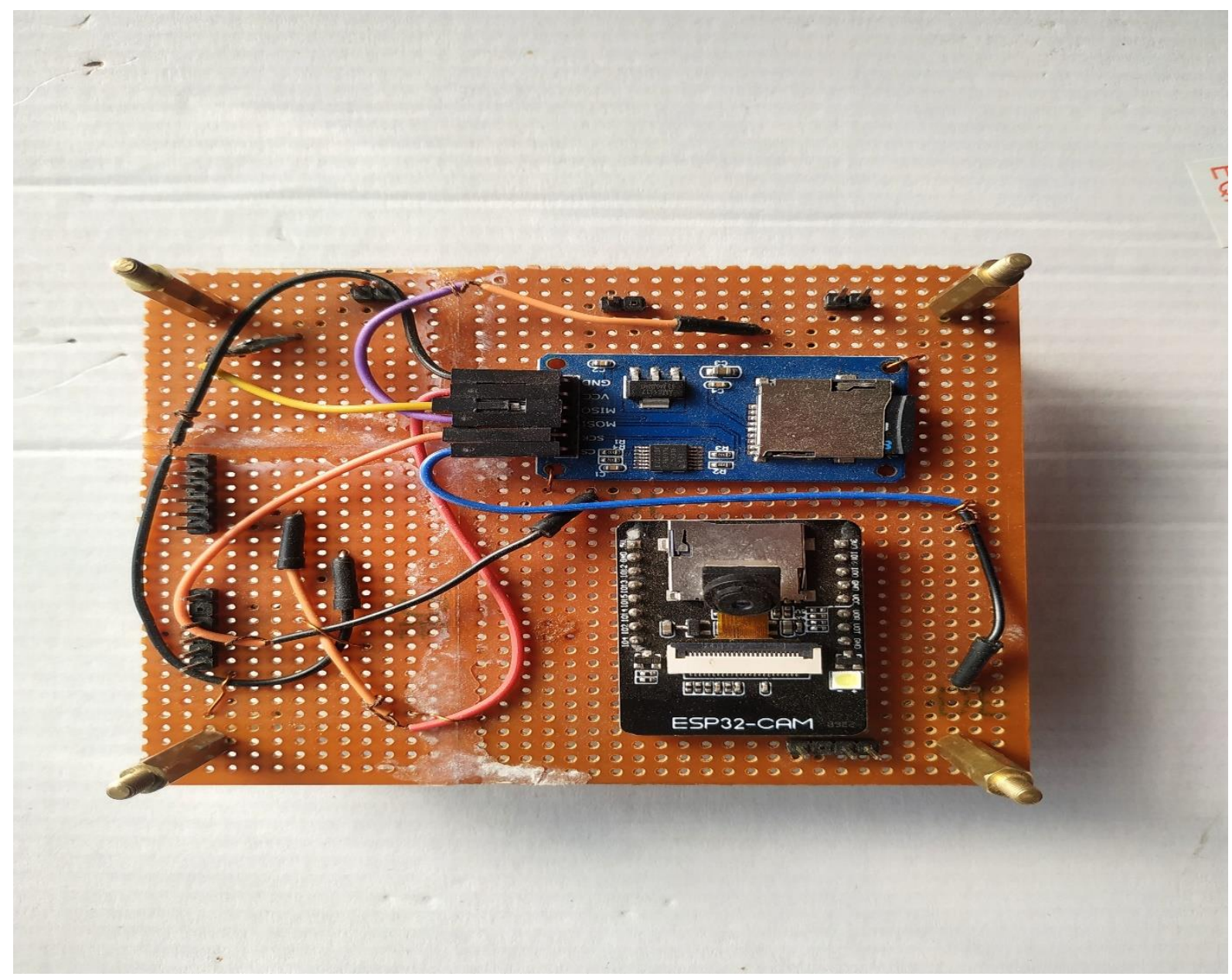

Fig. 2.6 OBC Stack-2

\subsection{Communication system}

Communication device provides a mode of contact between a source transmitter and the receiver at different areas on Earth [13]. The radio wire assimilates two signals and stores the data that originates from those signs [13]. Satellite interchanges communicate and get signals utilizing the extremely high recurrence scope of $1-50 \mathrm{GHz}$ [13]. The recurrence ranges or groups are distinguished by letters. Signs in the lower scope of the satellite recurrence range and sent with low force, and in this manner, bigger reception apparatuses are expected to get these signs. Our satellite preparing pack correspondence framework essentially comprises of two segments: HC-12 and Arduino Uno as the main motherboard. The HC-12 handset is fit for imparting up to conceivably past $1 \mathrm{~km}$ [16]. HC-12 will be aligned with the Arduino Uno from the OBC. Arduino will be fueled through the EPS. HC-12 will get the information from Arduino Uno by serial communication. HC-12 will take the information spared by the OBC in the double organization 
and in the wake of getting the information HC-12 will speak with the ground station's HC-12 and pass the information. At long last, the Communication framework is portrayed intricately in section 3. Here, Fig. 2.7 shows the COM stack.

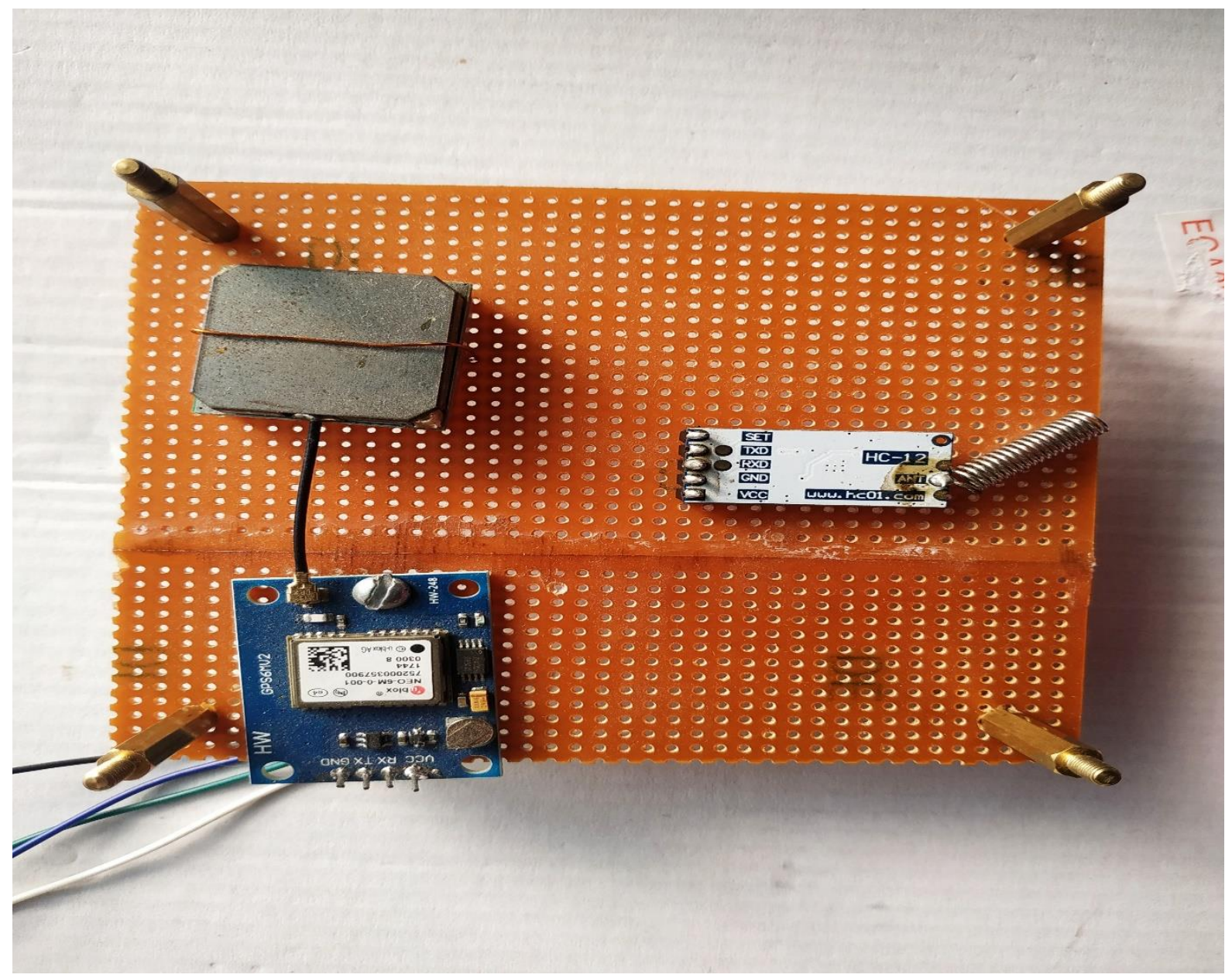

Fig. 2.7 COM Stack

\subsection{Ground Station}

The ground portion of the satellite communication system primarily consists of two-component: Arduino Nano and HC-12 module. Such is the ground station transmission and the ground station receipt. The transmitting ground station transmits the satellite data signals. In comparison, the receiving ground station receives satellite information signals [17]. The ground station may sometimes be used for both transmitting and receiving. In our project, the main components of the 
ground station are the HC-12 module and Arduino Nano Board. Finally, the Ground station system is described elaborately in chapter 3 .

As a satellite and ground satiation uses the same law of communication to communicate with each other [19]. Our ground station protocol is based on standardization of frequency, bandwidth and data rate and modulation scheme. Therefore, we have used HC12 transceiver as our main component to communicate with the satellite as we use in the communication part of the satellite. We have also used Arduino Nano as our main motherboard. In our ground station, we mainly used these two components. Here HC12 transceiver and Arduino Nano will be calibrated. The communication between satellite and ground station will be serial. In our ground station, we had a big challenge which communicator we will use in our ground station and satellite because of a lot of transceivers in the market. Therefore we have come up with a decision to use the HC12 transceiver as the HC-12 has 100 supported channels spaced $400 \mathrm{kHz}$ apart, eight transmit levels, eight supported baud rates and three different working modes[16]. Normally it has a speed of about $500 \mathrm{MHz}$ and a range of around 1 kilometer [16]. Our Arduino Nano which a clock speed is around $16 \mathrm{MHz}$ [18]. With these two components we have made our ground station and we will describe it elaborately in section 3. Fig. 2.8 shows the ground station stack below.

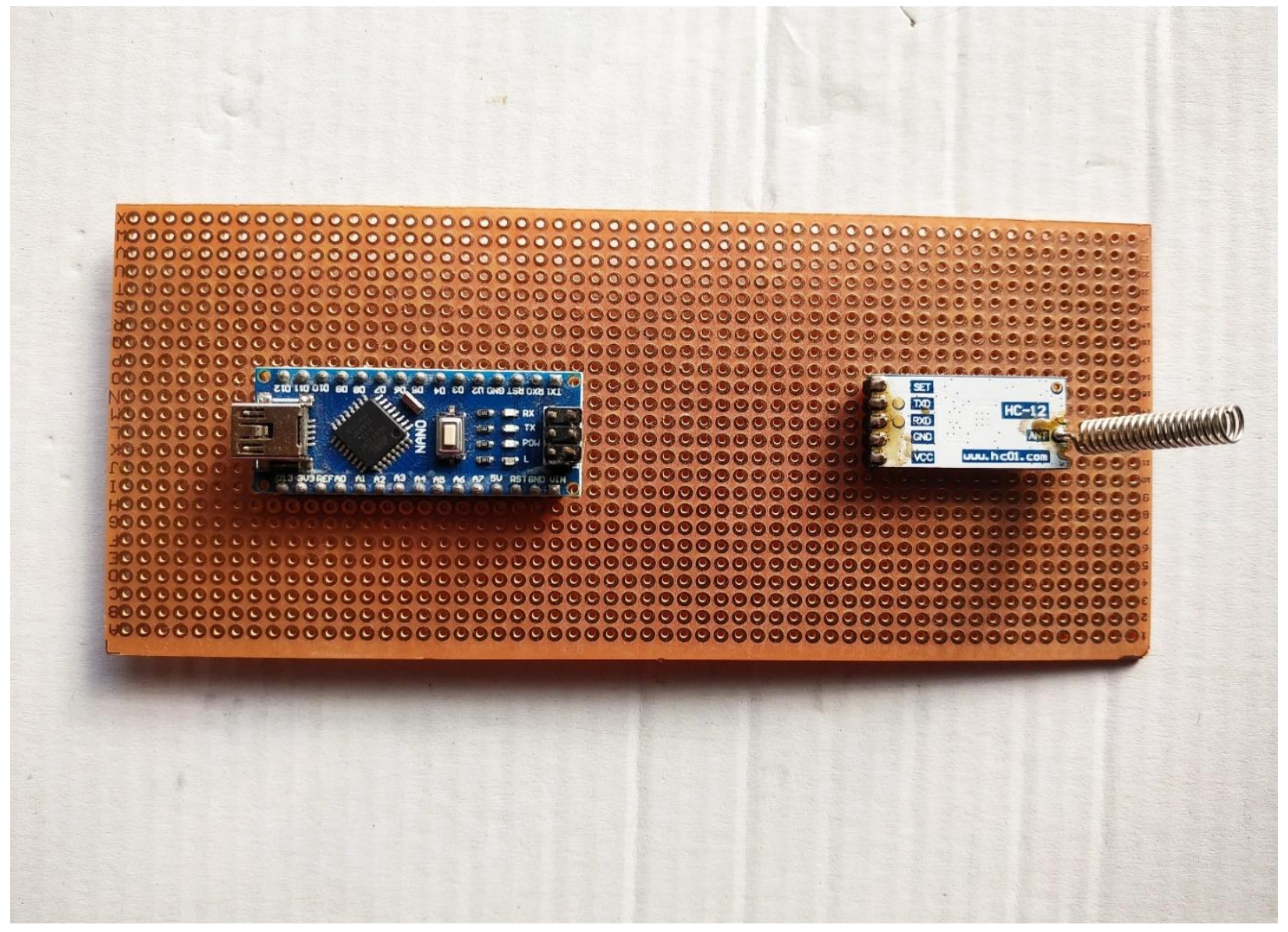

Fig. 2.8 Ground Station Stack 


\section{Chapter 03}

\section{Mechanical Model and Electrical Simulation}

\subsection{Introduction}

In this segment, there is a description of our 3D model of the training kit and electrical circuit simulation by software. The 3D model was designed by SolidWorks software and the electrical stimulation was conducted by Proteus. We designed the 3D model based on our hardware measurement and was divided into two parts: 1) Outer Chassis and 2) Inner Stack-wise Chassis. And the electrical circuits were simulated by Proteus to make sure they are working properly. And the ground station part was done by LabVIEW software.

\subsection{Developing Mechanical Model}

At the time of designing our mechanical 3D model, we simply took the standard measurement of a cube-satellite. Our hardware is approximately $10 \mathrm{~cm} * 10 \mathrm{~cm} * 9.8 \mathrm{~cm}$. As a result, our 3D model is based on that measurement. We divided it into two parts:

(1) Outer Chassis

and (2) Inner Stack-wise Chassis.

The Outer chassis is the cover of the stack chassis of the training kit. The measurement of the outer chassis is $10 \mathrm{~cm} * 10 \mathrm{~cm} * 10 \mathrm{~cm}$. Then, the stack-wise chassis consists of 5 stacks. Each stack contains the circuits of the sub-systems. The stacks are added to each other by hexagonal spacers. After that, we made a split-view video of our model so that the design can be shown easily. We conducted the whole modeling by SolidWorks software. After designing, we conducted the stress and strain analysis to test the endurance ability of the chassis.

\subsection{Outer Chassis}

As described previously, the outer chassis is the outer shell of the kit. The measurement of the outer chassis is $10 \mathrm{~cm}^{*} 10 \mathrm{~cm} * 10 \mathrm{~cm}$. It has a Cap and a bottom lid which will be screwed with the main body after the stack chassis is put inside. The element we used was Acrylic to design the chassis. It is designed in such a way that our camera sensor gets a clear range and the signals do not get blocked during transmission. The designed model is very common as the horizontal shape gives more strength to the vertical pillars. As a result, the stress and strain of the model are more endurable. Here, Fig. 3.1 shows the outer chassis model below. 


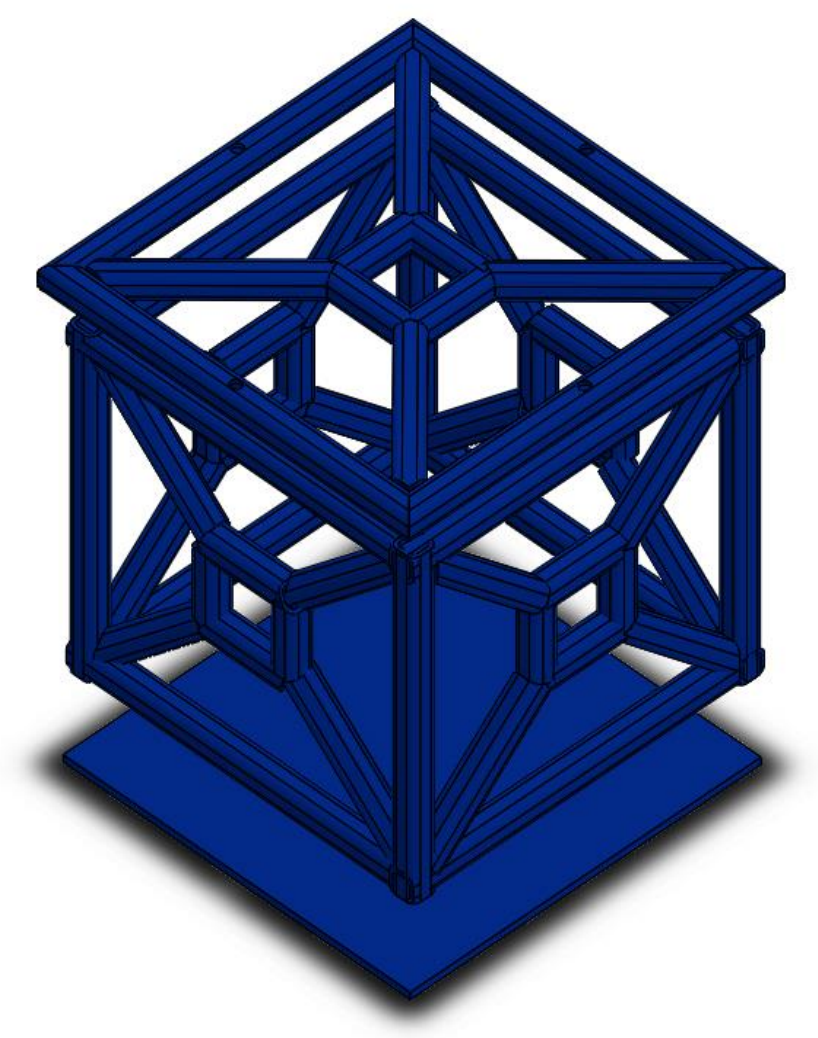

Fig. 3.1 Outer Chassis

\subsection{Inner Stack-wise Chassis}

The inner stack-wise chassis is a combination of all the individual stacks of the sub-systems of the kit. There are 5 stacks altogether. The 5 stacks are EPS-1, EPS-2, OBC-1, OBC-2 and COM stack. The stacks are added through $2 \mathrm{~cm}$ long hexagonal spacers with one another. The inner chassis model is shown in Fig. 3.2 below. 


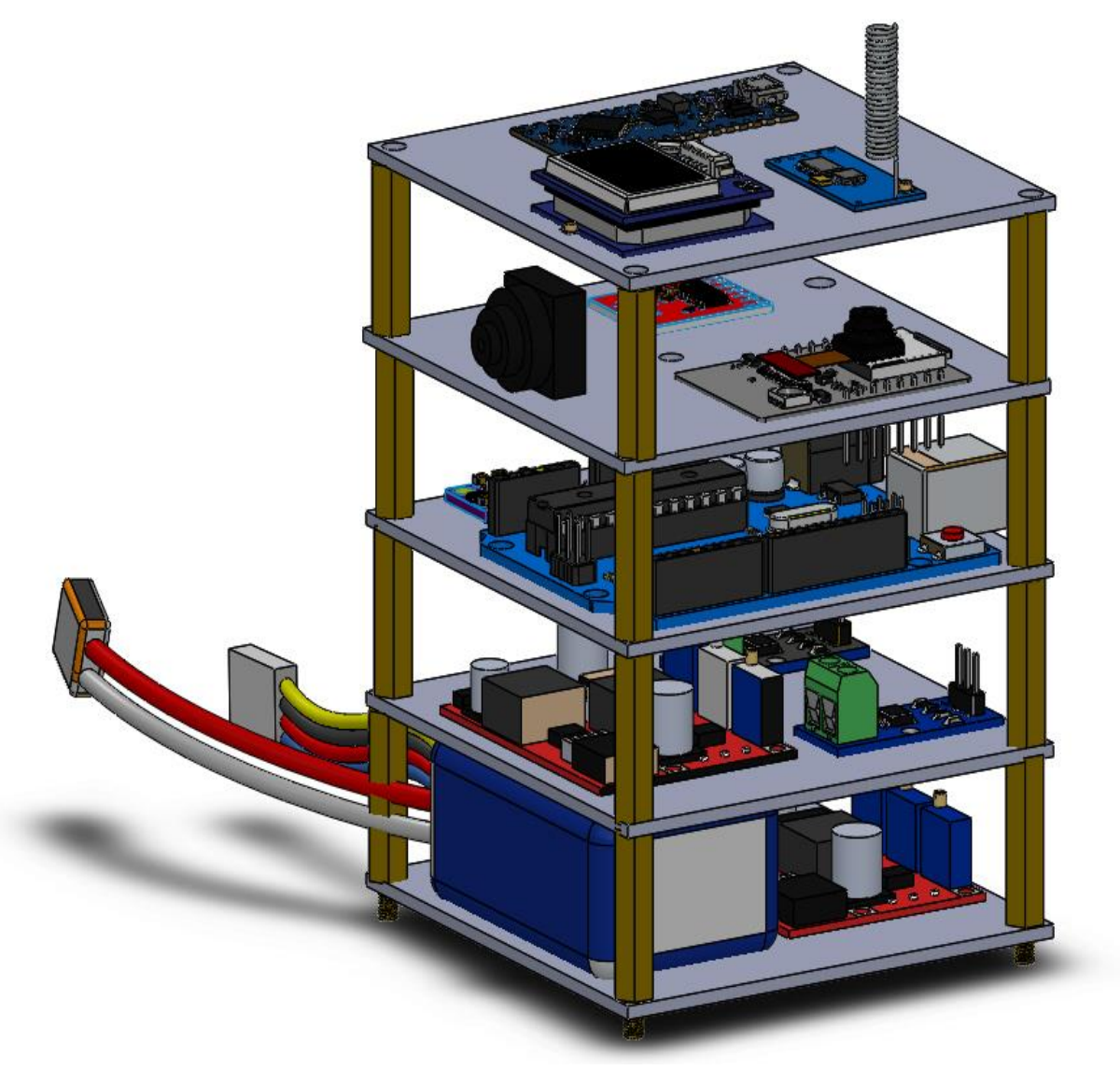

Fig. 3.2 Inner stack-wise Chassis

\subsection{Stress-Strain Analysis}

The stress-strain analysis was conducted to test the endurance of the training kit. We designed the 3D with Acrylic as it would give the design more durability and less weight. The horizontal ' $\mathrm{X}$ ' shape gives more strength to the vertical pillars. As a result, the stress and strain of the model are more endurable. Here, Fig. 3.3 shows the stress-strain analysis report. 
Model name: Outer_chassis_Cage

Study name: Static_Cage(-Default< As Machined $>-$ -

Plottype: Upper bound axial and bending Stress 1

Deformation scale: 15.787

$\overbrace{x}^{Y}$

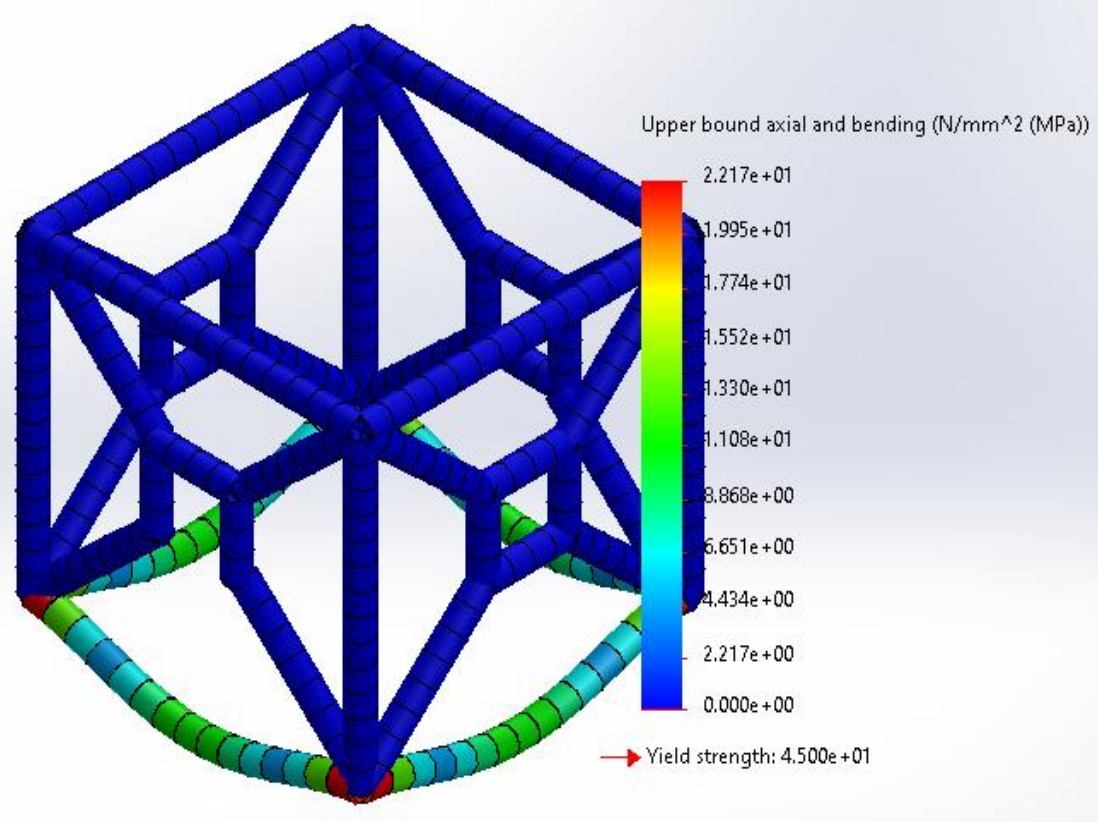

Fig. 3.3 Stress-Strain analysis

\subsection{Exploded Videos Rendering}

The exploded-view video was rendered to show the design easily to the audience. The split-view shows individual stacks connected with spacers and how it is connected with the outer chassis. Here is the split-view image shown in Fig. 3.4. 


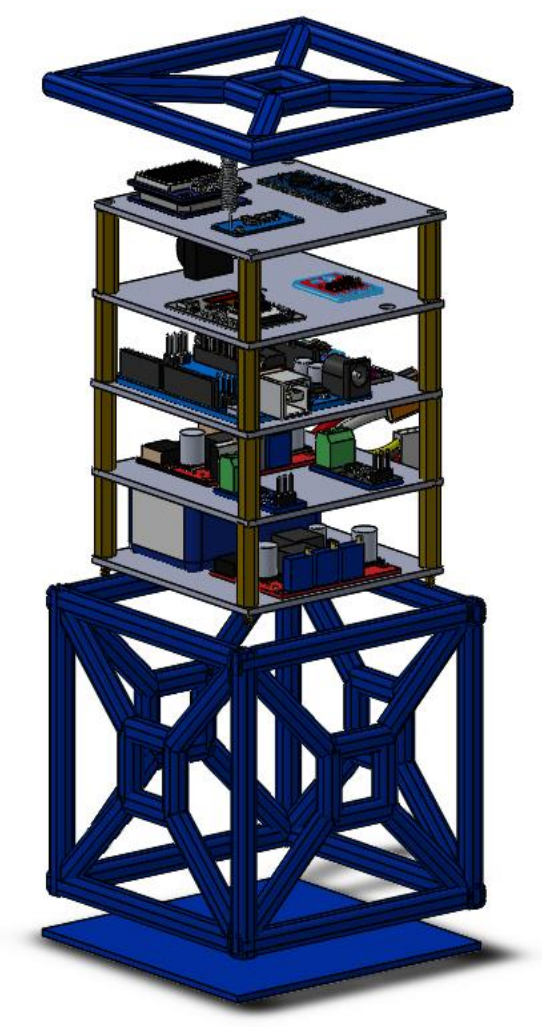

Fig. 3.4 Split-view rendering

\subsection{Schematics}

The sub-systems were also designed by Proteus software to simulate the circuits. As mentioned before, there was some unavailability of sensor library for Proteus. As a result, we had to use the sensor available in Proteus. Therefore, we had to make some changes that vary from our hardware design. For instance, we could not simulate the camera sensor and IMU sensor on Proteus. Besides, there was no ready-made library for buck and boost converter. We had to design both manually. Based on availability, we used DHT11 and BME280 sensor with a microSD card module for the onboard computer part and Xbee for the Communication system.

Here, we simulated the buck converter circuit by PROTEUS software. 


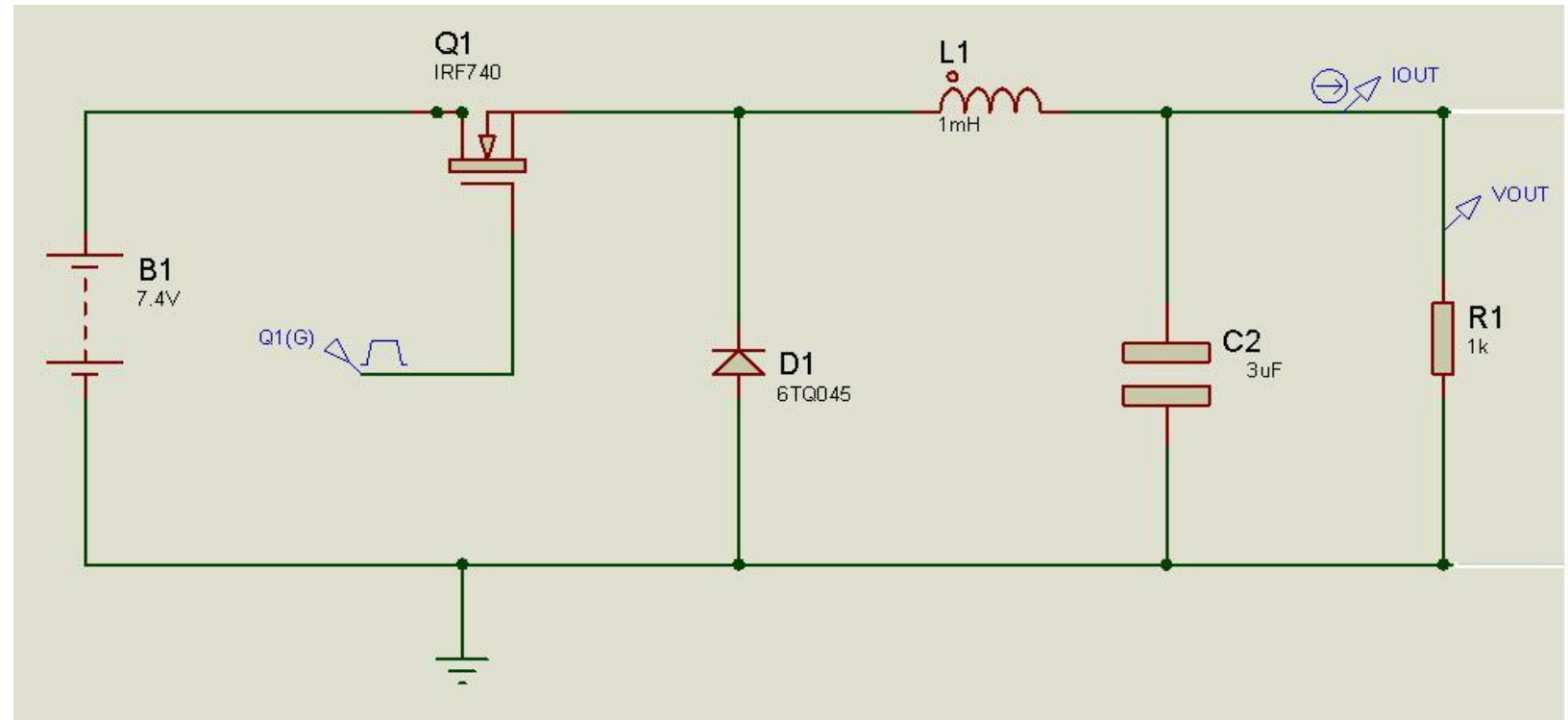

Fig. 3.5 The circuit of the buck converter

In SMPS circuits, where the DC output voltage has to be lower than the DC input voltage, the Buck Converter is used. Many times in the electronics world we find the need to reduce one DC voltage to a lower one. In our project, we need $5 \mathrm{~V}$ from a $7.4 \mathrm{~V} \mathrm{Li}$-ion battery. To get this voltage, we just add an LM2596 buck converter with the 7.4V Li-ion battery and it regulates the voltage down to $5 \mathrm{~V}$. With the help of a buck converter, we can easily convert the voltage from $7.4 \mathrm{~V}$ to $5 \mathrm{~V}$. It is shown in this subsection how the simulation model is configured to obtain various frequency functions. Here, by using PROTEUS software, we simulate the buck converter. Fig. 3.5 shows the circuit of the buck converter.

In our satellite training kit, the two Li-ion batteries will provide us 7.4V. However, most of our components are working on $5 \mathrm{~V}$. So, we have to convert the voltage by using a buck converter. We need MOSFET IRF740, diode, capacitor, inductor, resistor, and pulse generator to build a buck converter. In the pulse generator, we have set the value of pulse width $33 \%$ and the frequency 50 $\mathrm{kHz}$. The table below shows us the parameter values used in the buck converter simulation. 
It is shown in this subsection how the simulation model is constructed to obtain various frequency functions. Here, by using PROTEUS software, we simulate a boost converter. Here, Fig. 3.6 shows the circuit diagram of a boost converter.

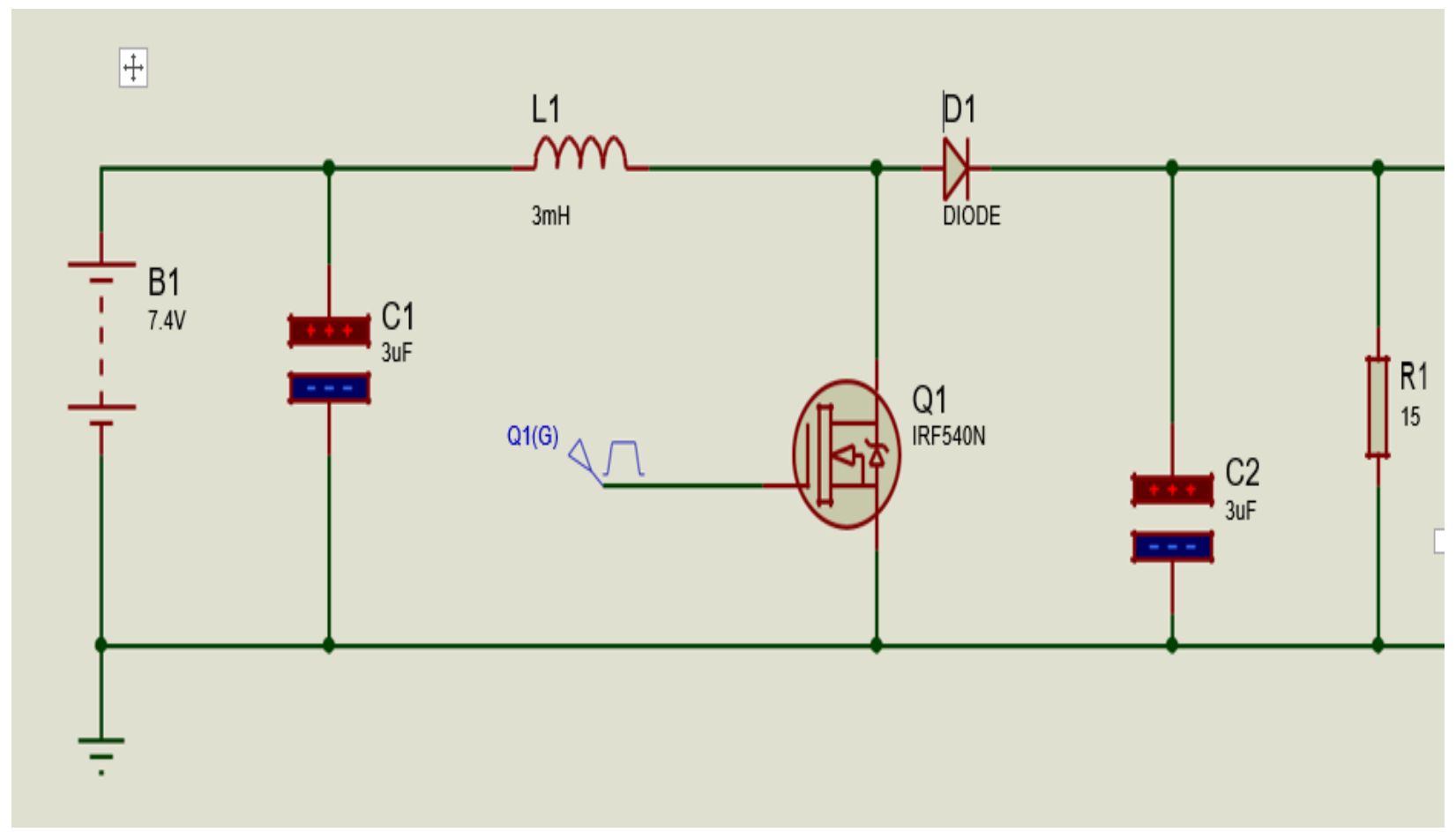

Fig. 3.6 The circuit of the boost converter

We need MOSFET IRF740, diode, capacitor and inductor, resistor, and pulse generator to build a boost converter. In the pulse generator, we can set the value of pulse width $33 \%$ and the frequency $50 \mathrm{kHz}$. Table 1 below describes the parameter values used in the boost converter simulation. 


\begin{tabular}{|l|l|}
\hline Parameter & Value \\
\hline Resistor, R1 & $15 \mathrm{ohms}$ \\
\hline Inductor, L1 & $3 \mathrm{mH}$ \\
\hline Frequency & $50 \mathrm{kHz}$ \\
\hline $\begin{array}{l}\text { Battery } \\
\text { Voltage, B1 }\end{array}$ & $7.4 \mathrm{~V}$ \\
\hline Capacitor, C2 & $3 \mathrm{uF}$ \\
\hline
\end{tabular}

Table-1: Values of different parameters.

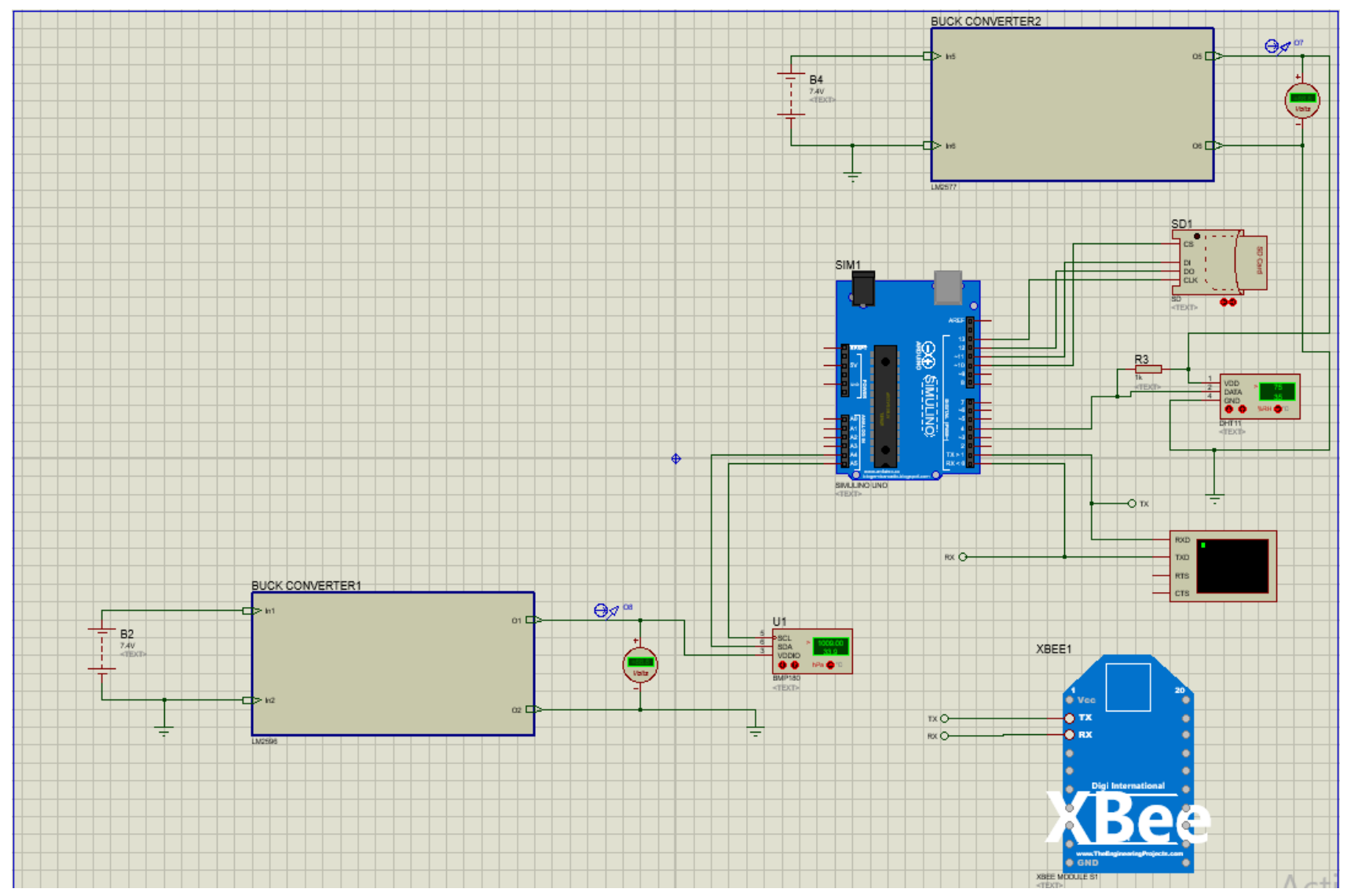

Fig. 3.7 All the Sub-systems compiled together 
As mentioned earlier, there was a scarcity of proteus library while choosing the sensors for OBC. We could not find all the sensors in Proteus that we used in the hardware. Hence, we used the DHT11 and BMP180 sensors based on availability. Then, we used the micro SD card module to store the sensor data. All the modules are calibrated with the Arduino Uno shown in Fig. 3.7. We can see the sensor data in the virtual monitor as shown in the figure below. The simulation is shown in Fig. 3.8.

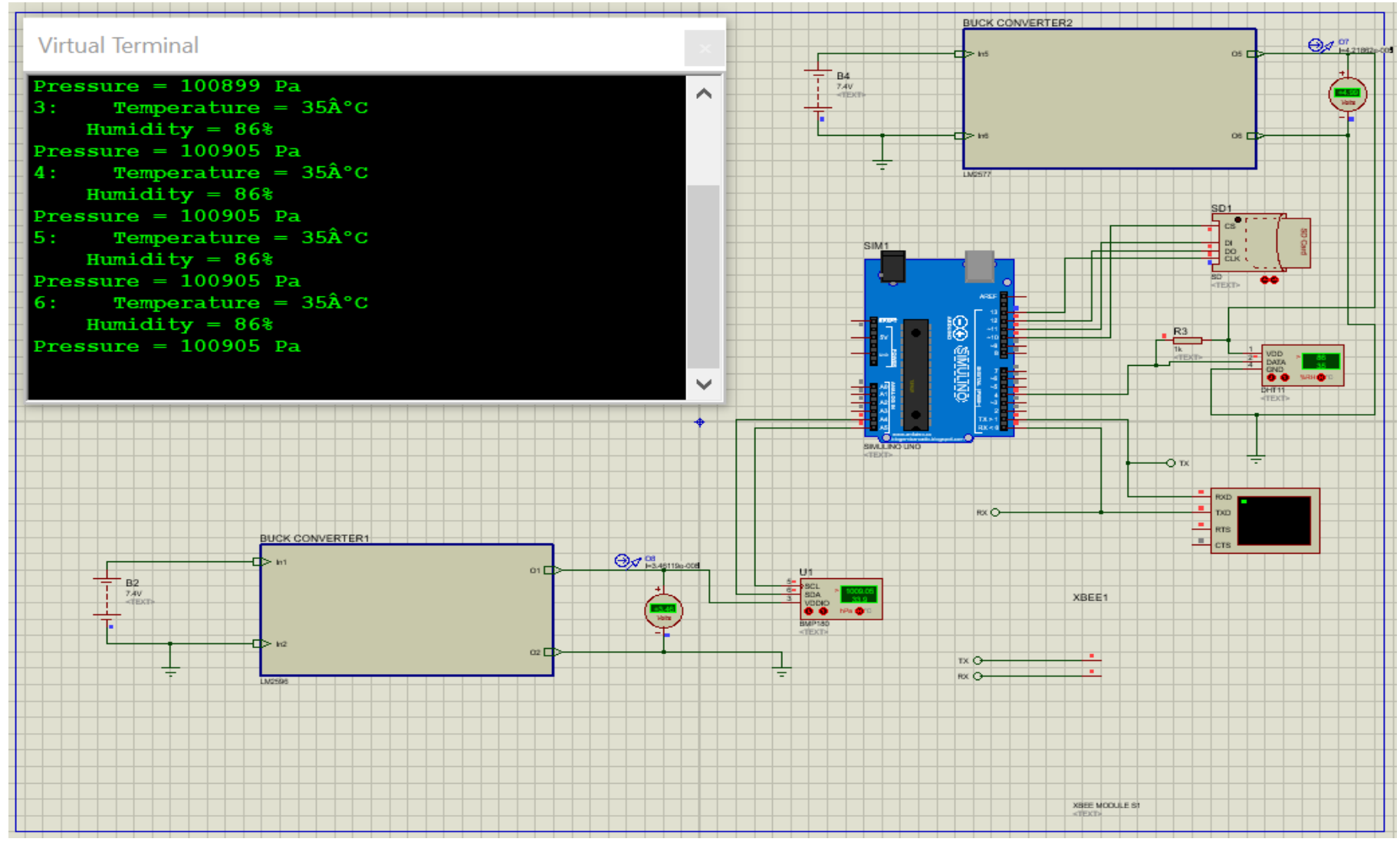

Fig. 3.8 Proteus simulation

We have previously discussed in chapter-3 that Xbee is not available in the local market and it is costly. Hence, we did not use it in our hardware project. However, in Proteus simulation, we found out that the Xbee library is available and easy to simulate. Therefore, in the software simulation of the communication part, we used Xbee as our serial transceiver module. Here, Xbee along with the other sensors are connected with Arduino Uno. After all the data is received by Xbee, it starts 
to send all the data to our ground station that we designed in LabVIEW software. Here, Fig. 3.9 shows the ground station layout.

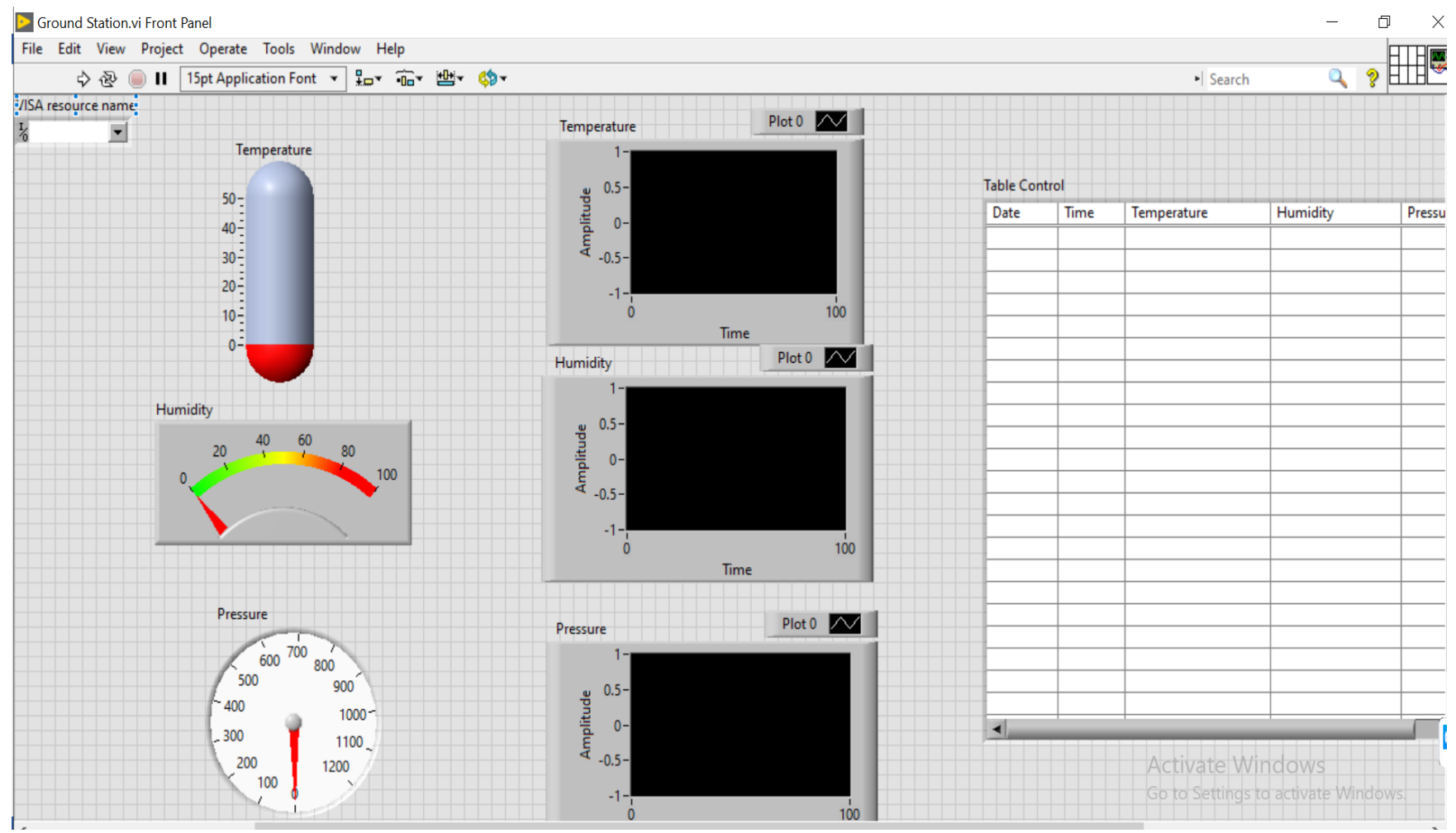

Fig. 3.9 Ground Station Layout

Then, the ground station was interfaced with the Proteus simulation file to receive data. Fig. 3.10 shows the virtual interface of the Ground Station. To interface serially, we used Configure Virtual Serial Port software. The sensor data that was transmitted by the Xbee module was received by the Ground Station. Here, the received data is the same as the transmitted data that is shown by the virtual monitor. 


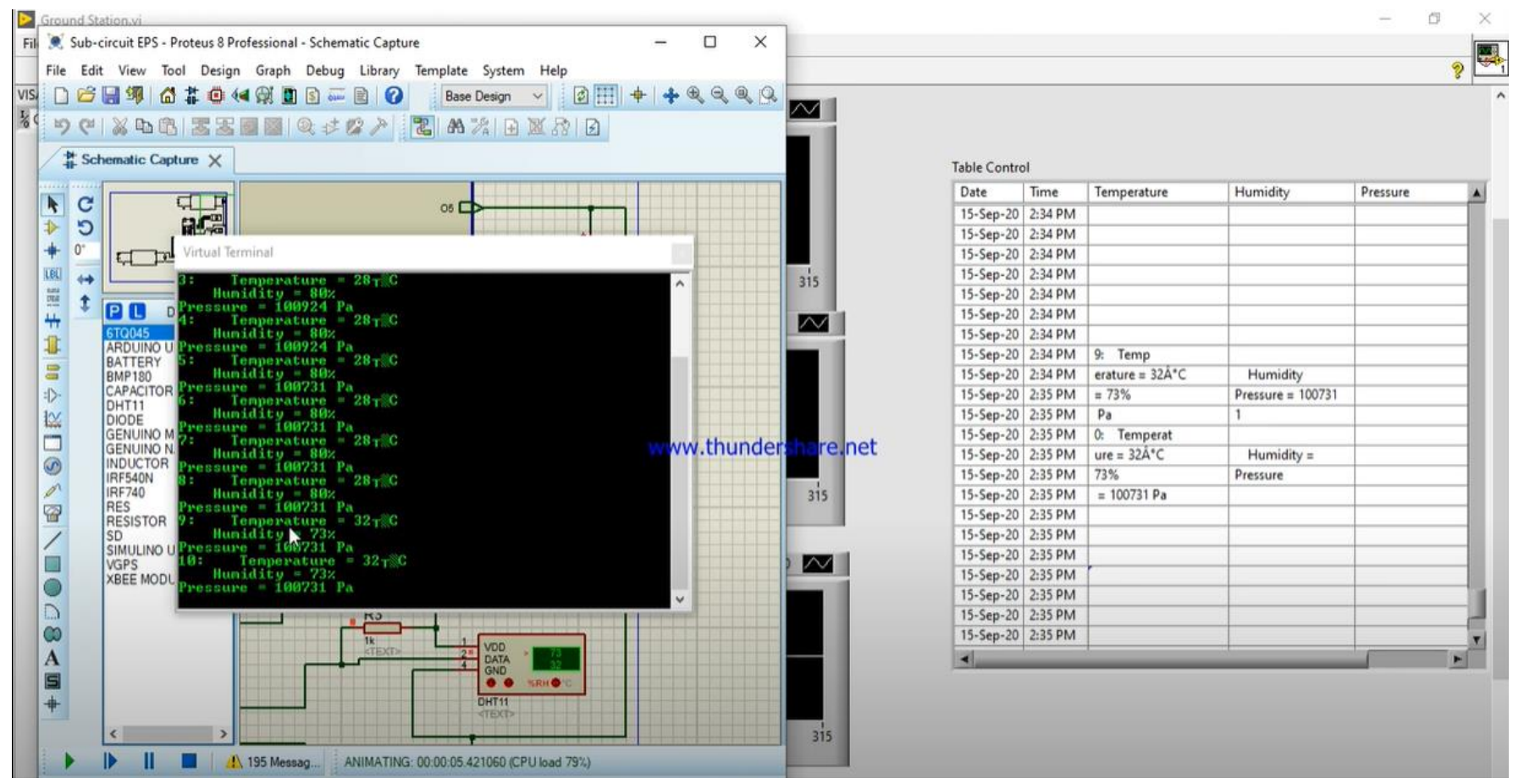

Fig. 3.10 Virtual interface of Ground Station 


\section{Chapter 4}

\section{Design and Assemble of the Training Kit}

\subsection{Introduction}

In this chapter, the basic concept of the sub-systems is discussed. A network of electrical components used to supply electrical power is an Electrical Power System (EPS). The most important thing is that electrical power systems supply the loads that perform a function with electricity [19]. Then, the basic role of the On-board Computer System (OBC) is to maintain communication between all the sub-systems. The satellite's OBC is solely responsible for initiating dataflow between motherboard hardware and Payload Sensors. The role of the Communication System (COM) refers to the payload data exchange between the training kit and the Ground Station. Next, the Ground Station (GS) is responsible for receiving and processing the payload data. Finally, this chapter gives an overview of all the sub-systems of our training kit.

\subsection{The Operations of EPS}

Before starting the EPS design, the first step is to know exactly our objectives and content. The main purpose of the Electrical Power System (EPS) is to provide a stable and continuous power supply for the other sub-systems [20]. Therefore, a continuous and reliable power source is necessary. The other sub-systems of our training kit cannot work without an electrical power system [7]. Thus, the EPS is the lifeline of the satellite networks [7]. Here, batteries are the most important part of the EPS. In our project, power is obtained from the $3.7 \mathrm{~V} \mathrm{Li}$-ion batteries. The batteries have to store enough energy to supply the whole satellite training kit. The electrical power system of our project consists of four 3.7V Li-ion batteries, one LM2596 Buck converter, one LM2577S Boost converter and a voltage sensor. 


\subsubsection{Connection Diagram of EPS}

In our project, we have used four $186503.7 \mathrm{~V} 4200 \mathrm{mAh}$ Li-ion battery. Our two Li-ion batteries will provide $7.4 \mathrm{~V}$ which will be connected to the DC-DC Buck converter. The output of the buck converter will be connected to a voltage sensor. Then the voltage sensor will be calibrated with Arduino UNO. Another two Li-ion batteries will be provided 7.4V which will be connected to the DC-DC boost converter. DC-DC boost converter will be also calibrated with Arduino UNO. The figure below shows the EPS connection diagram for us. Fig. 4.1 shows the connection diagram of the EPS below.

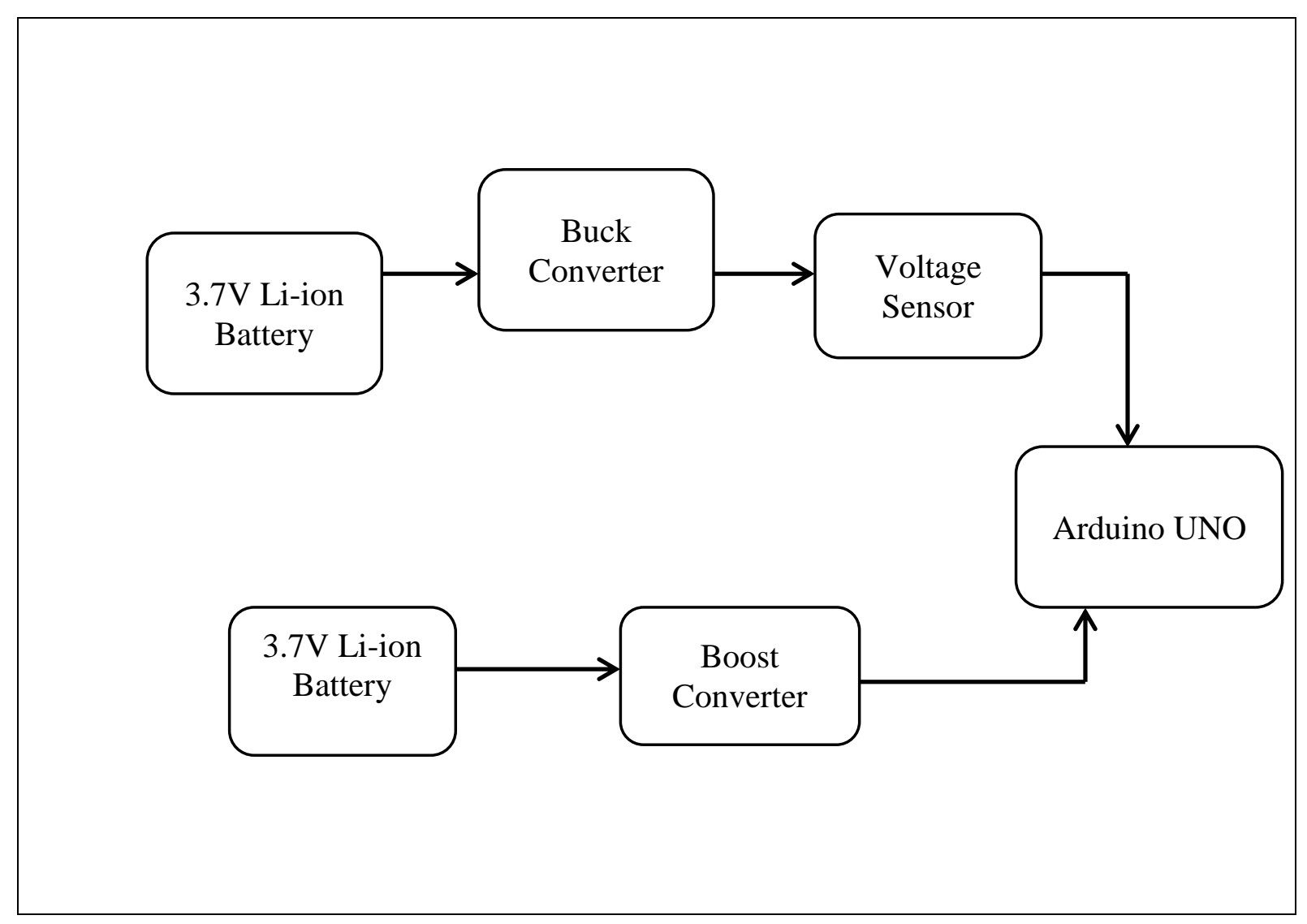

Fig. 4.1 Connection Diagram of EPS 


\subsubsection{Battery}

A battery transforms chemical energy through a chemical reaction into electrical energy. Generally, batteries are a collection of one or more cells whose chemical reactions in a circuit release a flow of electrons. A battery must be capable of generating sufficient power to provide the output power needed. There are a lot of batteries are available in the local market. It is a difficult task to pick the right battery. The battery is a critical component of the electrical power system. Thus, it is wise to choose a model of batteries that have already been used in several successful missions. Eventually, we have chosen the Li-ion battery for its good specifications. In our project, our chosen batteries are rechargeable. The primary benefits of Li-ion battery cells are that they have around four times the nickel-cadmium or nickel-metal hydride battery density energy [21]. Li-ion batteries are very lightweight and pliable and almost any size or shape can be created [21]. The popularity of Li-ion batteries is rising and they are the preferred power source for most consumer products today. The battery we have chosen is rated at $3.7 \mathrm{~V}$ with $4200 \mathrm{mAh}$. Fig. 4.2 shows the battery below.

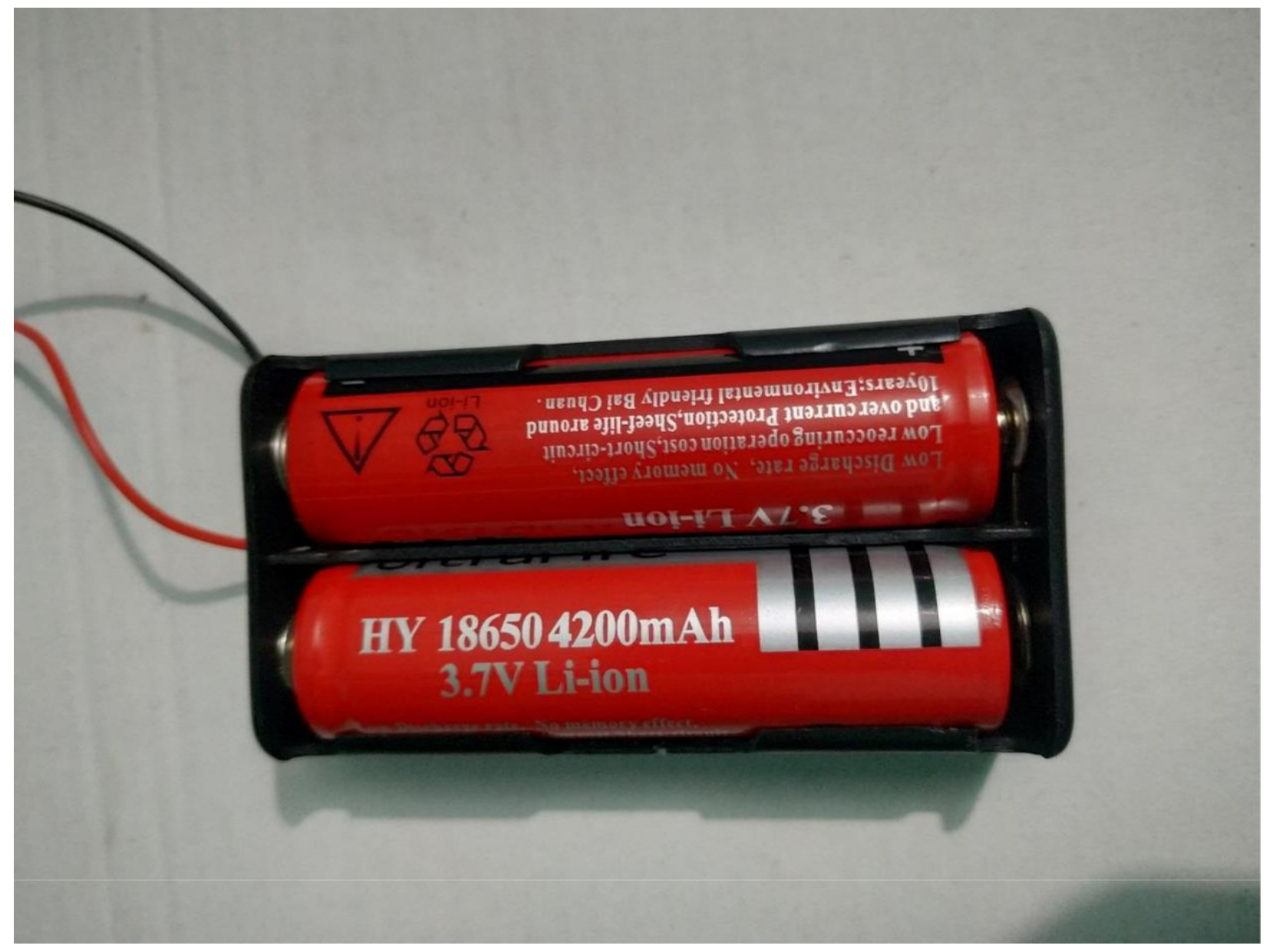

Fig. 4.2 Two 3.7V 4200mAh Li-ion battery 


\subsubsection{Battery Charger}

In our project, we have used four 18650 3.7V Li-ion battery. We have used Universal Dual Battery Charger for Li-ion Battery so that we can charge our four batteries. This product is brand new and has good performance. It is designed to charge the batteries quickly and safely. It can charge all kinds of 3.7 V Lithium Battery. It stops automatically when charging is complete [22]. The figure of the battery charger is given below in Fig. 4.3.

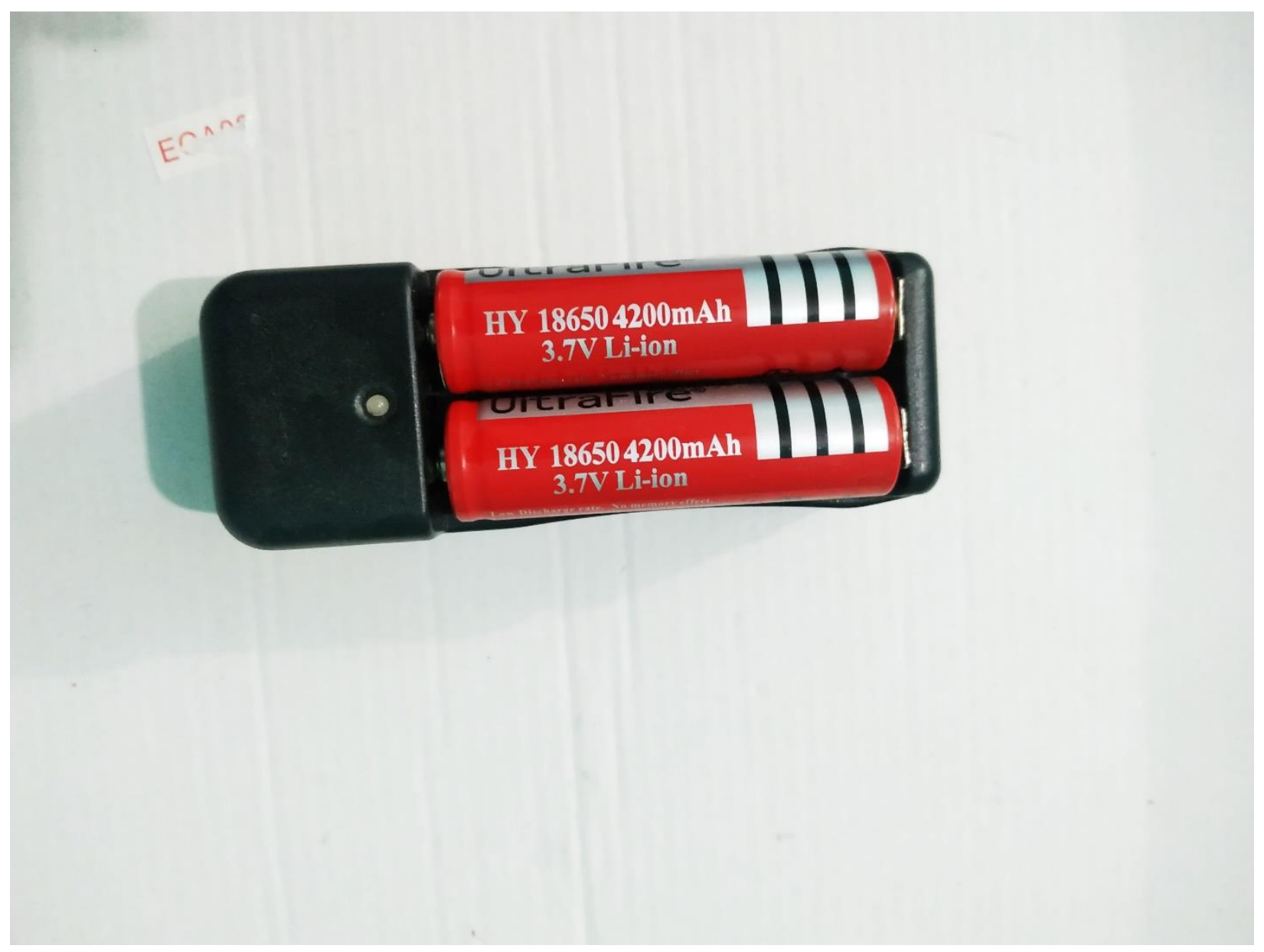

Fig. 4.3 Battery Charger 


\subsubsection{Buck converter}

A DC to DC power converter which steps down the voltage is a buck converter or a step-down converter. It has an output voltage that is lower than the voltage of the input. In our project, we have chosen LM2596 Buck Converter for its convenient specifications. The LM2596 has the highest $92 \%$ conversion efficiency and the switching frequency is $150 \mathrm{kHz}$ [23]. Then, the range of output voltage is $1.25-26 \mathrm{~V}$ and output current is maximum 3A [23]. In this converter, the diode has zero voltage-drop and zero current-flow and the inductor has zero series-resistance [23]. In our project, we have used the LM2596 Buck converter to reduce the voltage from the source batteries. The LM2596 Buck converter is shown in Fig. 4.4.

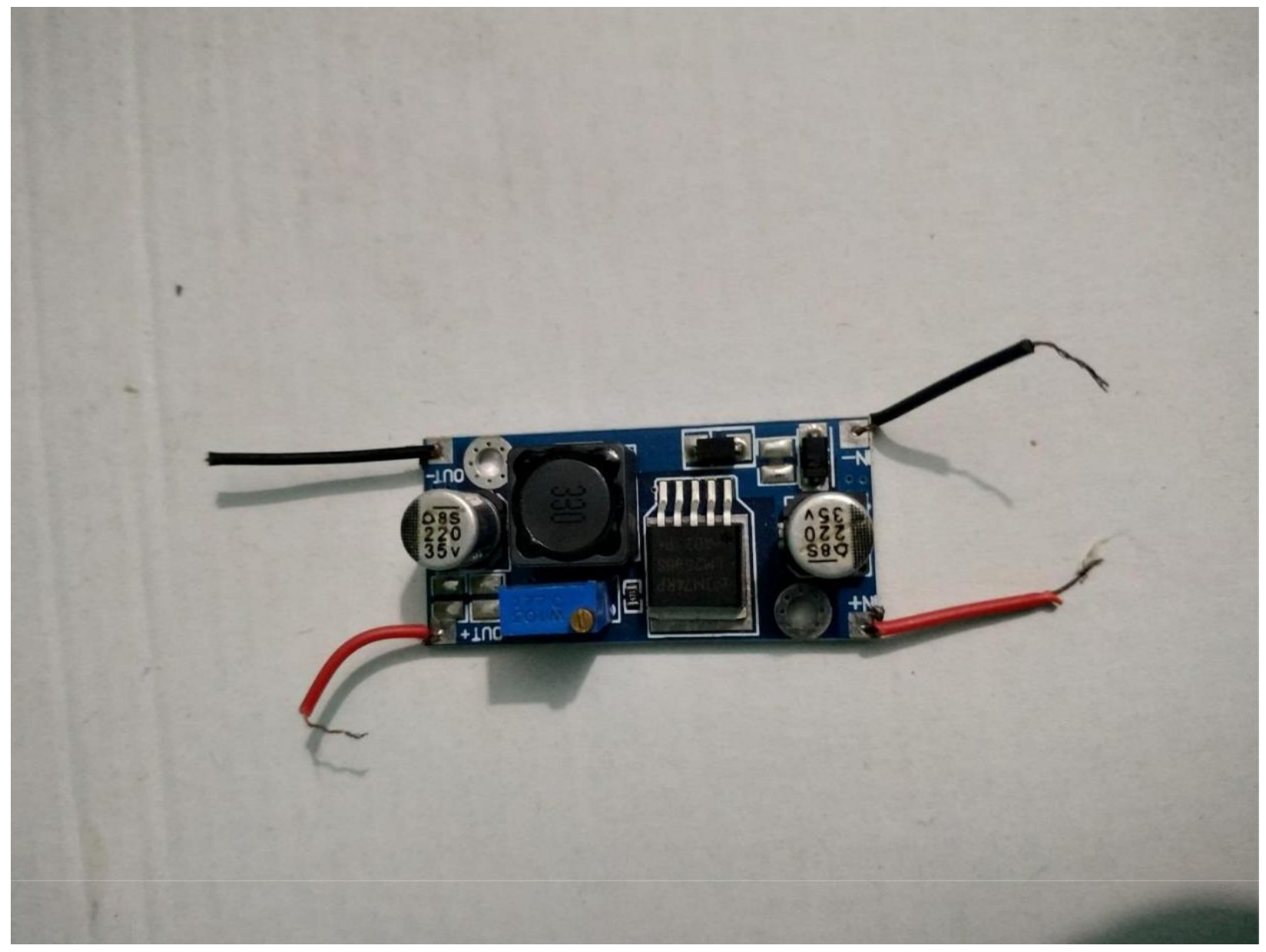

Fig. 4.4 LM2596 Buck converter 
In Switched-Mode Power Supply (SMPS) circuits, the Buck Converter is used where the DC output voltage has to be lower than the DC input voltage. In the electronics world, sometimes we have to reduce one DC voltage to a lower one. In our project, we need a $5 \mathrm{~V}$ voltage from two 3.7V Li-ion batteries set in the battery case. To get this voltage, we just add an LM2596 buck converter with the $7.4 \mathrm{~V} \mathrm{Li}$-ion battery case and it regulates the voltage down to $5 \mathrm{~V}$. With the help of a buck converter, we can easily convert the voltage from $7.4 \mathrm{~V}$ to $5 \mathrm{~V}$. It is shown in this subsection how the simulation model is configured to obtain various frequency functions.

\subsubsection{Boost converter}

A DC-DC power converter that increases the voltage is a Boost converter (step-up converter). A boost converter is one of the simplest types of the switch-mode converter. It takes an input voltage and boosts it or increases it. Everything it comprises is an inductor, a semiconductor switch, a diode, and a conductor. Power for the boost converter can come from any suitable DC source, such as batteries, solar panels, grinders and DC generators [24]. A DC to DC converter with an output voltage greater than the source voltage is a boost converter. We can easily convert the voltage from $7.4 \mathrm{~V}$ up-to $40 \mathrm{~V}$ with the help of a boost converter. The boost converter is shown below in Fig.

4.5 .

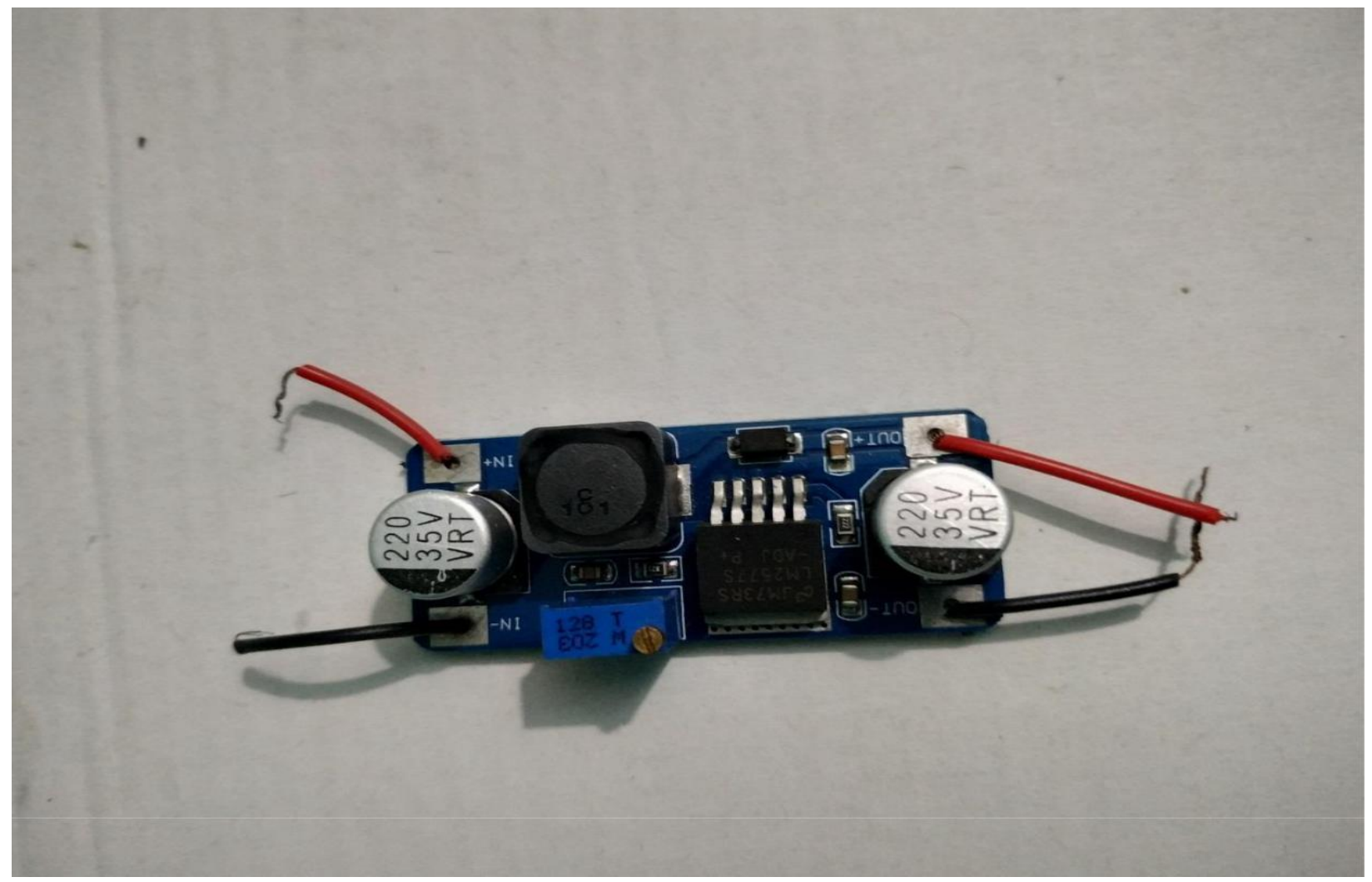

Fig. 4.5 LM2577S Boost Converter 


\subsubsection{Voltage Sensor}

The Voltage Sensor is an accurate, low-cost voltage measurement sensor that is based on the resistive voltage divider design theory. The voltage sensor is used to calculate and track the voltage level of an object. The introduction of voltage sensor techniques and current sensor techniques has become an excellent alternative for traditional methods of calculating current and voltage. We have selected one voltage sensor that is small, cheap and available. The range of input voltage is 0 to $25 \mathrm{~V}$. The Dimensions of the voltage sensor is $4 \mathrm{~cm} \times 3 \mathrm{~cm} \times 2 \mathrm{~cm}[25]$. This voltage sensor does not require any external components. It has 5pins in total - VCC, GND, Signal(S), + and - pins[25]. It is very easy to interface with an Arduino or any other microcontroller. We have linked the voltage sensor S and (GND) pins to the Arduino Analog Pin and GND respectively. We used it to measure the voltage of the Arduino Uno. Here the voltage sensor is shown in Fig. 4.6.

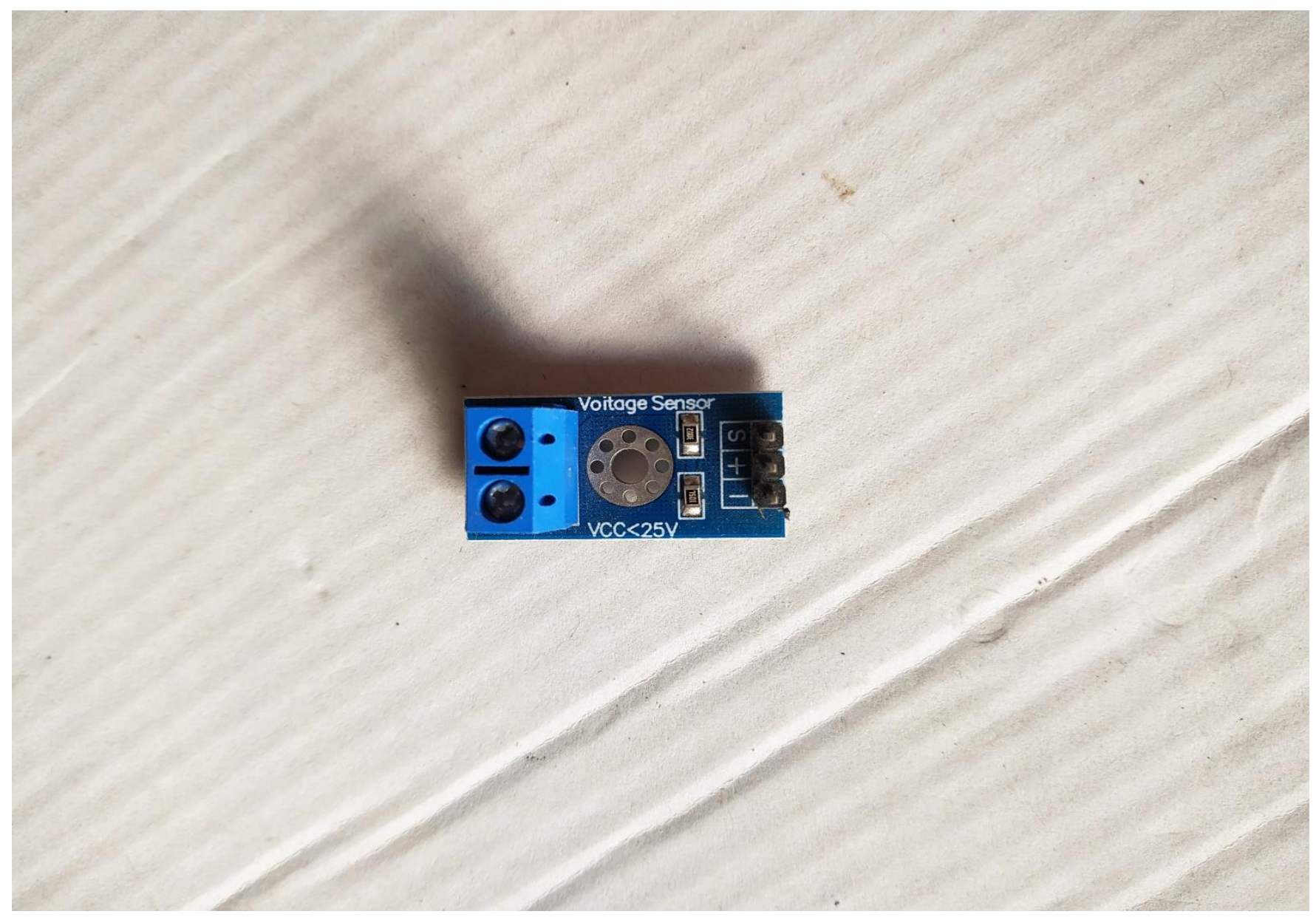

Fig. 4.6 Voltage Sensor 


\subsubsection{Power Requirements of Components}

Our satellite training kit's power requirements in-total depend on the power requirements of the individual components and how the components are used for operations together. Component and sub-system power specifications, including voltage and current levels, must be kept up-to-date during the design process to allow iterative input of accurate information into the simulation. We have calculated the overall power both in nominal mode and active mode. A description of the power demands of the above components is shown in Table- 2 below.

\begin{tabular}{|c|l|l|l|l|l|l|l|}
\hline \multirow{2}{*}{$\begin{array}{l}\text { Sub- } \\
\text { system }\end{array}$} & \multirow{2}{*}{$\begin{array}{l}\text { Name of } \\
\text { Components }\end{array}$} & \multicolumn{3}{|c|}{ Nominal mode } & \multicolumn{3}{c|}{ Active mode } \\
\cline { 2 - 8 } & $\begin{array}{l}3.7 \mathrm{~V} 4200 \mathrm{mAh} \\
\text { Li-ion battery }\end{array}$ & $3.7 \mathrm{~V}$ & $42000 \mathrm{~mA}$ & $15.54 \mathrm{~W}$ & $3.7 \mathrm{~V}$ & $4200 \mathrm{~mA}$ & $15.54 \mathrm{~W}$ \\
\hline \multirow{5}{*}{ EPS } & $\begin{array}{l}\text { Module } \\
\text { Lp2577S Step }\end{array}$ & $5 \mathrm{~V}$ & $3 \mathrm{~A}$ & $15 \mathrm{~W}$ & $40 \mathrm{~V}$ & $6 \mathrm{~A}$ & $240 \mathrm{~W}$ \\
\cline { 2 - 8 } & $\begin{array}{l}\text { LM2596 DC-DC } \\
\text { Adjustable Step } \\
\text { Down (Buck) } \\
\text { Module }\end{array}$ & $4.5 \mathrm{~V}$ & $3 \mathrm{~A}$ & $13.5 \mathrm{~W}$ & $40 \mathrm{~V}$ & $6 \mathrm{~A}$ & $240 \mathrm{~W}$ \\
\cline { 2 - 8 } & $\begin{array}{l}\text { Voltage } \\
\text { Sensor Module }\end{array}$ & $5 \mathrm{~V}$ & $10 \mathrm{~mA}$ & $0.05 \mathrm{~W}$ & $5.5 \mathrm{~V}$ & $13 \mathrm{~mA}$ & $0.0715 \mathrm{~W}$ \\
\hline
\end{tabular}




\begin{tabular}{|c|l|l|l|l|l|l|l|}
\hline COM & $\begin{array}{l}\text { HC12 Wireless } \\
\text { Transceiver } \\
\text { Module }\end{array}$ & $3.3 \mathrm{~V}$ & $30 \mathrm{~mA}$ & $0.099 \mathrm{~W}$ & $5.5 \mathrm{~V}$ & $100 \mathrm{~mA}$ & $0.55 \mathrm{~W}$ \\
\hline
\end{tabular}

\begin{tabular}{|c|c|c|c|c|c|c|c|}
\hline \multirow{5}{*}{$\mathrm{OBC}$} & $\begin{array}{l}\text { BME280 } \\
\text { Temperature, } \\
\text { Humidity \& } \\
\text { Pressure Sensor }\end{array}$ & $3.3 \mathrm{~V}$ & $0.5 \mathrm{uA}$ & $\begin{array}{l}0.0000016 \\
5 \mathrm{~W}\end{array}$ & $3.6 \mathrm{~V}$ & $350 \mathrm{uA}$ & $0.00126 \mathrm{~W}$ \\
\hline & $\begin{array}{l}\text { GY-9250 } 9 \text { DOF } \\
\text { IMU Sensor } \\
\text { Module }\end{array}$ & $2.5 \mathrm{~V}$ & $280 \mathrm{uA}$ & $0.0007 \mathrm{~W}$ & $4 \mathrm{~V}$ & $350 \mathrm{uA}$ & $0.0014 \mathrm{~W}$ \\
\hline & $\begin{array}{l}\text { ESP32-CAM } \\
\text { WiFi + Bluetooth } \\
\text { Camera }\end{array}$ & $3.3 \mathrm{~V}$ & $310 \mathrm{~mA}$ & $1.023 \mathrm{~W}$ & $3.6 \mathrm{~V}$ & $1200 \mathrm{~mA}$ & $4.32 \mathrm{~W}$ \\
\hline & $\begin{array}{l}\text { Micro SD TF } \\
\text { Card Module }\end{array}$ & $5 \mathrm{~V}$ & $80 \mathrm{~mA}$ & $0.4 \mathrm{~W}$ & $5.5 \mathrm{~V}$ & $200 \mathrm{~mA}$ & $1.1 \mathrm{~W}$ \\
\hline & $\begin{array}{l}\text { GY-NEO-6M V2 } \\
\text { GPS Module }\end{array}$ & $3.3 \mathrm{~V}$ & $10 \mathrm{~mA}$ & $0.033 \mathrm{~W}$ & $3.6 \mathrm{~V}$ & $67 \mathrm{~mA}$ & $0.2412 \mathrm{~W}$ \\
\hline
\end{tabular}

Table-2: The power requirements of components. 


\subsection{On-Board Computer}

This segment describes available onboard computer components that are used in our satellite training kit. An On-Board Computer (OBC) summary is first discussed, along with the on-board computer specifications. Then the block diagram and the OBC (on-board computer) sensor calibration are displayed. This entire chapter is also focused on the topic of various sensors that we used in our satellite training kit. Three separate sensors were used in our project: the ESP32CAM sensor that is our main payload, followed by the BME280 Temperature, Humidity and Pressure Sensor, GY-9260 9 DOF IMU sensor and the GY-NEO-6 M V2 GPS sensor. The specification of these four sensors and a basic description are given in the chapter.

\subsubsection{The Operations of $\mathrm{OBC}$}

A satellite training kit is comprised of a variety of sub-systems, each performing its unique mission. An OBC's primary role is to promote cooperation between those various sub-systems [13]. The satellite's onboard computer is responsible for initiating dataflow between onboard hardware and compressing images. The Command and Data processing portion of the satellite will be on board the computer. It also plans and controls the satellite's payload activities. For its survival in the space environment, it serves as the satellite's heart and brain [13]. They communicate with the numerous other subsystems and sensors to guarantee the survival of the satellites. The on-board computer capabilities control very much the configuration of the rest of the satellite. They need optimization and careful scheduling to ensure that the on-board machine does not conflict with other criteria for real-time response. OBC will perform those operations:

- $\quad$ Memory Check

- $\quad$ Communication Window Check

- Health Monitoring Task

- Diagnostic Task

- $\quad$ Sequencer Task

- $\quad$ Synchronization Task

- Attitude Determination. 


\subsubsection{Block diagram and sensor calibration}

The on-board computer is the part of the satellite training kit that handles Command and Data. Fig. 4.7 demonstrates the OBC block diagram.

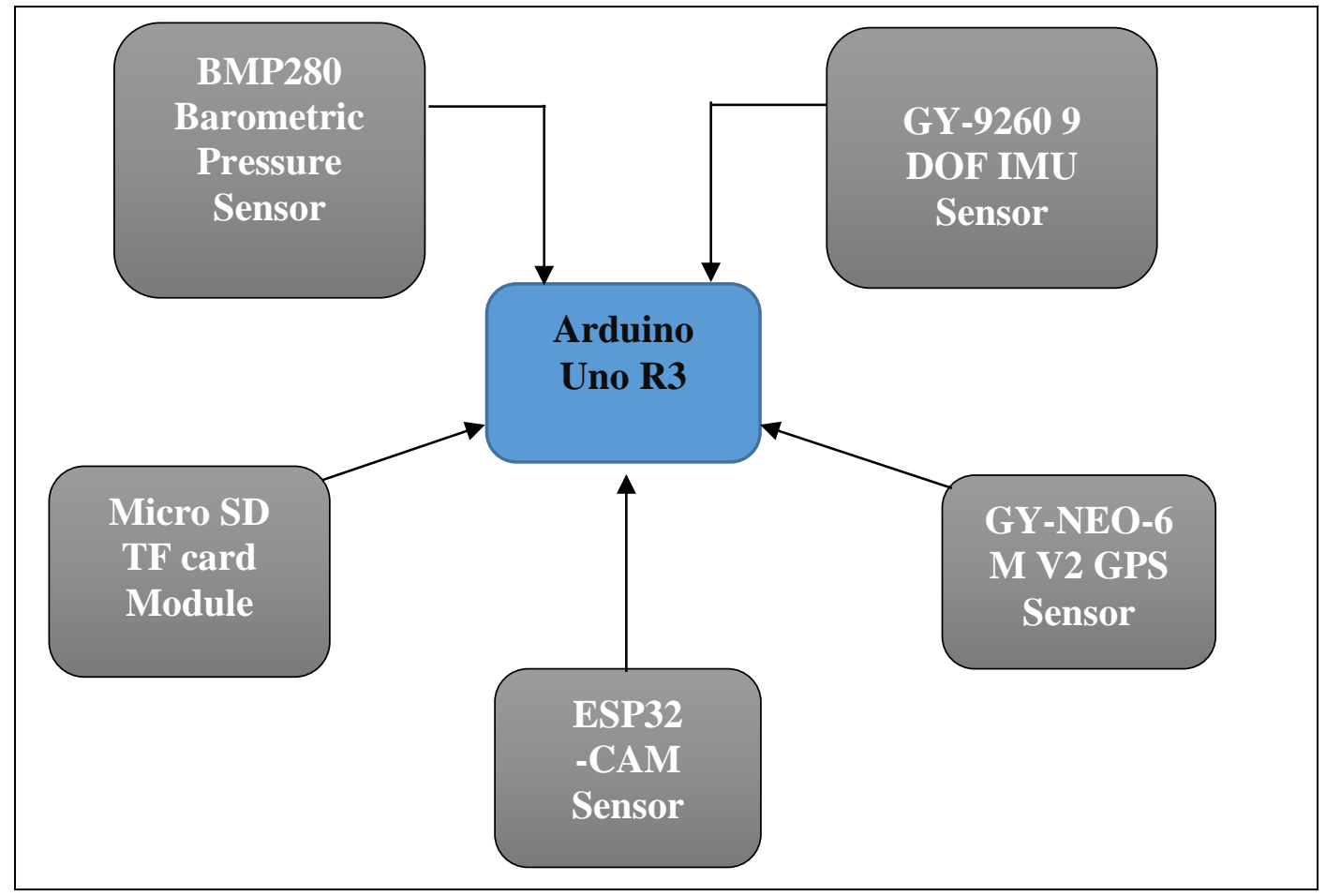

Fig. 4.7 Block Diagram of the On-Board Computer system. 


\subsubsection{Arduino Uno}

The microcontroller board we used for the OBC system is an Arduino Uno R3. It is a public platform for electronics that works on both hardware and software. This board has been a pioneer for loads of distinct applications and projects. Compared with other microcontroller platforms the boards are relatively cheap and very easy to use. However, it does give teachers and students some benefit over other schemes. The Arduino Uno is based on the ATmega328P micro-chip that comes pre-programmed with a bootloader. That specification allows us to upload new code without any external hardware programmer. This board possesses 14 digital input or output pins along with six analog inputs [26]. It contains a ceramic $16 \mathrm{MHz}$ resonator that allows the board to create waves of specific frequencies up to $16 \mathrm{MHz}$ and to choose specific frequencies up-to $16 \mathrm{MHz}$ from a signal [26]. The USB port can be used to power up as well as to program the board. However, the power jack can only be used to power up the board [26]. Next, the reset key is to reset the board. Lastly, the AVR tiny programming header is an In-Circuit Serial Programming (ICSP). This feature allows the microcontroller to be re-programmed without disconnecting from the circuit. It can simply be connected either to a computer with a USB cable or with an AC-to-DC adapter or to any battery for power. That is why we have chosen the Arduino Uno will be used to calibrate all OBC (Onboard Computer) payloads in this project. Here, the Arduino Uno R3 is shown in Fig. 4.8 .

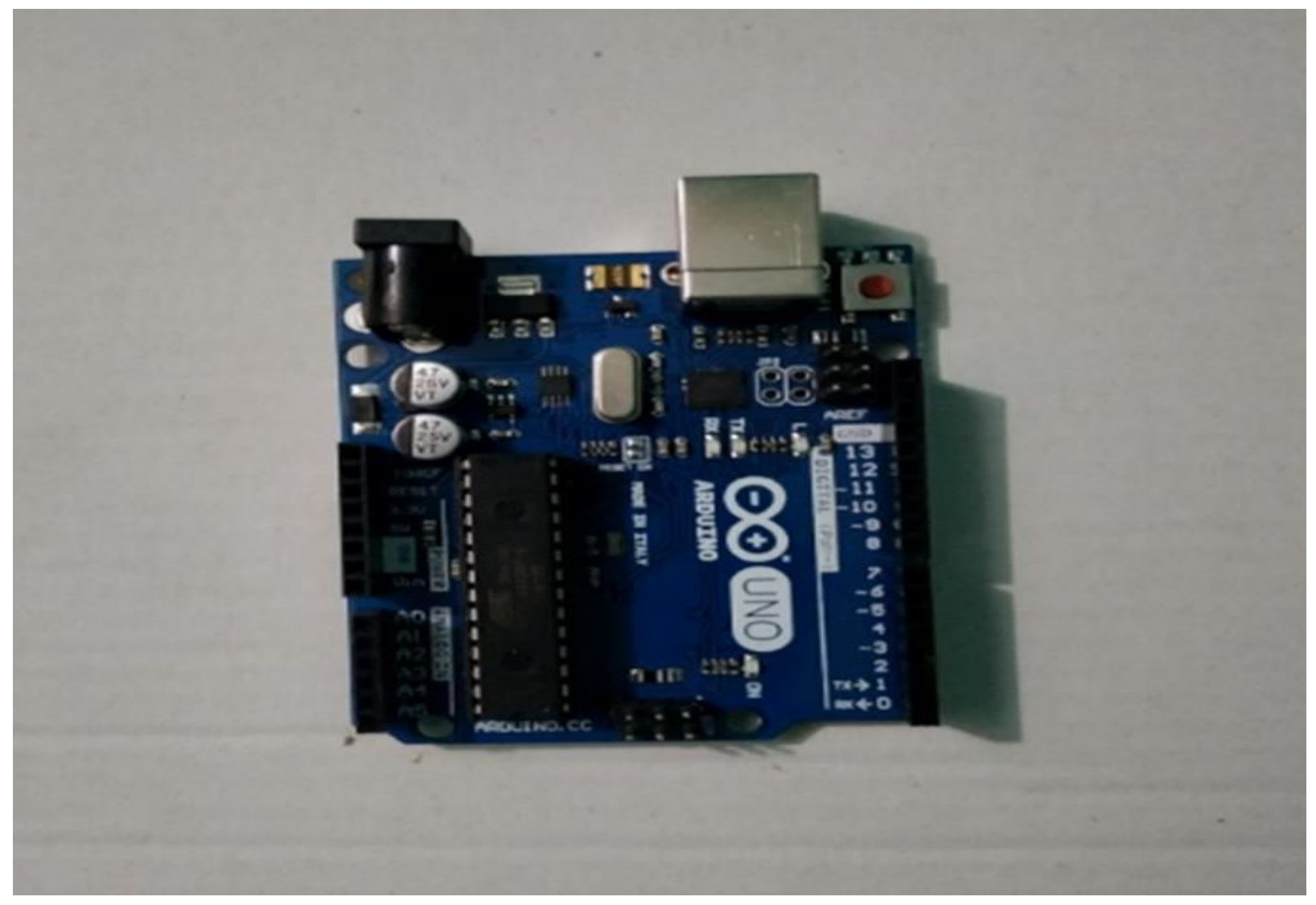

Fig. 4.8 Arduino Uno R3 


\subsection{Payloads}

We used Arduino Uno as our motherboard for our Onboard computer portion. Our key pay-load sensor is the ESP-32 CAM sensor. This camera sensor possesses a built-in SRAM of $520 \mathrm{~KB}$, an external PSRAM of $4 \mathrm{M}$ and SPI Flash of $32 \mathrm{Mbit}$. It supports six interfaces including UART / SPI / I2C / PWM / ADC / DAC and has a serial port limit of 115200 bps. We used the BME280 module as our temperature, humidity \& pressure sensor, GY-9260 9 DOF module as the IMU sensor and GY-NEO-6 M V2 module as our GPS sensor. We used a Micro SD TF Card Module to store all of the payload data as a backup. All these payload sensors are calibrated using the Arduino Uno.

\subsubsection{Camera sensor}

We will be taking a picture of this project by using an ESP32-CAM camera. The function of the sensor is to take a photo and save it in the micro SD card module. ESP32-CAM is a combination chip of single $2.4 \mathrm{GHz} \mathrm{Wi}-\mathrm{Fi}$ and Bluetooth. It is designed to achieve the highest performance in ultra-low power of $40 \mathrm{~nm}$ and low RF. The small 10gram chip demonstrates adequate robustness, versatility, and reliability in the aspect of applications and control scenarios. Its operating voltage is $5 \mathrm{~V}$. The required output current varies from $6 \mathrm{~mA}$ up-to $310 \mathrm{~mA}$ depending on the operating modes [27]. The ESP32 contains a ROM of $448 \mathrm{~KB}$ for booting and core functions [27]. This 9 IO module has an external PSRAM of $4 \mathrm{M}$ along with one built-in SRAM of $520 \mathrm{~KB}$ for data and instructions on-chip [27]. It possesses an internal calibrated RC oscillator and another internal calibrated oscillator of $8 \mathrm{MHz}$. Besides, it has an SPI Flash of $32 \mathrm{Mbit}$ and 3 different picture output format sizes including JPEG/BMP/GRAYSCALE [20]. Moreover, this sensor supports six interfaces including UART / SPI / I2C / PWM / ADC / DAC and has a serial port limit of 115200 bps. Fig. 4.9 shows the ESP32 CAM sensor. 


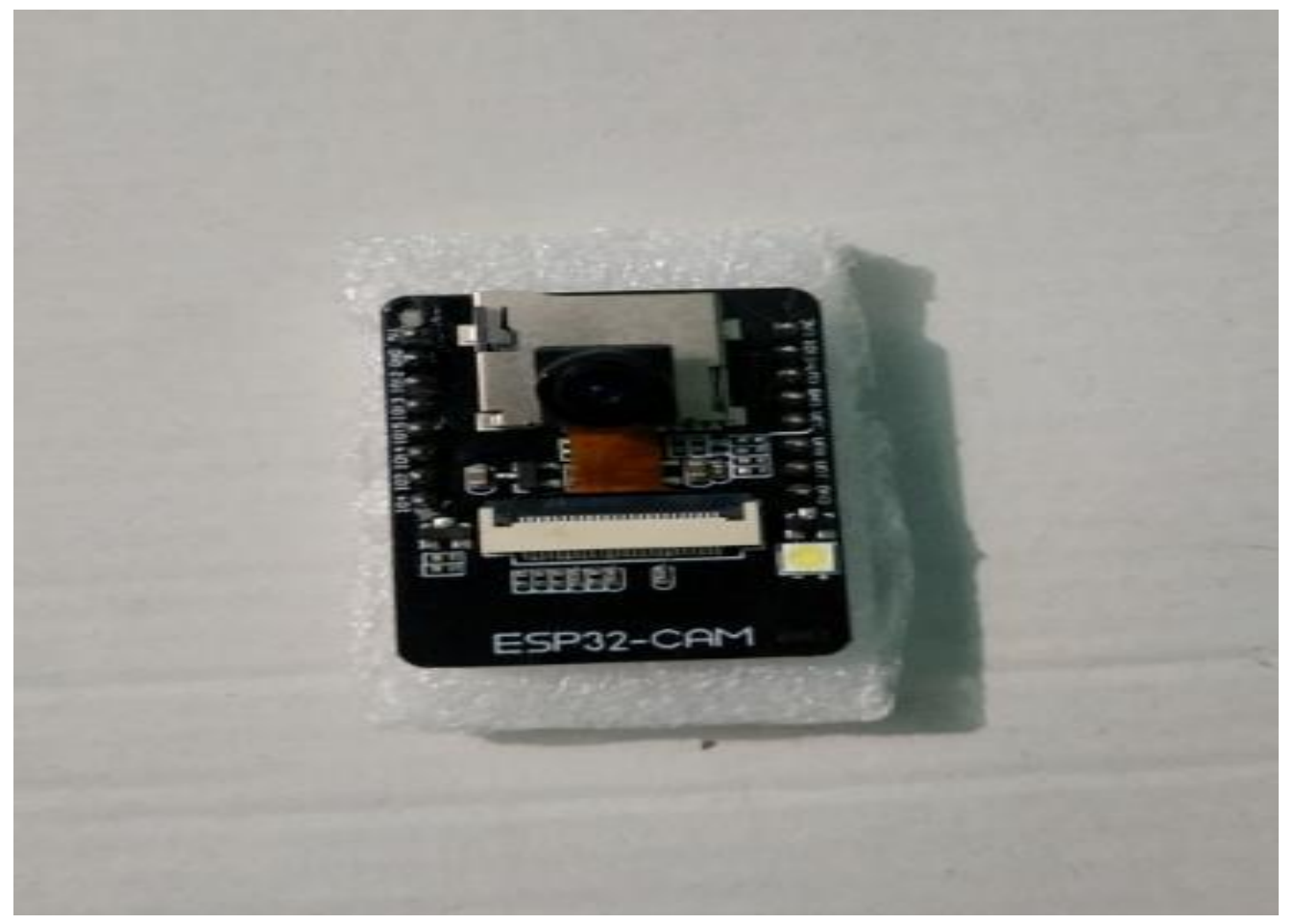

Fig. 4.9 ESP32-CAM sensor

\subsubsection{Micro SD Card module}

The MicroSD TF Card adapter is a Micro SD card reader module for reading and writing through the file system. We will use the micro SD TF card module to store the payloads data as a backup. The user module of the SD Card (Secure Digital Memory Card) implements an interface of the SD / MMC cards. The Communications interface of this module is a standard SPI interface that enables the chip to read and write functions for a microcontroller device. It also uses one or more port pins for chip collection, card detection and notification to secure the data. And, this module supports two kinds of cards: an SD card (Micro SD card $(<=2 \mathrm{G})$ and Micro SDHC card $(<=32$ $\mathrm{G}$ ) [28]. It has a power range of between $4.5 \mathrm{~V}$ to $5.5 \mathrm{~V}$. And the required current varies from 0.2 $\mathrm{mA}$ up to $200 \mathrm{~mA}$ [28]. The micro SD card is shown in Fig. 4.10. 


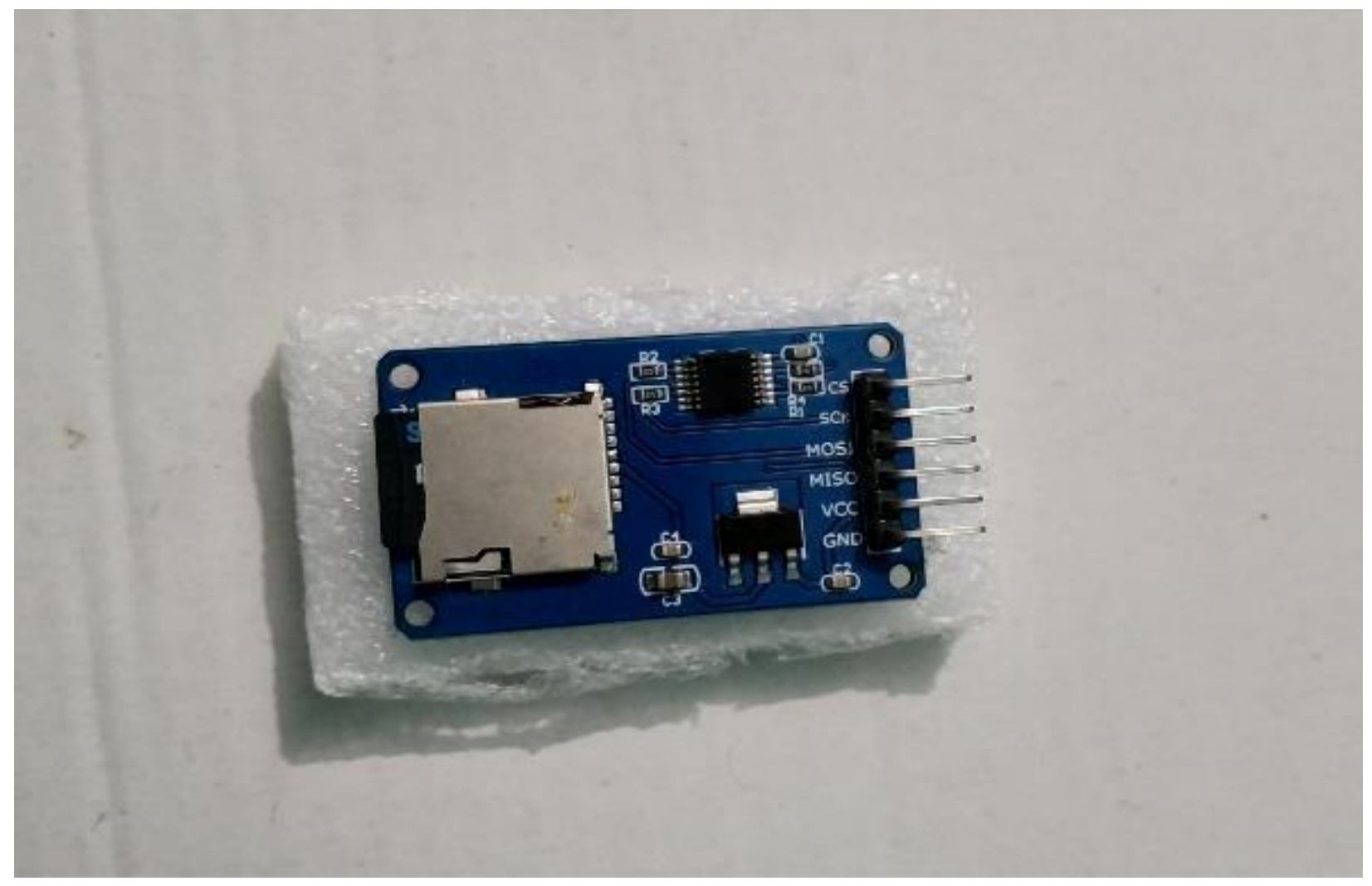

Fig. 4.10 Micro SD Card module

\subsubsection{Barometric Pressure Sensor}

We used the BMP280 sensor in our project to measure temperature, humidity and pressure. The BMP280 is a combined digital sensor for moisture, pressure, and temperature with validated sensing concepts. This 6 pin sensor is easily compatible with battery-powered devices because of its low power consumption. The BME280 achieves high performance and accuracy in all humidity and pressure calculation related projects because of its lower noise. This $11.5 \mathrm{~mm} * 15 \mathrm{~mm}$ sensor provides an extremely fast response time over a Temperature range of 40 to $+85{ }^{\circ} \mathrm{C}$ [29]. Besides, it can estimate the ambient temperature and dew point at any particular time. And the barometric pressure with extremely high sensitivity and resolution can calculate air pressure from 300 up to $1100 \mathrm{hPa}$ [30]. Its output is used for changing the temperature of the pressure and humidity sensor, and can also be used for estimating. This sensor can be distributed from 1.71 to $3.6 \mathrm{~V}$ and deactivated when current usage decreases to $0.1 \mathrm{uA}$ [29]. Besides, the peak current of this module is $1.12 \mathrm{~mA}$. It can be interfaced with both I2C (up to $3.4 \mathrm{MHz}$ ) and SPI (3 and 4 wire, up to $10 \mathrm{MHz}$ ) [30]. The sensor is shown below in Fig. 4.11. 


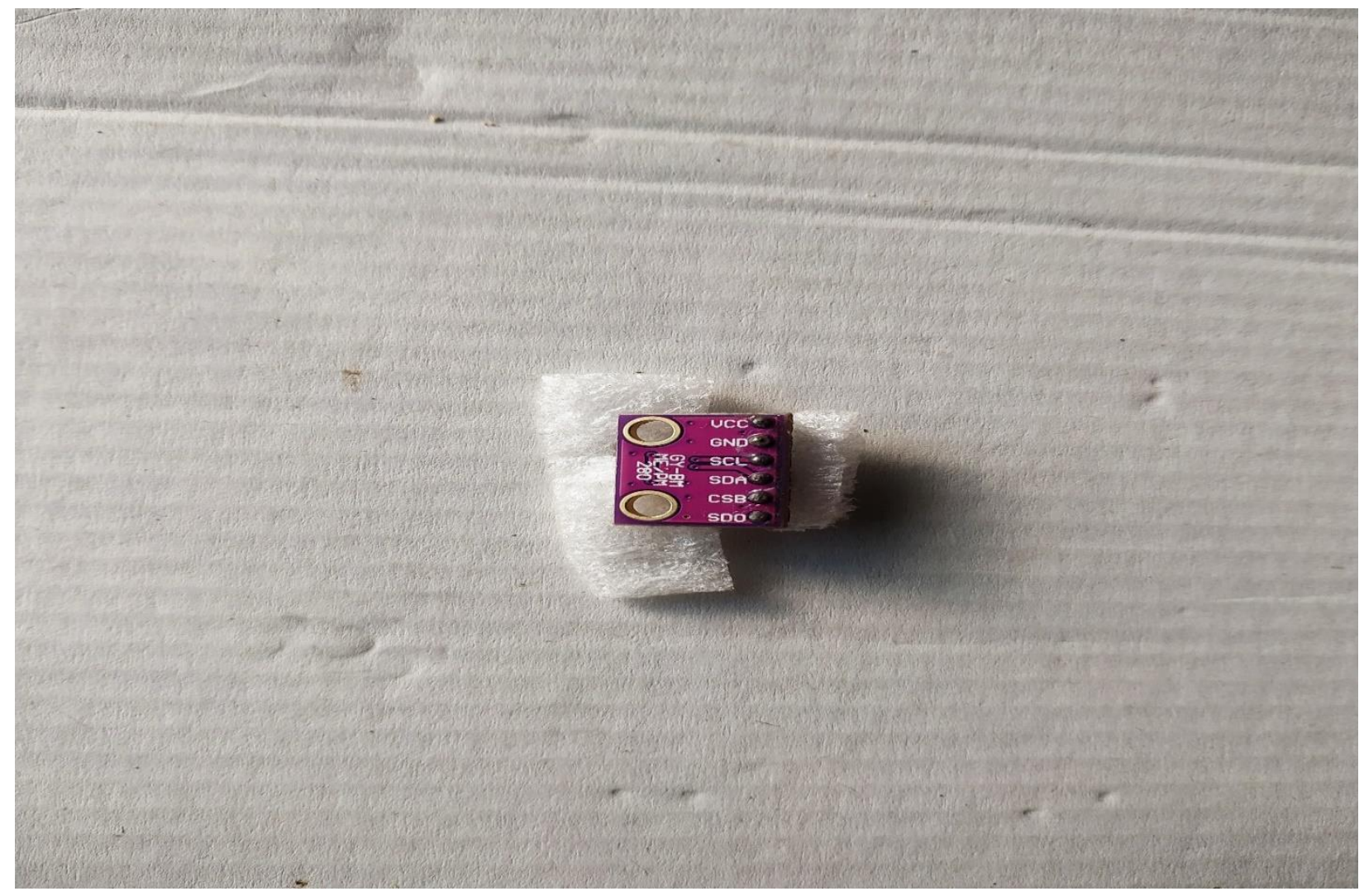

Fig. 4.11 BMP280 sensor

\subsubsection{GPS Sensor}

GPS is a satellite navigation device that orbits the Globe. We should have a good understanding of their positions since they give signals to us continuously. The daily life gadgets we use always send signals here and there. These signals are tracked by a GPS receiver on our computers. If the receiver determines the distance between four or more GPS satellites, it will be able to decode our position. GPS does not require any data to be transmitted by the user and functions independently of any telephone or internet reception, although the utility of GPS positioning data can be enhanced by these technologies [31]. We've used the GY-NEO-6 M V2 GPS sensor in our project. It has an advanced architecture and technology that suppresses source jamming and mitigates effects on multipath. The GY-NEO-6 M V2 GPS receivers have excellent navigation efficiency even in the most difficult environments. Its compact design and power and memory options make GY-NEO$6 \mathrm{M} \mathrm{V} 2$ GPS modules suitable for mobile devices powered by DC batteries with very low space and cost constraints [31]. The operating voltage is $3.3 \mathrm{~V}$. However, both $5 \mathrm{~V}$ and $3.3 \mathrm{~V}$ logic levels can define the Tx and Rx pin. Moreover, the celestial sensor data can be stored to onboard EEPROM by the chargeable backup battery (in power down situations) [31]. It possesses one uBlox NEO-6M chip onboard that supports multi-copter positioning and hot starts. Then, the module has a high-gain active antenna along with the default Baud rate of 9600bps [31]. This 
module will help us navigate our satellite position and also navigate our ESP32-CAM sensor coordinates. Here, the GPS sensor is shown in Fig. 4.12.

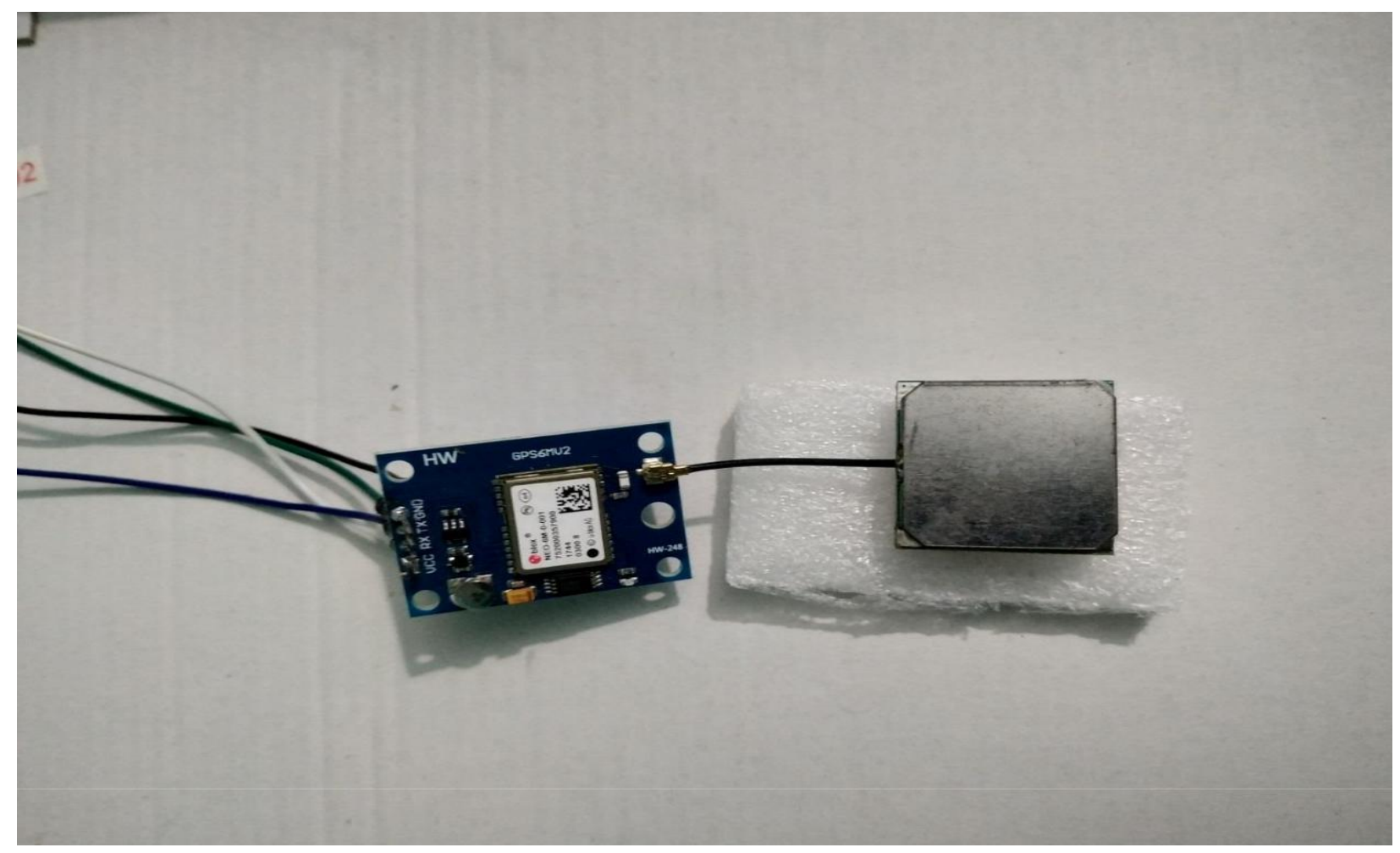

Fig. 4.12 GY-NEO-6 MV2 GPS

\subsubsection{IMU Sensor}

The MPU-9250 is the world's smallest 9-axis motion-tracking sensor that we are going to use as our Inertial Measurement Unit (IMU) sensor. This module comprises a 3-axis gyroscope, 3-axis accelerometer, 3-axis magnetometer along with a digital motion processor chip [32]. It is incorporated with the latest InvenSense design innovations. This module features three 16-bit ADC for digitizing the gyroscope outputs and three 16-bit ADCs for digitizing the accelerometer outputs and three 16-bit ADCs for digitizing the magnetometer outputs [32]. The Internal Digital Motion Processing engine supports advanced motion-processing and low power functions such as gesture recognition using programmable interrupts. The power supply of the sensor is 3 to $5 \mathrm{~V}$. The features of low power and high performance make it suitable for wearable sensors. This sensor can be interfaced with both SPI and I2C [32]. Fig. 4.13 shows the IMU sensor below. 


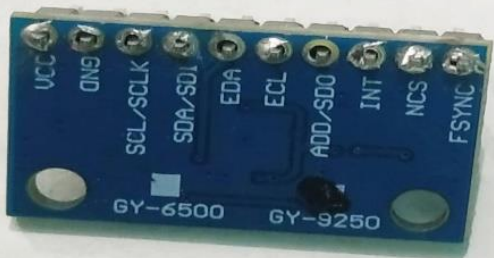

Fig. 4.13 IMU Sensor Module

\subsection{Communication System}

In this section, we discussed the communication system of our satellite training kit. A communication subsystem for any satellite is a critical functional feature, and cannot be ignored. Several other well-documented advances in the field of Nano-satellite engineering can have a profound impact on the communication subsystem. We established an outlook of our communication system shortly in this chapter. We have also introduced the basic idea of the Ground Station of our training kit. The ground station's key components are the HC-12 module and Arduino Nano. A ground station is of paramount importance for the success of the mission is the first and last piece of the communication link. Finally, a general overview of Ground Station is presented. 


\subsubsection{The operations of the Communication system}

A communication subsystem is a vital functional element for any satellite, and it cannot be overlooked. The method of communication is a method model that defines the communication exchange between two stations: the transmitter and the receiver. Signals or information moves through what is known as a conduit from source to distention, which is a way to use it to go from source to destination. The Communication System mainly defines the exchange of information between two points. An Antenna is a device or apparatus that radiates and receives electromagnetic waves. But they are used in transmitters as well as in receivers. An antenna is simply a metal structure, and sometimes a set of wires. The electromagnetic waves are polarized according to antenna location. Nano and Pico satellite communications systems are undergoing extremely rapid evolution. Early CubeSat carried basic beacon transmitters or could downlink only a small amount of data for housekeeping purposes, most of the time only. The image has changed drastically in recent times with many science missions flying and several more being suggested. Several commercial Earth observation systems are also being developed. This forced the designers of Nano-satellites to upgrade the communication sub-system to accommodate the data throughout required for current missions. Satellite/ground connectivity is also implemented using simple network protocols.

\subsubsection{Serial-Serial communication}

The technique of transmitting data one bit at a time, sequentially, over a communication channel or computer bus is serial communication in telecommunications and data transmission. This is in comparison with simultaneous communication with several parallel channels on a network, where many bits are sent in as a whole. The HC-12 transceivers can communicate for up to $1 \mathrm{~km}$ or more [16]. Our Arduino Nano will be calibrated with Hc-12 transceivers. Arduino will be powered through an Electrical power supply. The VCC pin of the HC-12 will be connected to Arduino Nano's $5 \mathrm{~V}$ pin. Hc-12 s Transmitting and Receiving pin will be connected to Arduino's digital pin. Hc-12 will receive the data from a memory card through Arduino Nano by serial 
communication method. Hc-12 will take those data saved by the onboard computer on the memory card in binary format after receiving the data Hc-12 will communicate with the ground station's Hc-12 and pass those data. Fig. 4.14 shows the communication block diagram.

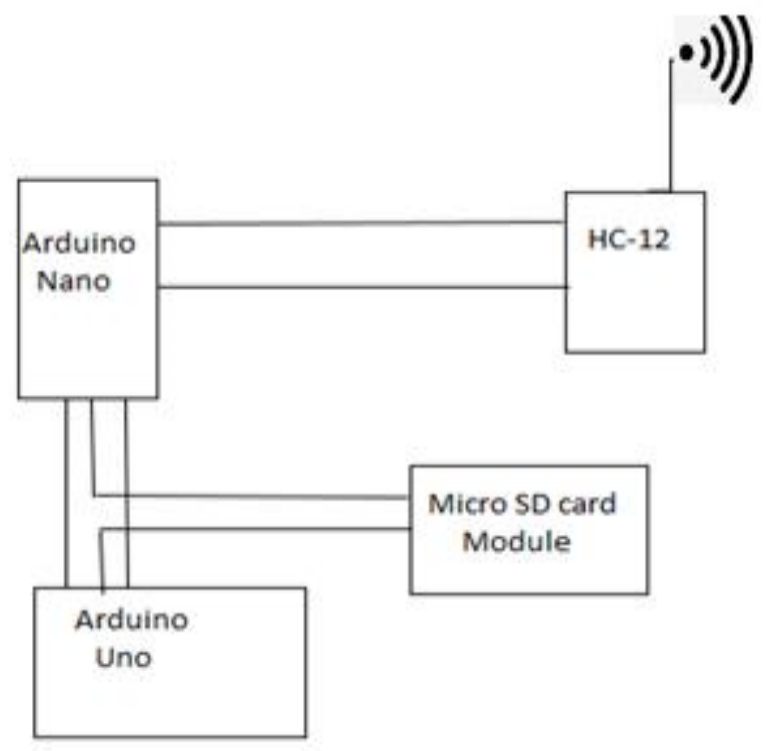

Fig. 4.14 Block diagram of the Communication System.

\subsubsection{Choosing components for Communication System}

There a lot of communication devices like Xbee, Zigbee Hc-12, etc. Xbee and Zigbee are quite similar to RF modules. They are full-duplex RF modules. However, these modules are costly and 
very hard to find in local markets. As our main focus is to make a satellite training kit and our budget is limited, therefore, we used HC-12 as our RF module which is cheaper than Xbee or Zigbee but the only major drawback is it is a half-duplex RF module. For our satellite training kit, the half-duplex transmission is good enough to observe the transmitting and receiving data. The Arduino Nano is a little, complete, and breadboard-accommodating board dependent on the ATmega328. The hardware of Arduino Nano is open source and it calibrates with Hc-12 easily. Therefore, Arduino Nano is used in this project. Here, the Zigbee board is shown in Fig. 4.15. Fig. 4.16 shows the Xbee module.

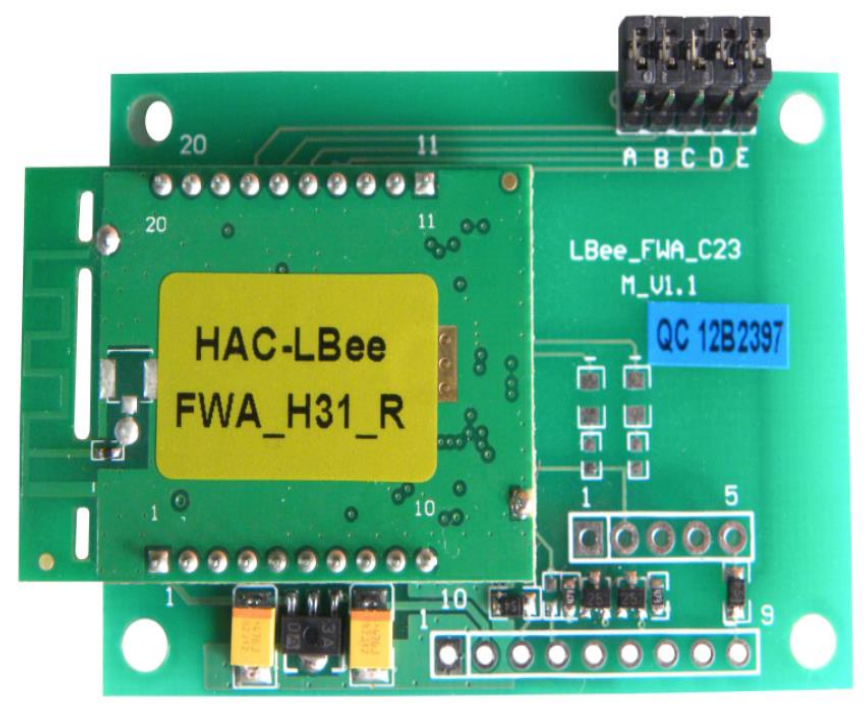

Fig. 4.15 Zigbee Board 


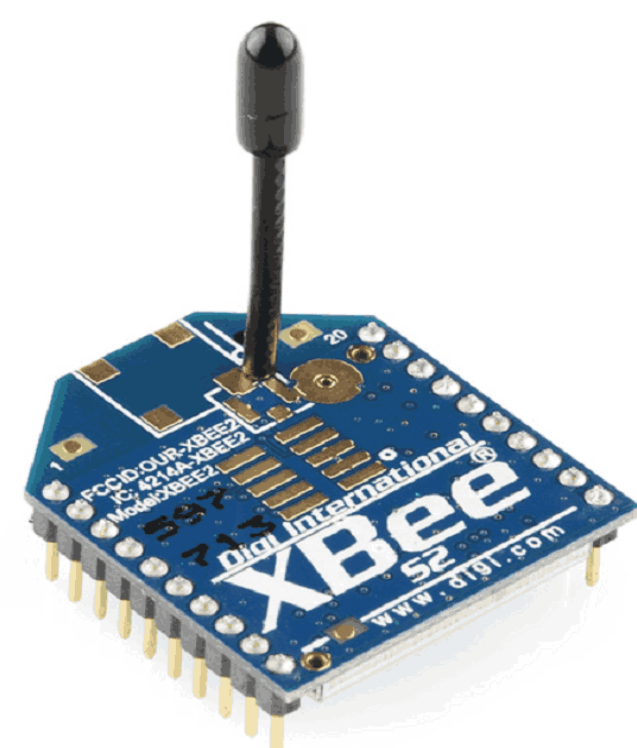

XBee Module

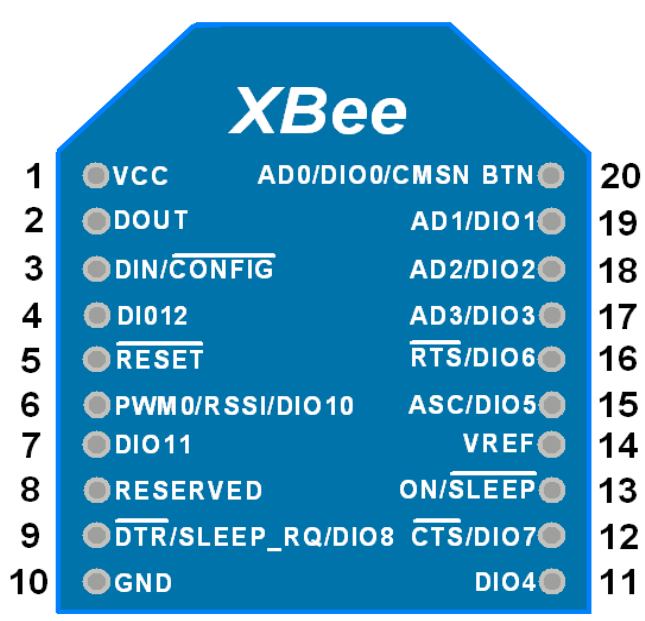

XBee Pin Configuration

Fig. 4.16 Xbee Module

\subsubsection{HC-12 module}

The HC-12 is a half-duplex wireless serial communication module capable of transmitting up to 1 $\mathrm{km}$, with 100 channels in the $433.4-473.0 \mathrm{MHz}$ range. HC-12 is a $20 \mathrm{dBm}(100 \mathrm{~mW})$ half-duplex transmitter coupled with a receiver. HC-12 transceiver, which offers a 4-pin TTL-level UART interface, with a 5th pin that is used to adjust the configuration of the module by entering "command" mode [16]. The HC-12 has 100 supported channels separated by $400 \mathrm{kHz}$, eight stages of transmission, eight supported baud rates, and three different modes of service [16]. Fig. 4.18 shows the picture of the HC-12 transceiver. Fig. 4.17 shows the HC12 module. 


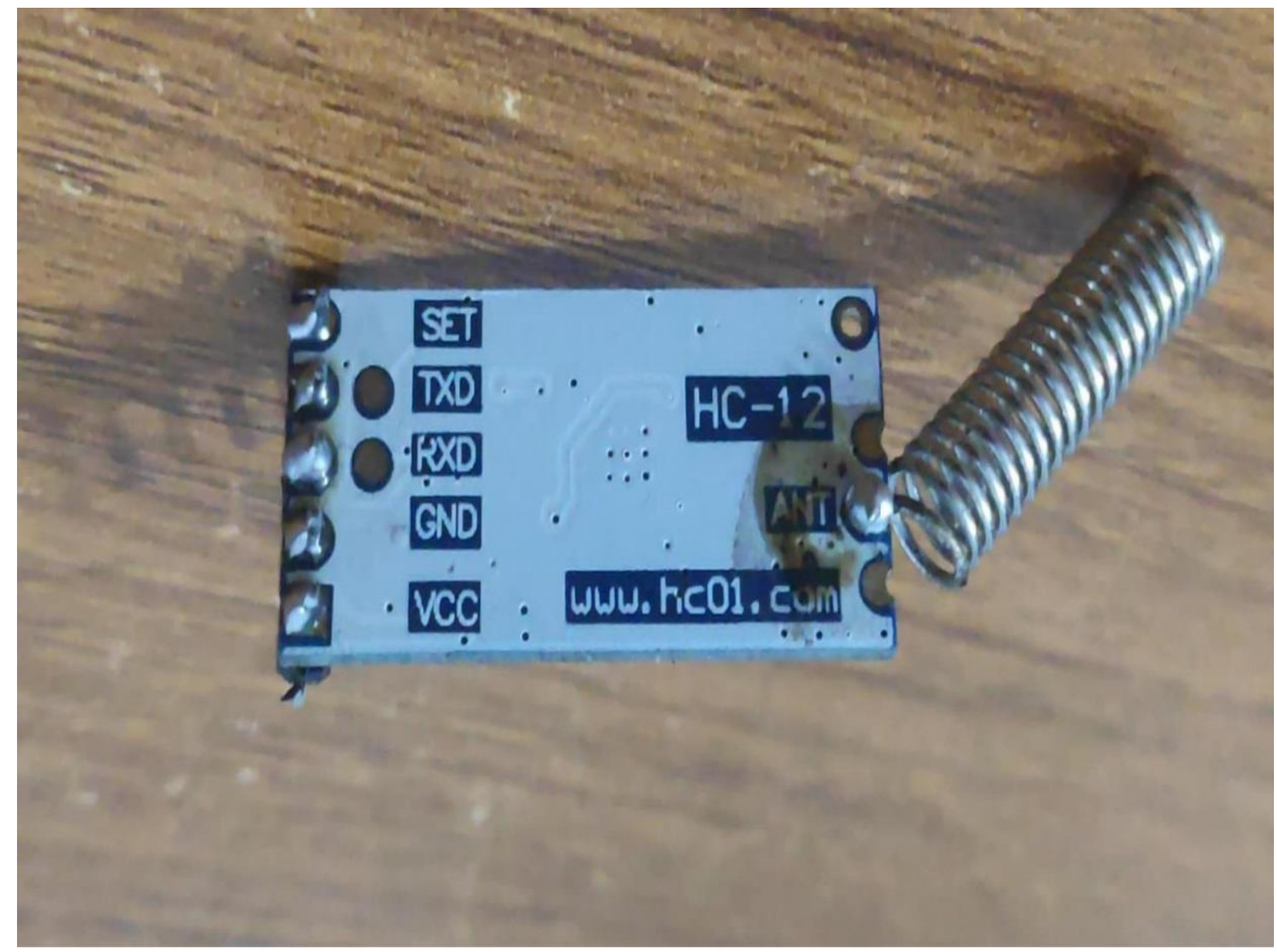

Fig. 4.17 HC-12 module

\subsubsection{HC-12 Working Method}

HC-12 module is utilized in physical wiring when replacing half-duplex communication [16]. The left gadget sends sequential port information to the module and the RXD port of the left module gets the sequential port information. At that point, it will consequently send the information into the air utilizing a radio wave. The correct module will naturally get the information and reestablish from TXD, the sequential port information initially sent by the left gadget [16]. The half-duplex state is available only between modules and they cannot receive and send data at the same time. The working methodology is shown in Fig. 4.18. 


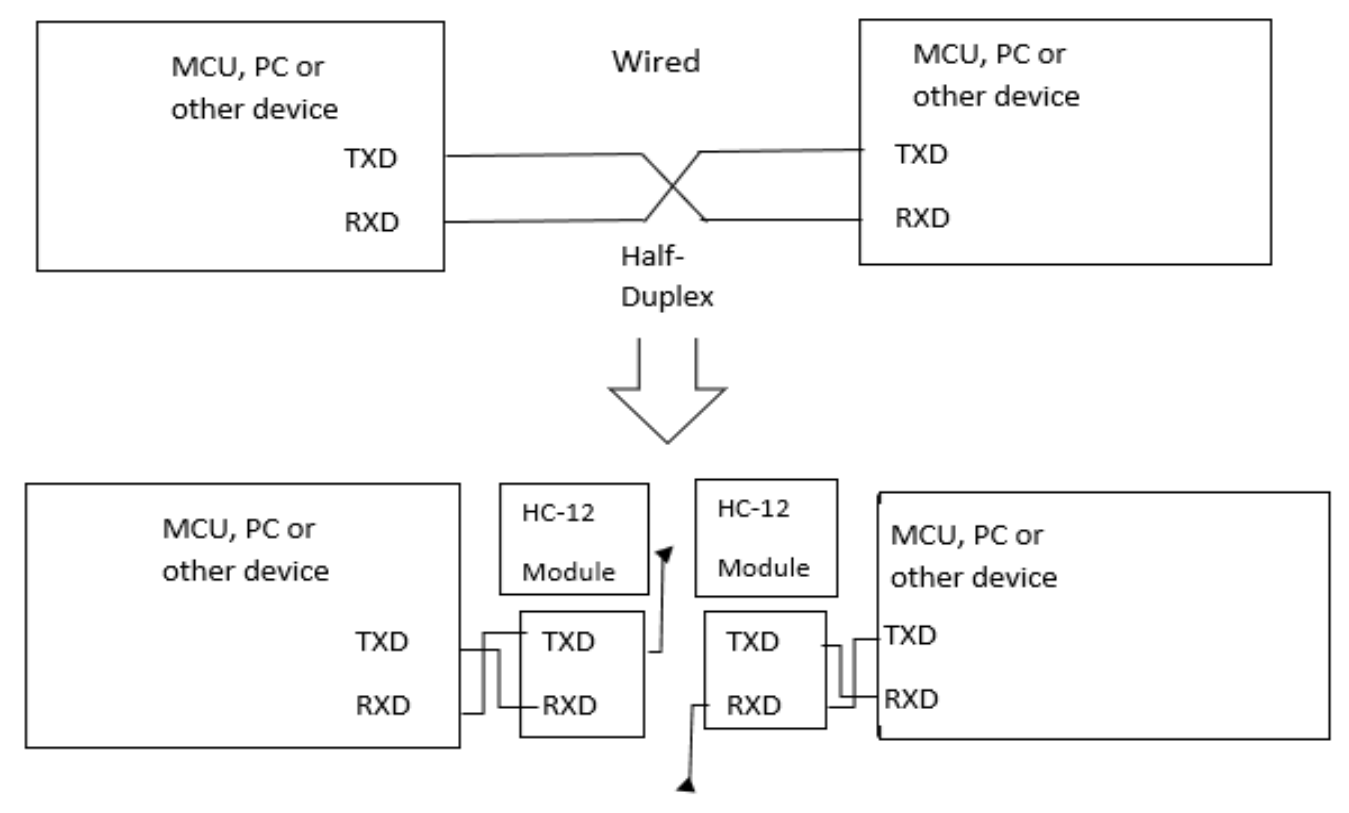

Fig. 4.18 HC12 wireless Serial port communication module

\subsection{The Role of Ground Station}

Ground stations are surface-based structures that are designed to provide satellite communication in real-time [10]. The crew at these stations relay radio signals to the satellite (uplink), receive transmissions of satellite data (downlink) and in some cases, serve as command and control centers for the satellite network [33]. The main objective is to track the satellite and receive its data to carry out the study afterward [33]. Data can be analyzed from the ground station, the satellite's altitude and motion, and information about its vital systems can be tracked, and decision-makers can control satellites [17]. If something goes wrong with a satellite, the crew at those stations is the first to find out [33]. They will be tasked with attempting to locate the source of the problem 
and to formulate a solution [17]. The ground station consists of an antenna that makes it very small for the system. The key components of ground stations are:

* Ground stations that have spacecraft radio interfaces

* Centers for mission control (or activities) from which spacecraft are controlled

* Ground networks, which link the other elements of the ground to one another

* Remote terminals, used by the support staff

If we want to send some kind of command to our OBC, then we have to send a signal to the HC12 of the communication system through our Ground Station. The HC-12 of the Ground station will receive data from the sensors through the HC-12 of the COM board. Then those data will be collected on a Laptop and analyzed via software. 


\section{Chapter 5}

\section{Field test of Satellite Training Kit}

\subsection{Introduction}

The objective of our field tests was to test the data transferring between the training kit and the ground station. These tests were used to identify the effectiveness of wireless serial communication. The field tests were conducted at different distances. The results for the different field test is described in the main segment.

\subsection{Test Setup}

We divided the test into two parts: I) Short-range and II) Long-range.

For the short-range test, both the kit and ground station were connected to different serial-ports of the computer. Thus, we could test that the receiving part (GS) is receiving the exact data sent by the kit. Then we separated the kit and placed it 3 meters apart from the ground station.

For the long-range test, we placed the kit 30 meters apart from the ground station. The communication range of $\mathrm{HC} 12$ is almost $1 \mathrm{~km}$. To test that range, 30 meters test was adequate for our kit.

\subsection{Field test for short-range}

For the short-range, we divided the procedure into two parts. Firstly, we connected the kit to one of the serial ports of the computer. So the kit was powered by a computer. And the ground station was connected to another serial port of the same computer. Through Arduino IDE software's serial monitor, we could test the exact data-communication process. We can see that 
the receiving part is receiving the same value. Here, the COM3 was the transmitting serial port and COM4 was the receiving serial port. The results are shown below in Fig. 5.1.

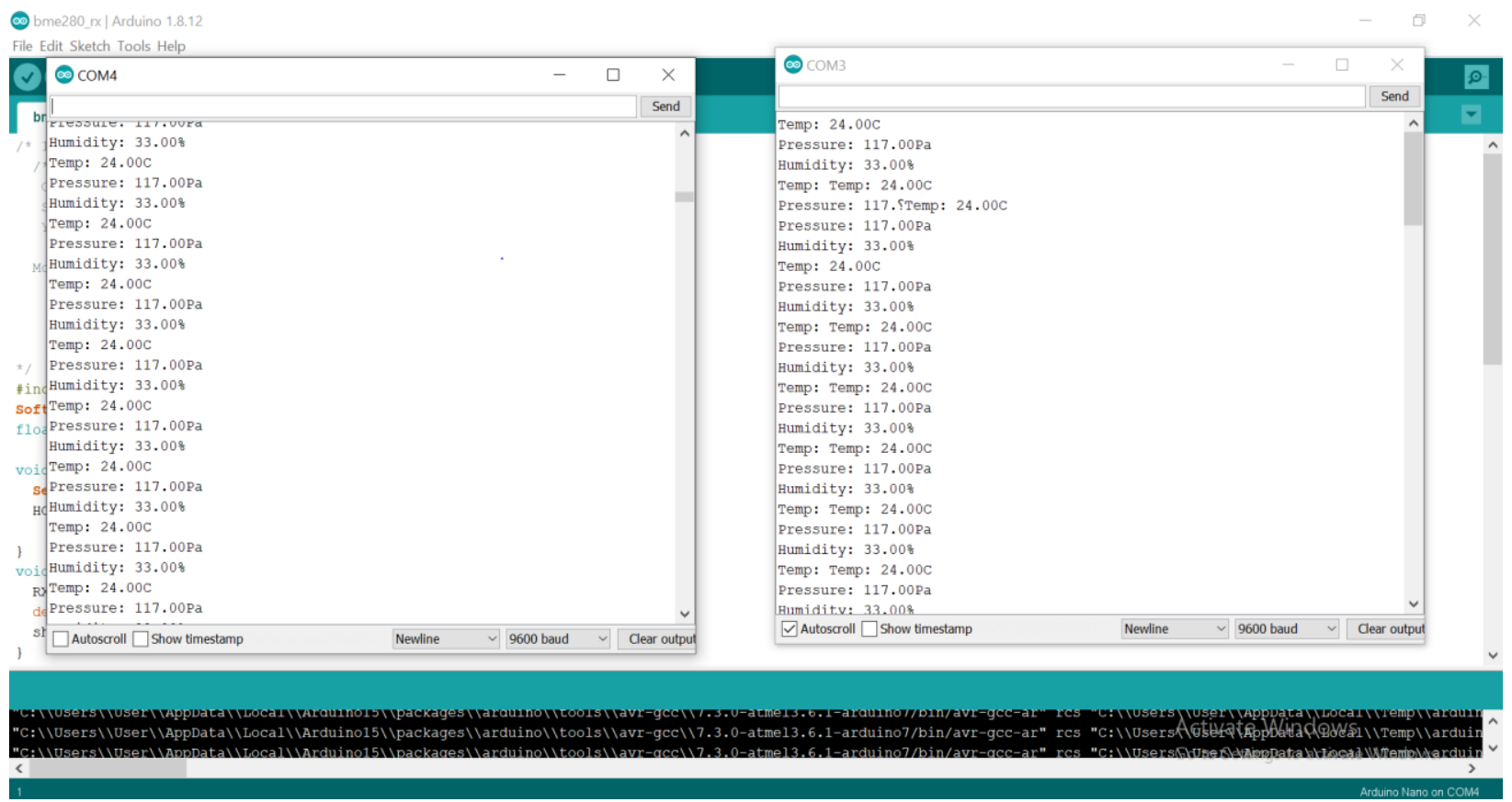

Fig. 5.1 Field test result for short-range

The IMU Sensor was calibrated with the Arduino board. The sensor was giving data about the movement of the training kit. The data is shown in Fig. 5.2.

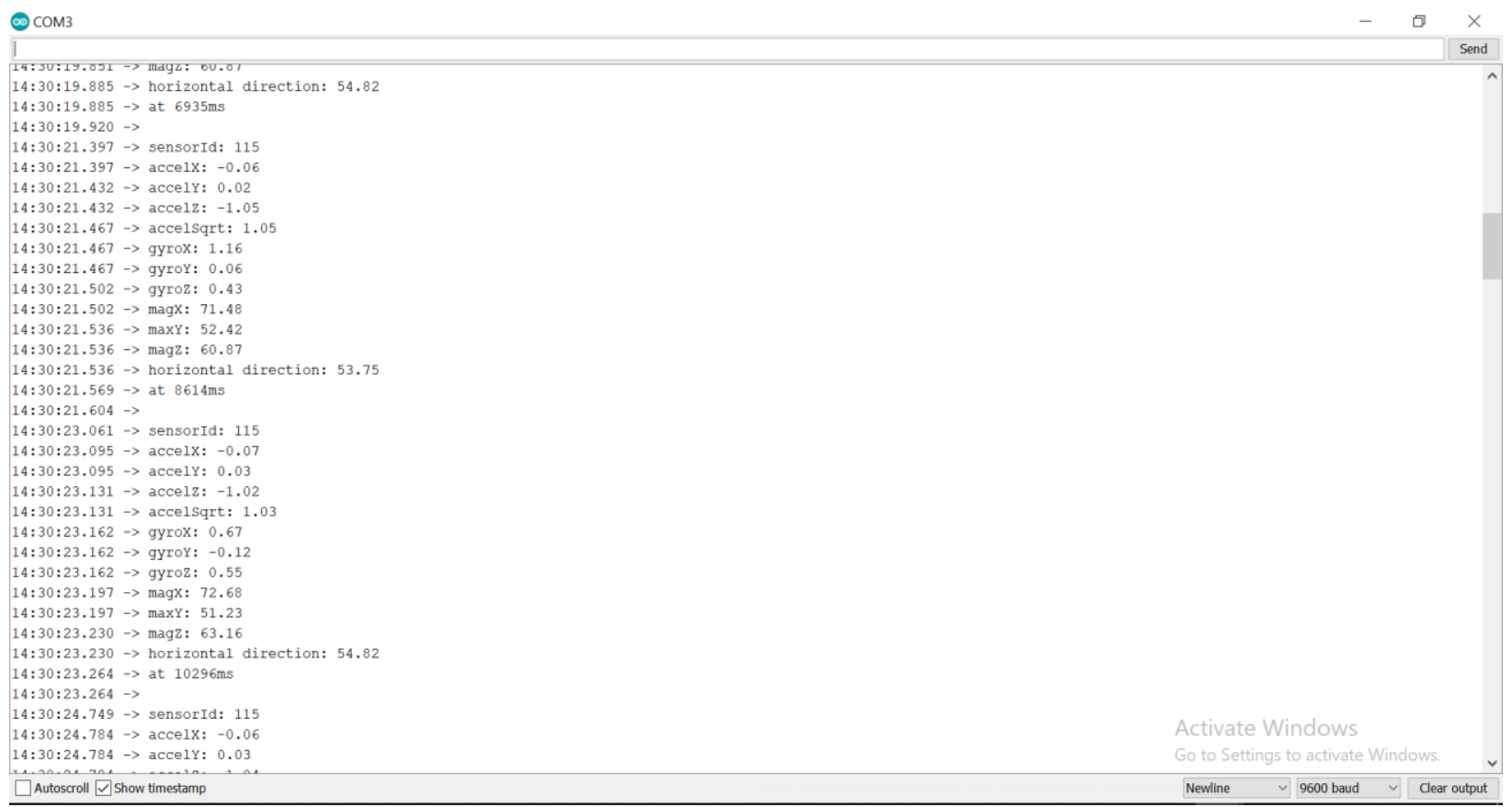

Fig. 5.2 IMU Sensor Data 
Similarly, the GPS Sensor was calibrated with the Arduino board. The GPS sensor was giving data about the positioning of the training kit. The sensor data is shown in Fig. 5.3.

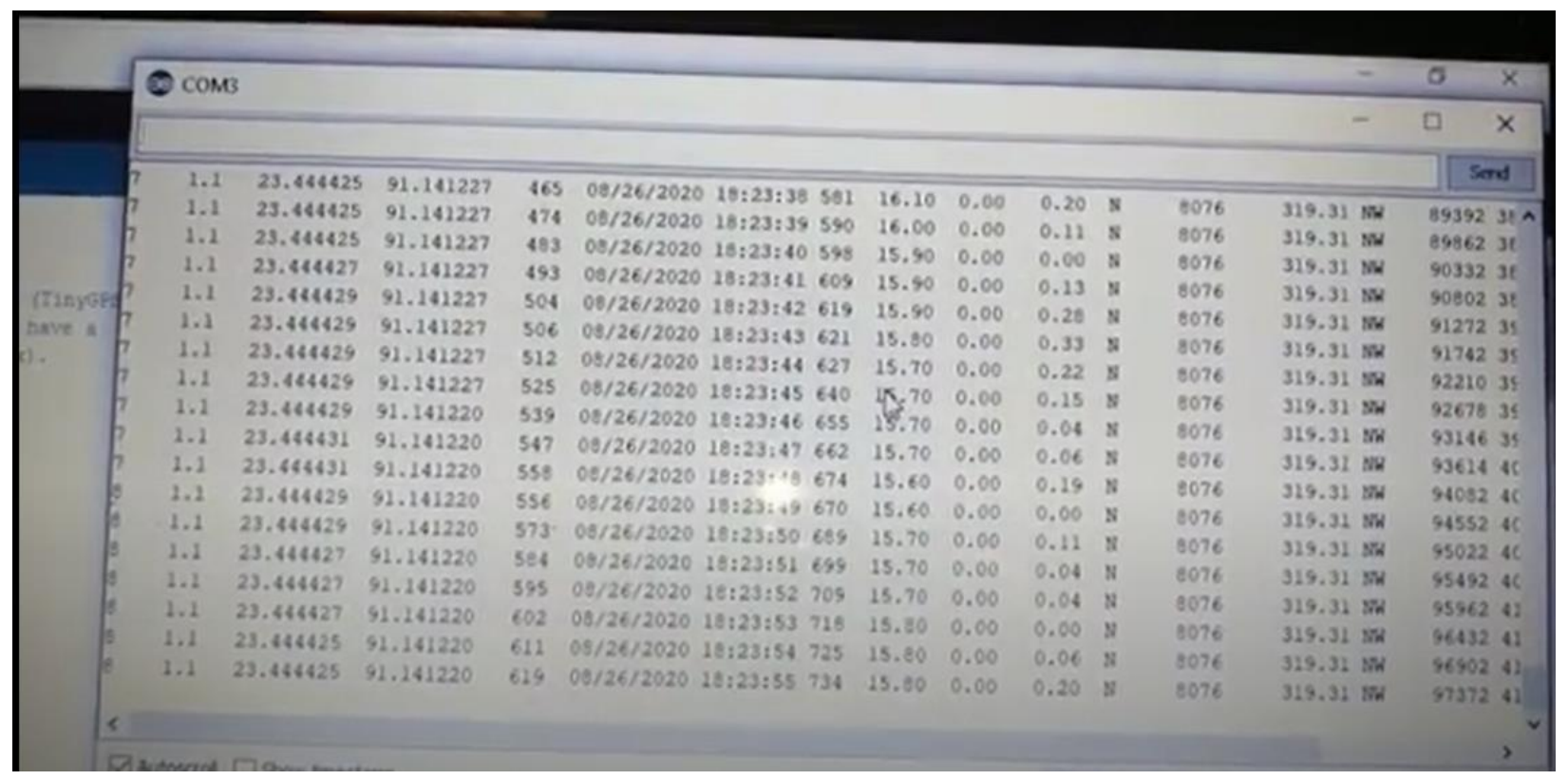

Fig. 5.3 GPS Sensor Data

We tried to log the BMP280 sensor data in the micro-SD card module. The logged data was saved in the SD card as a text file. The data logging results are shown in Fig. 5.4. 
DMP280LOG - Notepad

File Edit Format View Help

00

Pressure (64 bit): 101076.39

Temperature: 28.08

Humidity: 73.59

00

Pressure (64 bit): 101074.21

Temperature: 28.08

Humidity: 73.61

00

Pressure (64 bit): 101073.65

Temperature: 28.07

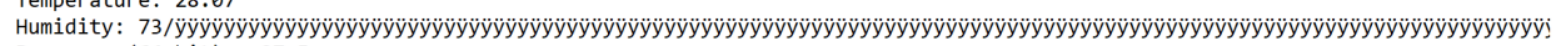

Pressure (64 bit): .97.5

Humidity: 73.60

.00

Pressure (64 bit): 101077.80

Temperature: 28.04

Humidity: 73.61

00

Pressure (64 bit): 101076.13

Temperature: 28.04

Humidity: 73.63

.00

Pressure (64 bit): 101079.07

Temperature: 28.03

Humidity: 73.65

Fig. 5.4 Data logging of the Micro-SD card module

The voltage sensor is responsible for measuring the voltage of the boost converter brunch. Here, we can see the voltage sensor measuring the voltage of the Arduino Uno board in the figure below. The voltage sensor data is shown in Fig. 5.5.

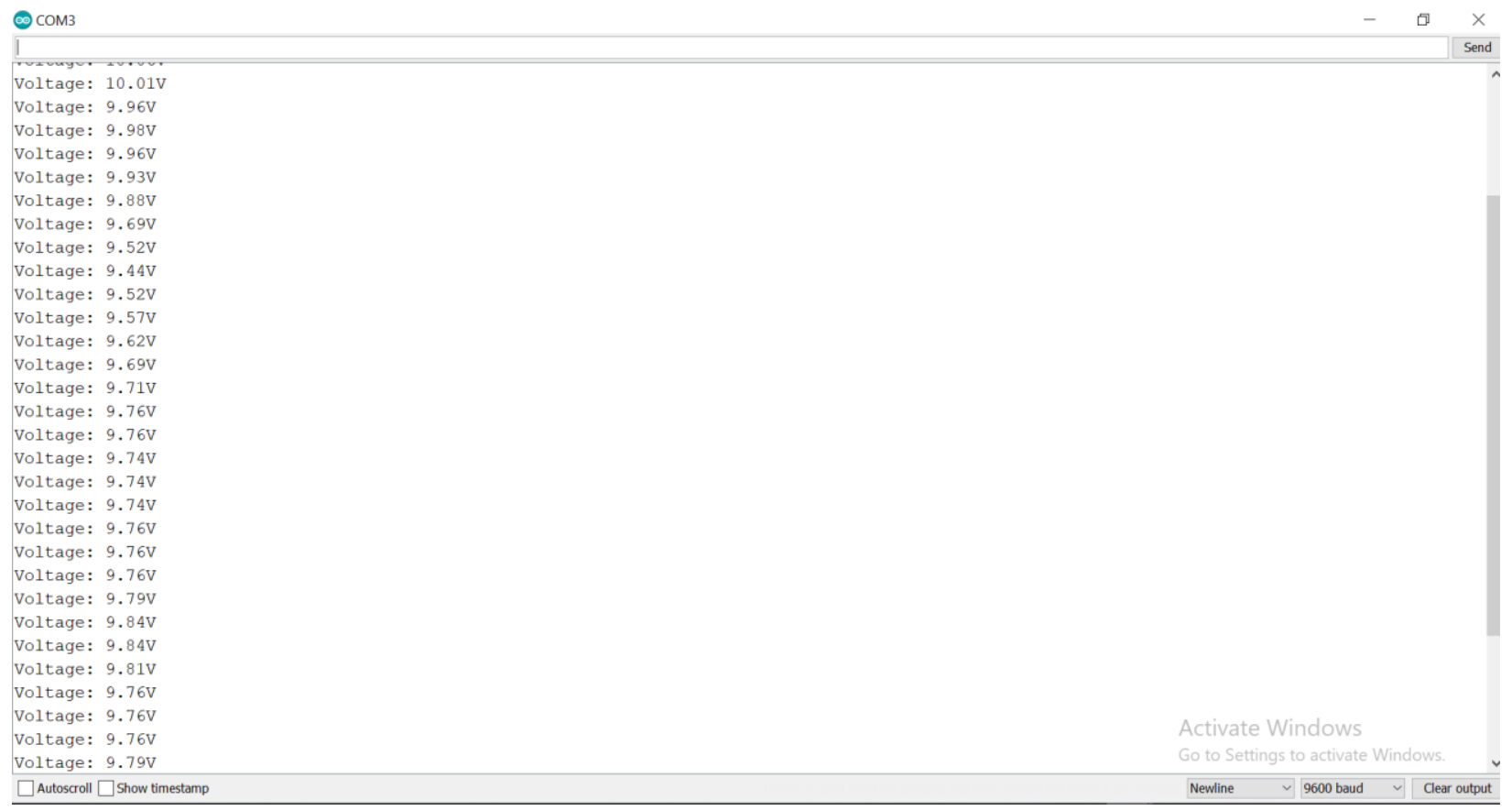

Fig. 5.5 Voltage Sensor Data 


\subsection{Field test for long-range}

For the long-range test, we placed the kit 30 meters apart from the ground station. And the ground station stack was connected with the computer. The kit was sending data from 30 meters distance by wireless serial communication. From the results, we can see the ground station was receiving the correct data. So, our wireless serial communication was successful. As a result, our training kit was executing perfectly. The results are shown below in Fig. 5.6.

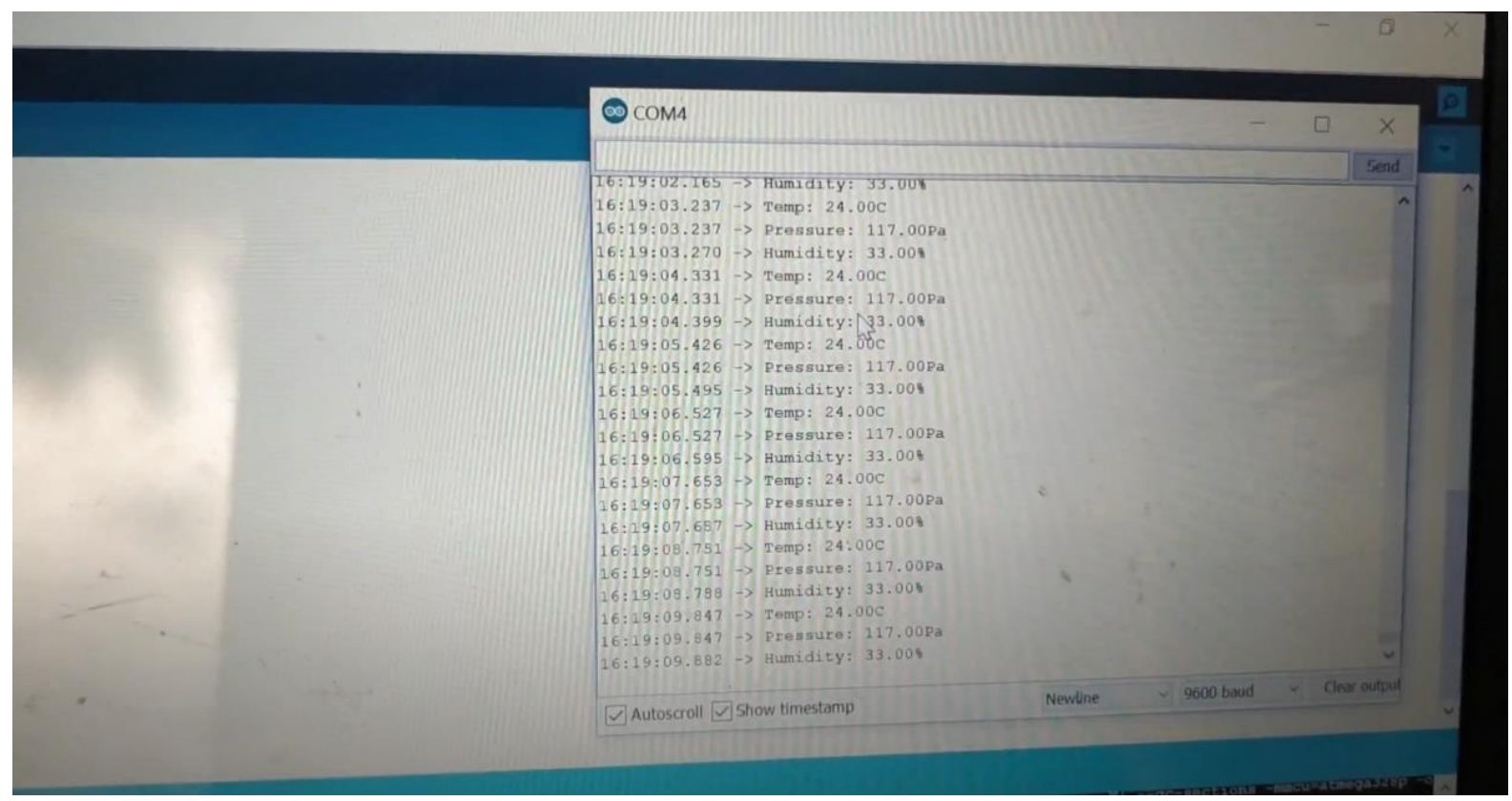

Fig. 5.6 Field test result for long-range 


\section{Chapter 6}

\section{Conclusion}

\subsection{Conclusion}

Our proposed satellite preparing unit is basic and simple for the students which are going to be utilized for instructive purposes. As referenced in a prior section enormous satellites are expensive, thusly everyone does not have the admittance to them. Numerous college understudies are keen on learning space framework designing, there are no legitimate courses instructed in colleges either. Besides, schools and undergrads have no clue about space-related ventures. Also, there are no missions, rivalries, workshops about space-related tasks, or exploration in our nation. Consequently, our underlying objective is to break the obstruction between open interest and space framework projects. Each understudy will have an unmistakable thought regarding satellite reproduction circuit, mechanical recreations just as electrical reenactments. The parts we utilized for making the satellite preparing unit are accessible in nearby markets, it will be simple for the students who need to execute the task. Our satellite preparing unit is trained to encounter the advancement cycle of a satellite in a brief timeframe and get the essential information on space innovation. We will monitor the individual changes of members to build up a more productive preparing pack for future work. We accept that these advancements will advance public and understudy interest in space designing and related fields.

\subsection{Future Goals}

As there was a pandemic going on around the world, the universities were closed down. As a result, we faced a lot of obstacles to complete this project. We had to work from our respective houses. After completing the simulation of our project, we will develop it with the components that we used in the simulation physically. Then we will try to interface all the payload sensors with the HC12 module so that the data can be sent wirelessly. Besides, we will try to give commands from the ground station wirelessly. Then, we will try to create the outer chassis. After developing the satellite kit, we will organize training sessions where the student will learn how the system is broken down into different subsystems, how to integrate those different subsystems into a fully functioning system, and how to test or debug it once it has been integrated. 


\section{References}

[1] Shamim Jahangir. (2019, 9th May). Philippines, Nepal set to rent Bangabandhu satellite. Available: https://www.daily-sun.com/post/391253/Philippines-Nepal-set-to-rent-Bangabandhusatellite

[2] Thales Alenia Space. (2020, 5 October). BANGABANDHU SATELLITE-1, THE PRIDE OF BANGLADESH!. Available:

https://www.thalesgroup.com/en/worldwide/space/news/bangabandhu-satellite-1-pride$\underline{\text { bangladesh }}$

[3] The Daily Star. (2017, June 04) Bangladesh's first nano-satellite Brac Onnesha launched into space. [Online]. Avaiable: https://www.thedailystar.net/country/bangladesh-first-nano-satellitebrac-university-brac-onnesha-launched-space-1415347

[4] M. Yamazaki and T. Zengo, "HEPTA-Sat Training Program: International Knowledge Transfer Using Hands-On Type CubeSat Education," Proceedings of the AIAA/USU Conference on Small Satellites, 2018.

[5] Oredsson M. (2010). Electrical Power System for the Cube-STAR Nanosatellite(Master's Thesis). University of Oslo, Oslo, Norway.

[6] Harford, T., 2019. The Cubesat Revolution Changing The Way We See The World. [online] BBC News. Available at: 〈https://www.bbc.com/news/business-48533945>

[7] M. Oredsson, "Electrical power system for the CubeSTAR nanosatellite," 2010.

[8] Cubesatshop.(2018,Feb.14). Eyesat classroom satellite [online].Available:https://www.cubesatshop.com/product/eyassat-classroom-satellite/

[9] George, A.,2018. The Sad, Sad Story of Laika, the Space Dog, and Her One-Way Trip into Orbit[online]. Available:https://www.smithsonianmag.com/smithsonian-institution/sad-storylaika-space-dog-and-her-one-way-trip-orbit-1-180968728/

[10] Tristancho J. (2010). Implementation of a Femto-satellite and a mini-launcher (Master's Dissertation). Universitat Politecnica de Catalunya, Barcelona, Spain.

[11] Dorn, L.T. Jr. 2009. NPS - SCAT: Electrical Power System, M.Sc. Thesis, Naval Postgraduate School, Monterey, CA, September 2009. 103 pages. 
[12]Ilbis, E. 2013. ESTCube-1 electrical power system - design, implementation and testing. Bachelor's Thesis. University of Tartu. Faculty of Science and Technology, Institute of Physics. 88 pages.

[13]Desai P. A. (2010).Design of On board Computers for a Nanosatellite(Master's Dissertation). Indian Institute of Technology, Kanpur, India.

[14] Bdspeedytech. (2017, Jan.10). ESP32-CAM WiFi + Bluetooth Camera Module [Online]. Available:

https://bdspeedytech.com/index.php?route=product $\% 2$ Fproduct\&product_id=3503\&search=esp $\% 2032 \% 20$ cam\&fbclid=IwAR1vEYjN2yhL8MnahsB8TL8-

Zj_NS8AWcS9OL8Zx0_JKLBKLrkSD3e_ycSQ

[15] Techshopbd. (2018, Oct.20). GPS Module GY-NEO-6M V2 [Online]. Available: https://www.techshopbd.com/product-categories/module/3028/gps-module-gy-neo-6m-v2techshop-bangladesh?fbclid=IwAR3XCE4qzOC_-EKV6q6whZMwN7aaPGsQwbmnHP2j5oek7h24QCaUHz-GBk

[16] Bdspeedytech. (2017, June.18). HC12 Wireless Transceiver Module [Online]. Available: https://bdspeedytech.com/index.php?route=product\%2Fproduct\&product $\mathrm{id}=2399 \&$ fbclid=IwA R08b7CWJ7bXC_JZICsimori9df5cdyk9tiYoV5pJR0a2ZR6FsDmnUxFhlk

[17]SAT-13.(1995). A Description of a Standard Small Satellite Ground Station for Use by WMO members. WMO/TD No. 660.

[18] Bdspeedytech. (2019, Feb.24). Arduino Nano R3 With Cable Official [Online]. Available: https://bdspeedytech.com/index.php?route=product\%2Fproduct\&product $\mathrm{id}=1265 \& \mathrm{fbclid}=\mathrm{IwA}$ $\underline{\text { R01OUqPw7RSy8en6DUTiRBI3tDughhmbuM9aOcSvIeHn7EtepmMQ5UsDXg }}$

[19] Dorn, L.T. Jr. 2009. NPS - SCAT: Electrical Power System, M.Sc. Thesis, Naval Postgraduate School, Monterey, CA, September 2009. 103 pages.

[20]Pierre Thirion, Test of prototypes of the EPS of student nanosatellite OUFTI-1, Internship Report, University of Liège, Liège, Belgium, 2009.

[21] Roboticsbd.(2018,Mar.26). 18650 Li-ion Rechargeable Battery [Online].Available: https://store.roboticsbd.com/tools-accessories/837-18650-li-ion-rechargeable-battery-robotics$\underline{\text { bangladesh.html }}$

[22]Storeroboticsbd (2018, Aug.12). Universal Dual Battery Charger for Li-ion Battery [Online]. Available: https://store.roboticsbd.com/components/763-aa-battery-holder-2s-robotics- 
bangladesh.html?fbclid=IwAR00knxoMAJhyAOQkNISgwEw4g_QdYe1QCnmEY69sou3FV2XBCQp2ddimc

[23] Bdspeedytech. (2018, Nov.13). DC-DC Buck and Boost Converter [Online]. Available: https://bdspeedytech.com/index.php?route=product $\% 2$ Fproduct\&product_id=2612\&fbclid=IwA R1OXYbkNNYCe69LofSd7DGLgbkEnTSHIQX4FOUbVeFlGDfO-C0_w-u55uM

[24] Bdspeedytech. (2018, Nov.13). DC-DC Buck and Boost Converter [Online]. Available: https://bdspeedytech.com/index.php?route=product\%2Fproduct\&product_id=2612\&fbclid=IwA R1OXYbkNNYCe69LofSd7DGLgbkEnTSHIQX4FOUbVeFlGDfO-C0_w-u55uM

[25] Bdspeedytech. (2018, Aug.). Voltage Sensor Module DC 0-25V [Online]. Available: https://bdspeedytech.com/index.php?route=product\%2Fproduct\&product_id=643\&fbclid=IwAR 1vEYjN2yhL8MnahsB8TL8-Zj_NS8AWcS9OL8Zx0_JKLBKLrkSD3e_ycSQ

[26] Bdspeedytech. (2017, Sep.5). Arduino Uno R3 With Cable Official [Online]. Available: https://bdspeedytech.com/index.php?route=product $\% 2$ Fproduct\&product $\mathrm{id}=1724 \& \mathrm{fbclid}=\mathrm{IwA}$ R3RsX_pHBMFf2nyP0CnkZZK7H-eqkd2dXT6jOQZixvAK6ChtPEgcxlp_nA

[27] Bdspeedytech. (2017, Jan.10). ESP32-CAM WiFi + Bluetooth Camera Module [Online]. Available:

https://bdspeedytech.com/index.php?route=product\%2Fproduct\&product_id=3503\&search=esp $\% 2032 \% 20$ cam\&fbclid=IwAR1vEYjN2yhL8MnahsB8TL8-

Zj_NS8AWcS9OL8Zx0_JKLBKLrkSD3e_ycSQ

[28] Bdspeedytech. (2018, Oct.25). SD Card Module [Online]. Available:

https://bdspeedytech.com/index.php?route=product/product\&product_id=3514

[29] Bdspeedytech. (2018, Oct.28). BMP280 Barometric Pressure Sensor [Online]. Available: https://bdspeedytech.com/index.php?route=product $\% 2$ Fproduct\&product $\_\mathrm{id}=259 \&$ search $=\mathrm{bmp} 2$ $\underline{\text { 80\&fbclid=IwAR3N3etbBBRg97VideR8GV6_GV7S6GdG4fsIUM9PXFvBVazJqxuL- }}$ $\underline{\text { WhoK5U }}$

[30] Components101. (2018, Sept.12).GY-BMP280 Module [Online]. Available: https://components101.com/sensors/gy-bmp280 module?fbclid=IwAR3OQSivYHiPb7jFPvhxNwlwzFAuYXJa1ykU9KzI0j5fEdw5cftfGiZ47Aw

[31] Techshopbd. (2018, Oct.20). GPS Module GY-NEO-6M V2 [Online]. Available: https://www.techshopbd.com/product-categories/module/3028/gps-module-gy-neo-6m-v2techshop-bangladesh?fbclid=IwAR3XCE4qzOC_-EKV6q6whZMwN7aaPGsQwbmnHP2j5oek7h24QCaUHz-GBk 
[32] Bdspeedytech.(2018,Nov.5). GY-9250 9 DOF IMU Sensor Module [Online]. Available: https://bdspeedytech.com/index.php?route=product\%2Fproduct\&product_id=251\&search=IMU \%20\&fbclid=IwAR3qhnchqfkI35YkvVnWrAnQ3ggt7r0v1NBdtzbcI2eb_N1YyrKRyIDfHTg

[33]D.Kerrouche, K., (2018). Design of a High Performance Electrical Power System for an Earth Observation Nano-Satellite. In The 2018 International Conference. Honolulu, HI, USA, September 2018. Beijing,China: Beihang University. 8. 


\section{Appendix}

\section{Code used for the Training Kit Payloads}

\section{BMP280 Sensor interfaced with HC12}

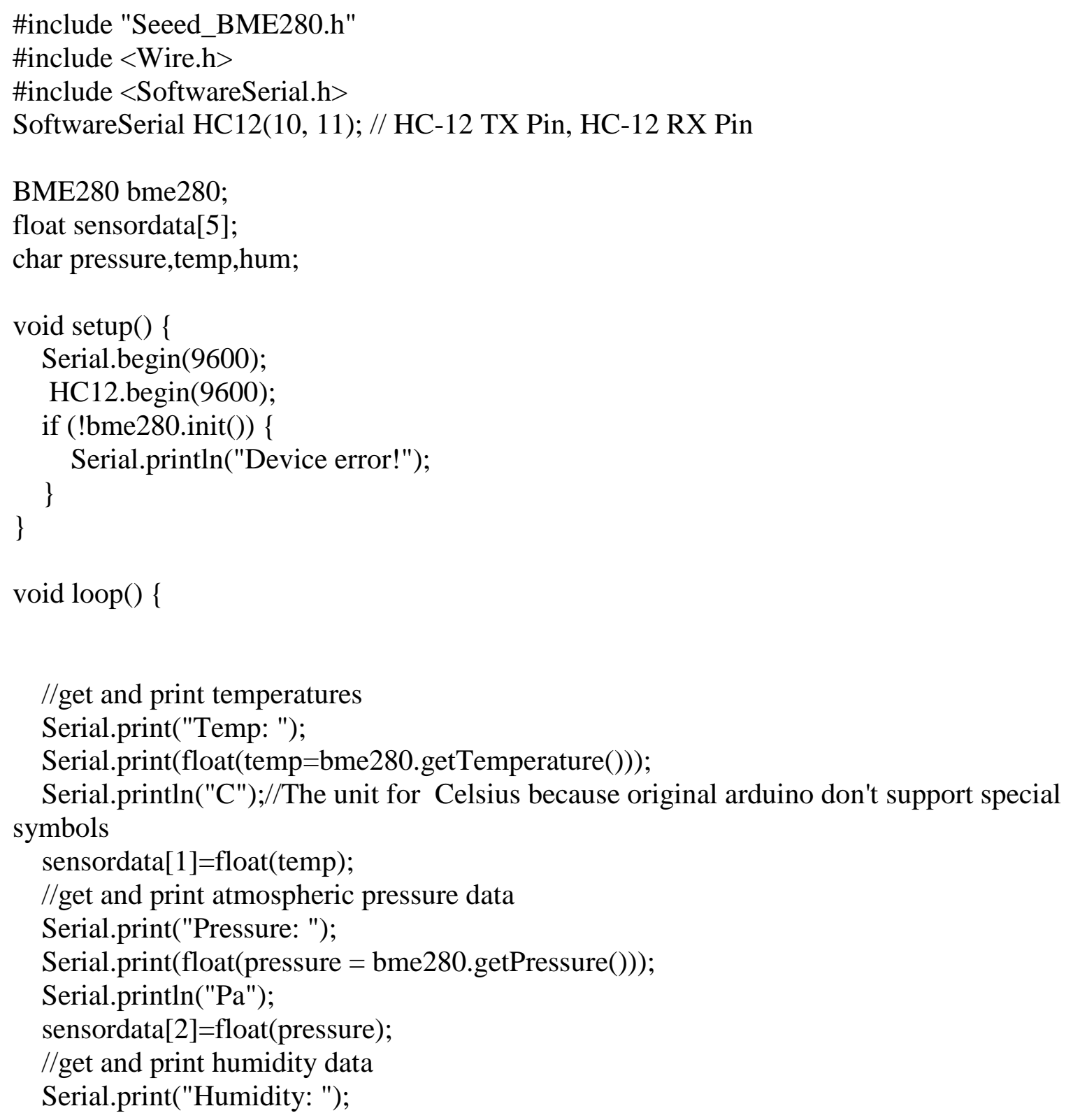




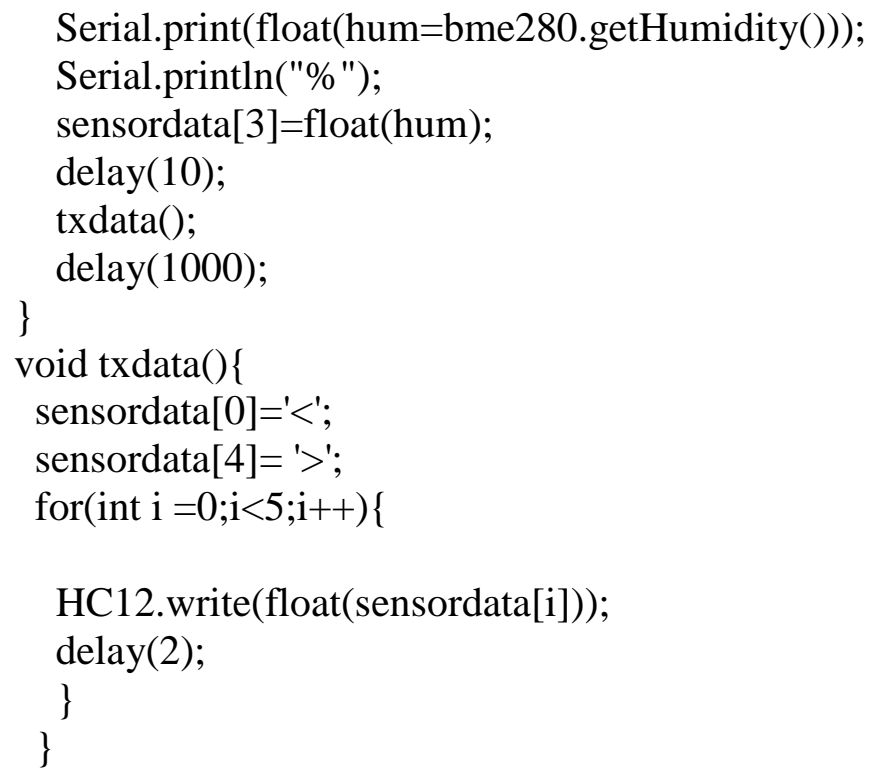

$\underline{\text { ESP32 CAM Sensor interfaced with SD card }}$

\#include "esp_camera.h"

\#include "Arduino.h"

\#include "FS.h"

// SD Card ESP32

\#include "SD_MMC.h" // SD Card ESP32

\#include "soc/soc.h" // Disable brownour problems

\#include "soc/rtc_cntl_reg.h" // Disable brownour problems

\#include "driver/rtc_io.h"

\#include <EEPROM.h> // read and write from flash memory

// define the number of bytes you want to access

\#define EEPROM_SIZE 1

// Pin definition for CAMERA_MODEL_AI_THINKER

\#define PWDN_GPIO_NUM 32

\#define RESET_GPIO_NUM -1

\#define XCLK_GPIO_NUM 0

\#define SIOD_GPIO_NUM 26

\#define SIOC_GPIO_NUM 27

\#define Y9_GPIO_NUM 35

\#define Y8_GPIO_NUM 34

\#define Y7_GPIO_NUM 39

\#define Y6_GPIO_NUM 36

\#define Y5_GPIO_NUM 21

\#define Y4_GPIO_NUM 19

\#define Y3_GPIO_NUM 18

\#define Y2_GPIO_NUM 5 


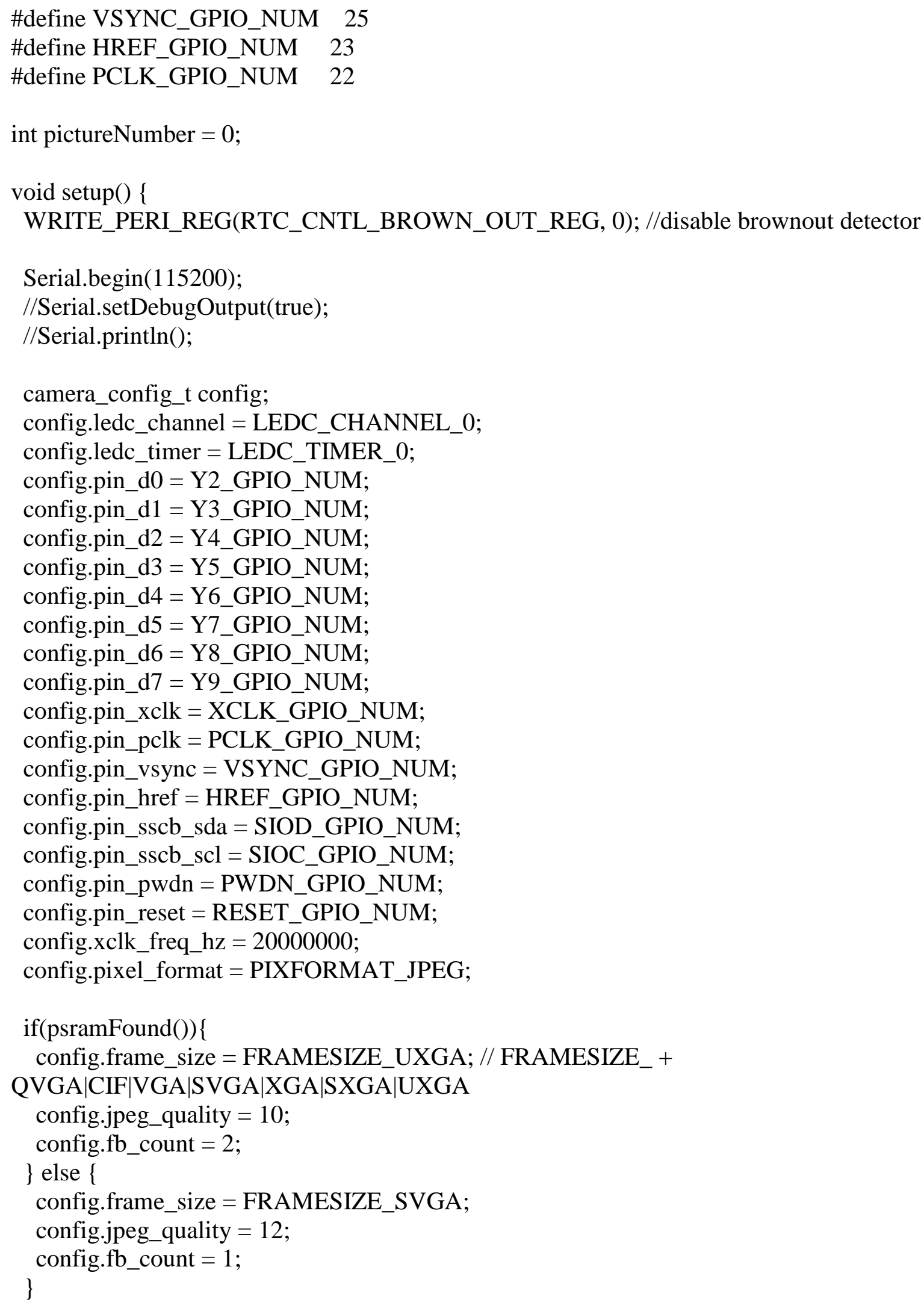




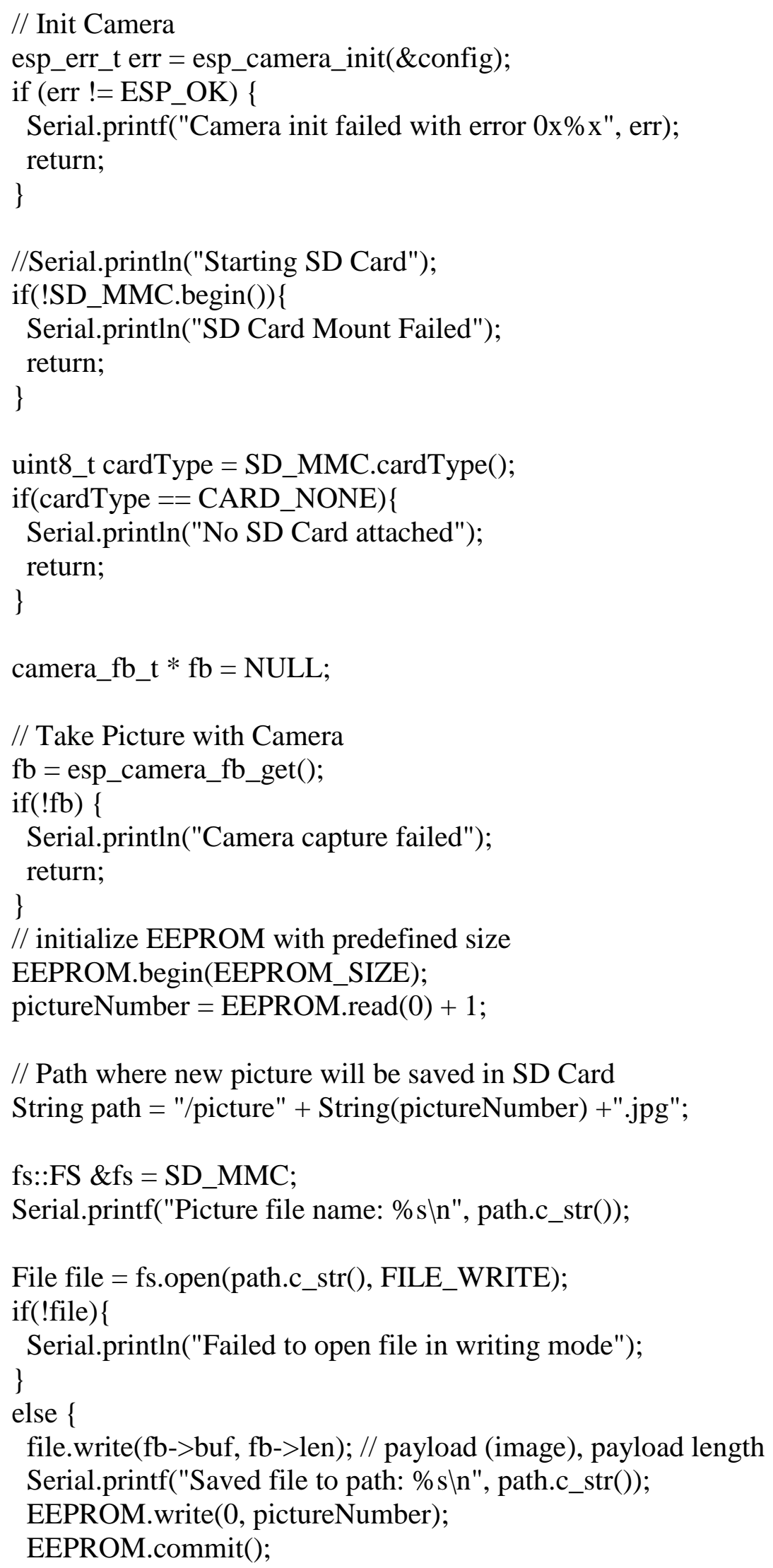




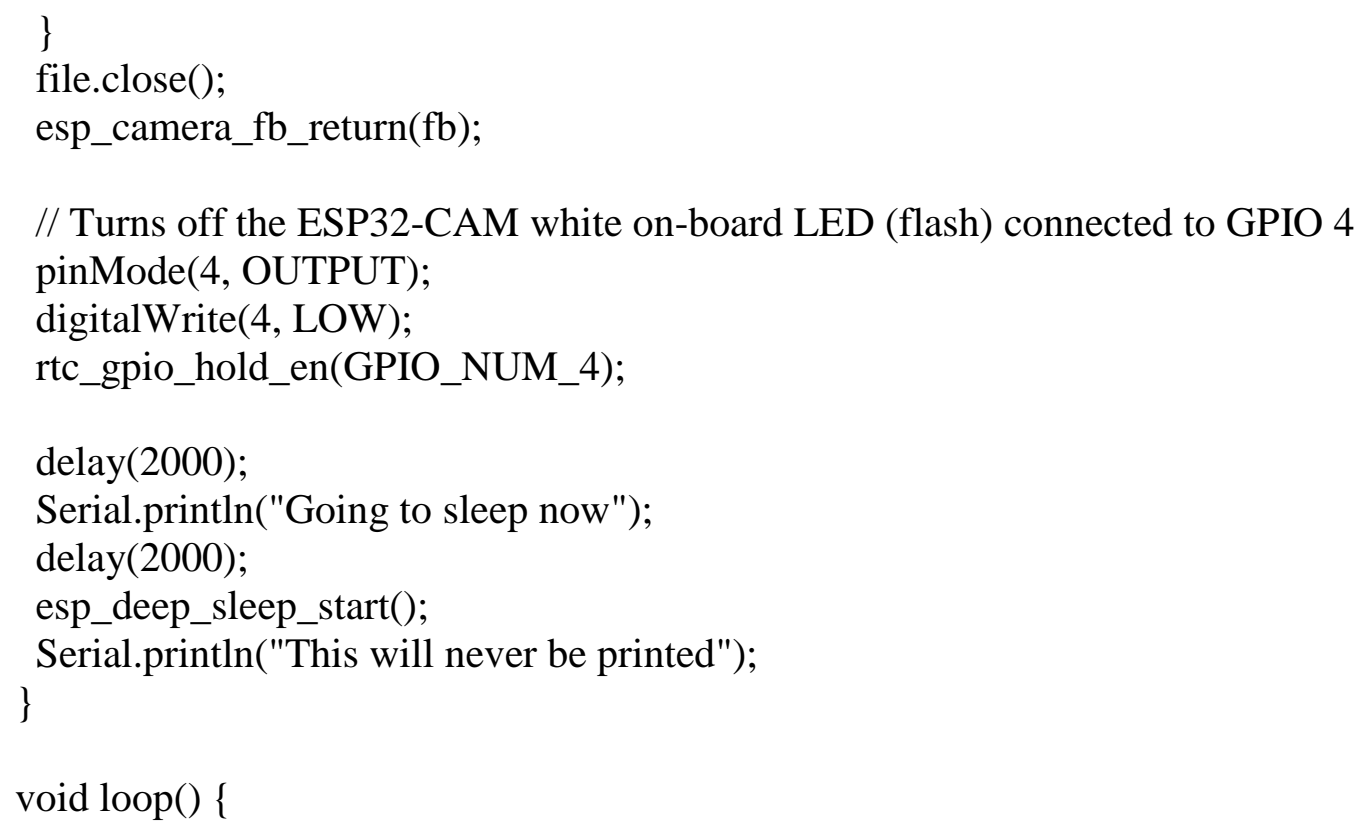

\section{$\underline{\text { IMU Sensor interfaced with } \mathrm{HC12}}$}

\#include <MPU9250_asukiaaa.h>

\#include <SoftwareSerial.h>

SoftwareSerial HC12(10, 11); // HC-12 TX Pin, HC-12 RX Pin

\#ifdef_ESP32_HAL_I2C_H_

\#define SDA_PIN 21

\#define SCL_PIN 22

\#endif

MPU9250_asukiaaa mySensor;

float sensordata[14];

float aX, aY, aZ, aSqrt, gX, gY, gZ, mDirection, mX, mY, mZ;

void $\operatorname{setup}()\{$

Serial.begin(9600);

HC12.begin(9600);

while(!Serial);

Serial.println("started"); 


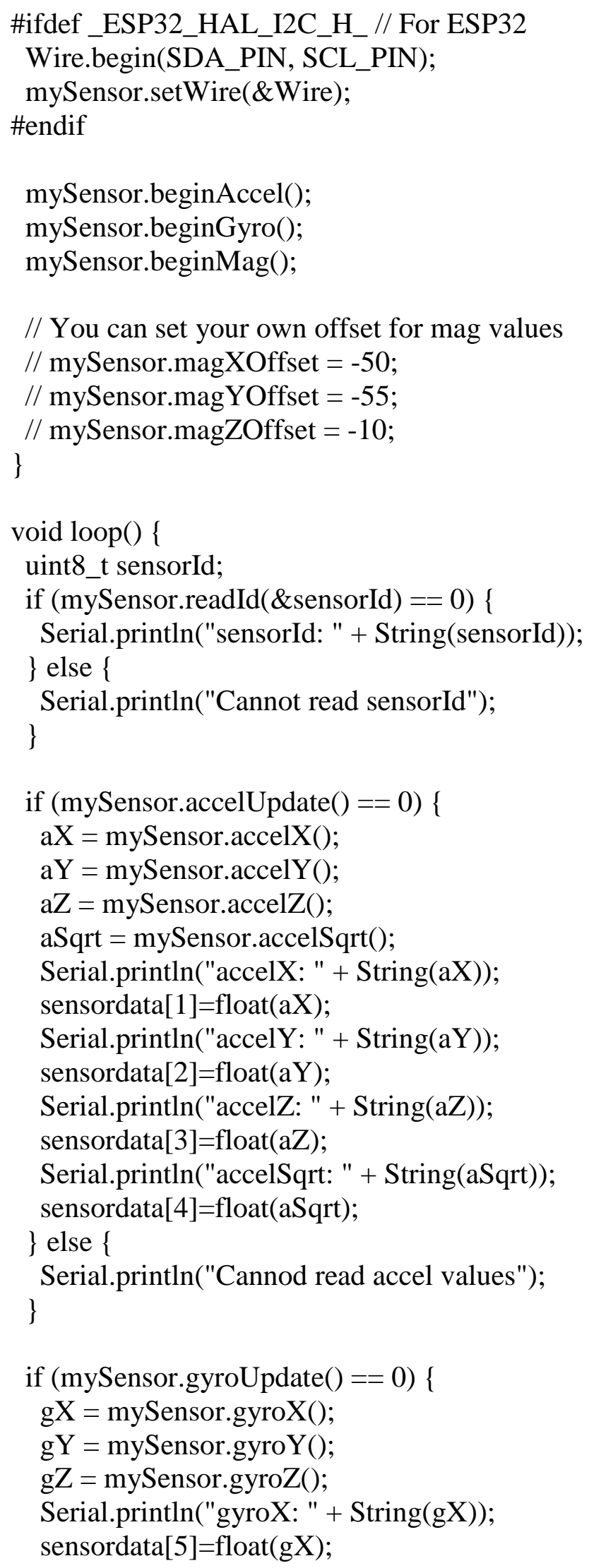




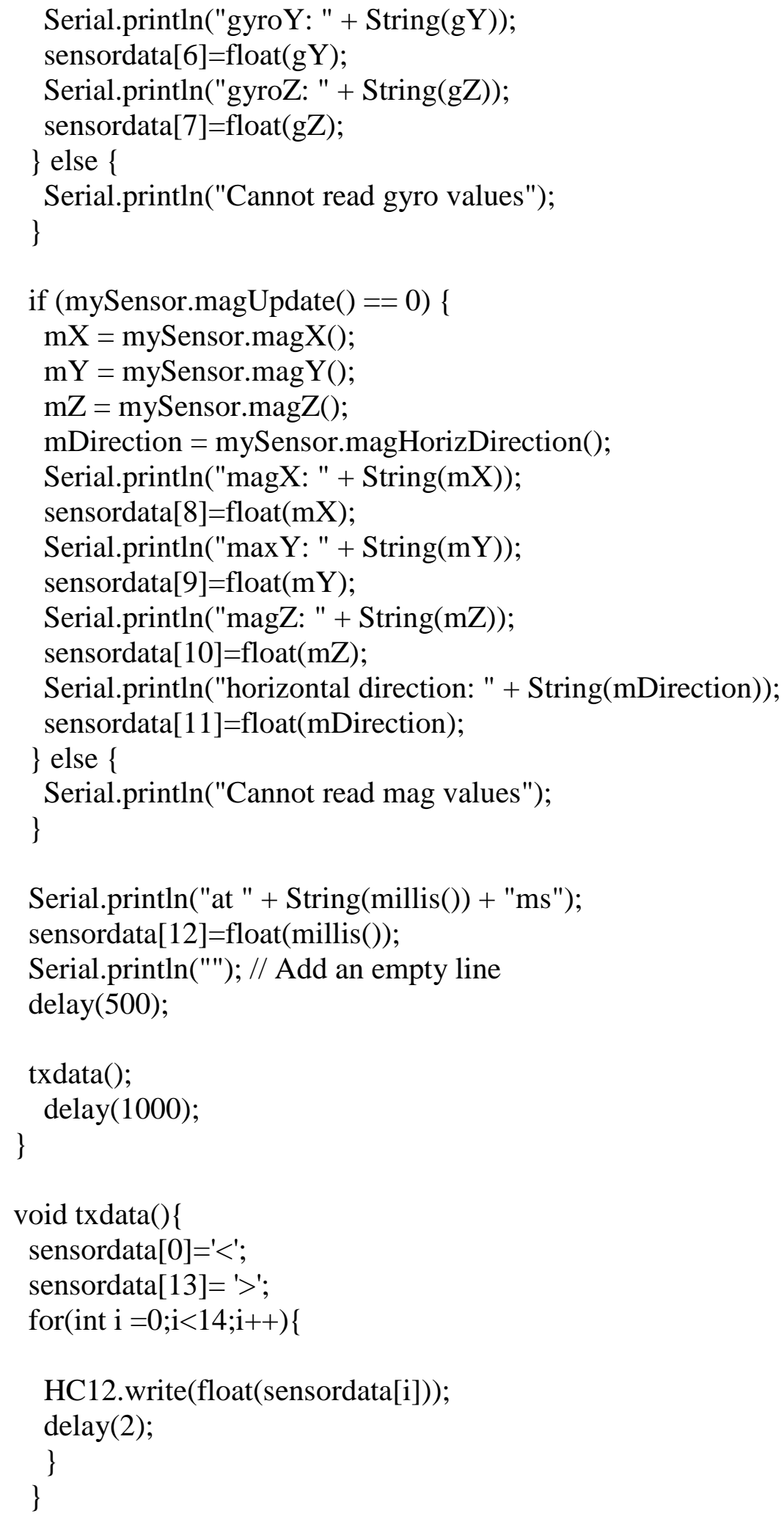

\section{GPS Sensor}


\#include <TinyGPS++.h>

\#include <SoftwareSerial.h>

static const int $\mathrm{RXPin}=4$, $\mathrm{TXPin}=3$;

static const uint32_t GPSBaud $=9600$;

// The TinyGPS++ object

TinyGPSPlus gps;

// The serial connection to the GPS device

SoftwareSerial ss(RXPin, TXPin);

void setup()

\{

Serial.begin(115200);

ss.begin(GPSBaud);

Serial.println(F("FullExample.ino"));

Serial.println(F("An extensive example of many interesting TinyGPS++ features"));

Serial.print(F("Testing TinyGPS++ library v. "));

Serial.println(TinyGPSPlus::libraryVersion());

Serial.println(F("by Mikal Hart"));

Serial.println();

Serial.println(F("Sats HDOP Latitude Longitude Fix Date Time Date Alt Course

Speed Card Distance Course Card Chars Sentences Checksum"));

Serial.println(F(" $\quad(\mathrm{deg}) \quad(\mathrm{deg}) \quad$ Age $\quad$ Age (m) --- from GPS ---- ---to London ---- RX RX Fail"));

Serial.println(F("$-)$;

\}

void loop()

\{

static const double LONDON_LAT $=51.508131$, LONDON_LON $=-0.128002$;

printInt(gps.satellites.value(), gps.satellites.isValid(), 5);

printFloat(gps.hdop.hdop(), gps.hdop.isValid(), 6, 1);

printFloat(gps.location.lat(), gps.location.isValid(), 11, 6);

printFloat(gps.location.lng(), gps.location.isValid(), 12, 6);

printInt(gps.location.age(), gps.location.is Valid(), 5);

printDateTime(gps.date, gps.time);

printFloat(gps.altitude.meters(), gps.altitude.isValid(), 7, 2);

printFloat(gps.course.deg(), gps.course.isValid(), 7, 2);

printFloat(gps.speed.kmph(), gps.speed.isValid(), 6, 2);

printStr(gps.course.isValid() ? TinyGPSPlus::cardinal(gps.course.deg()) : "*** ", 6); 


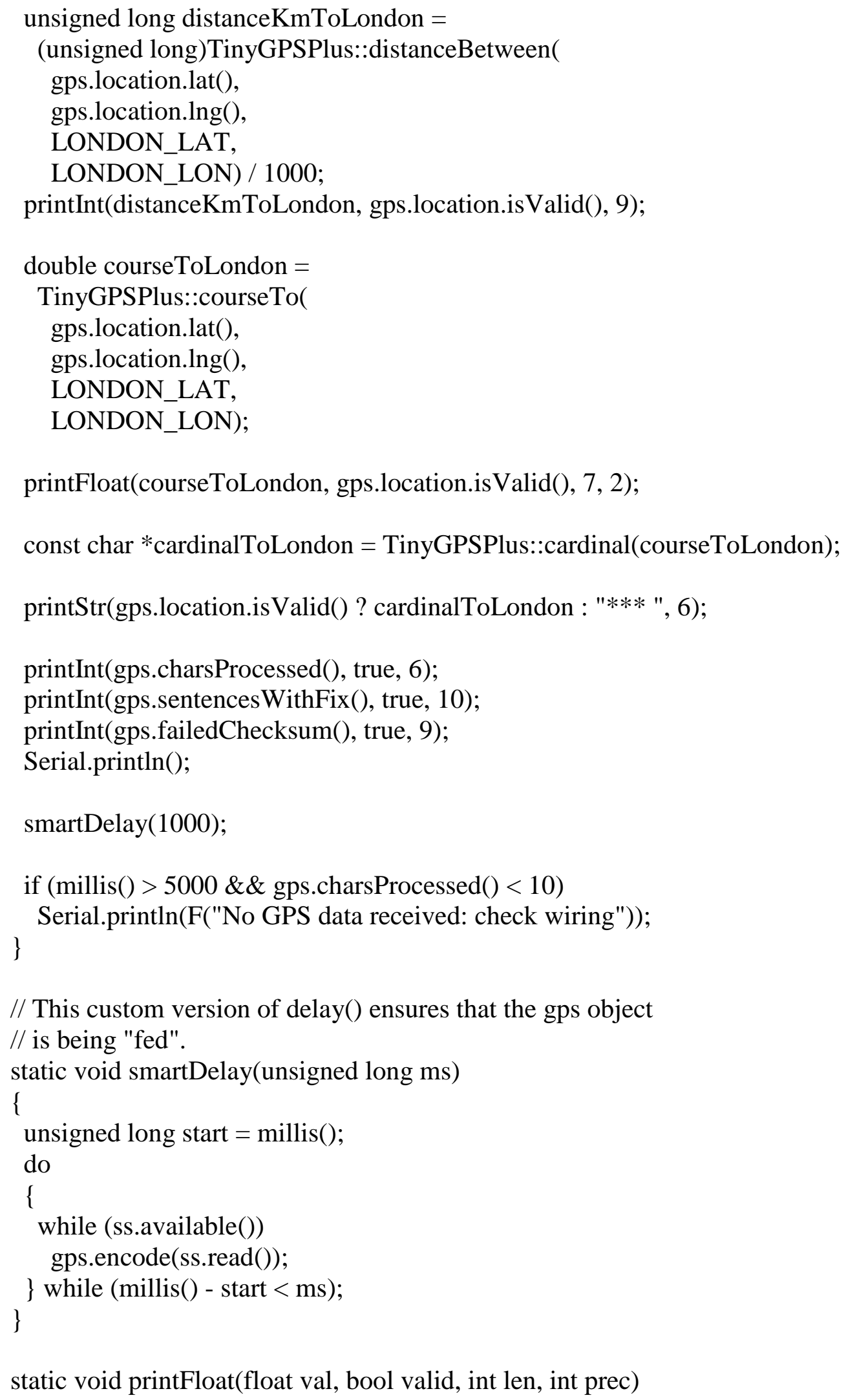




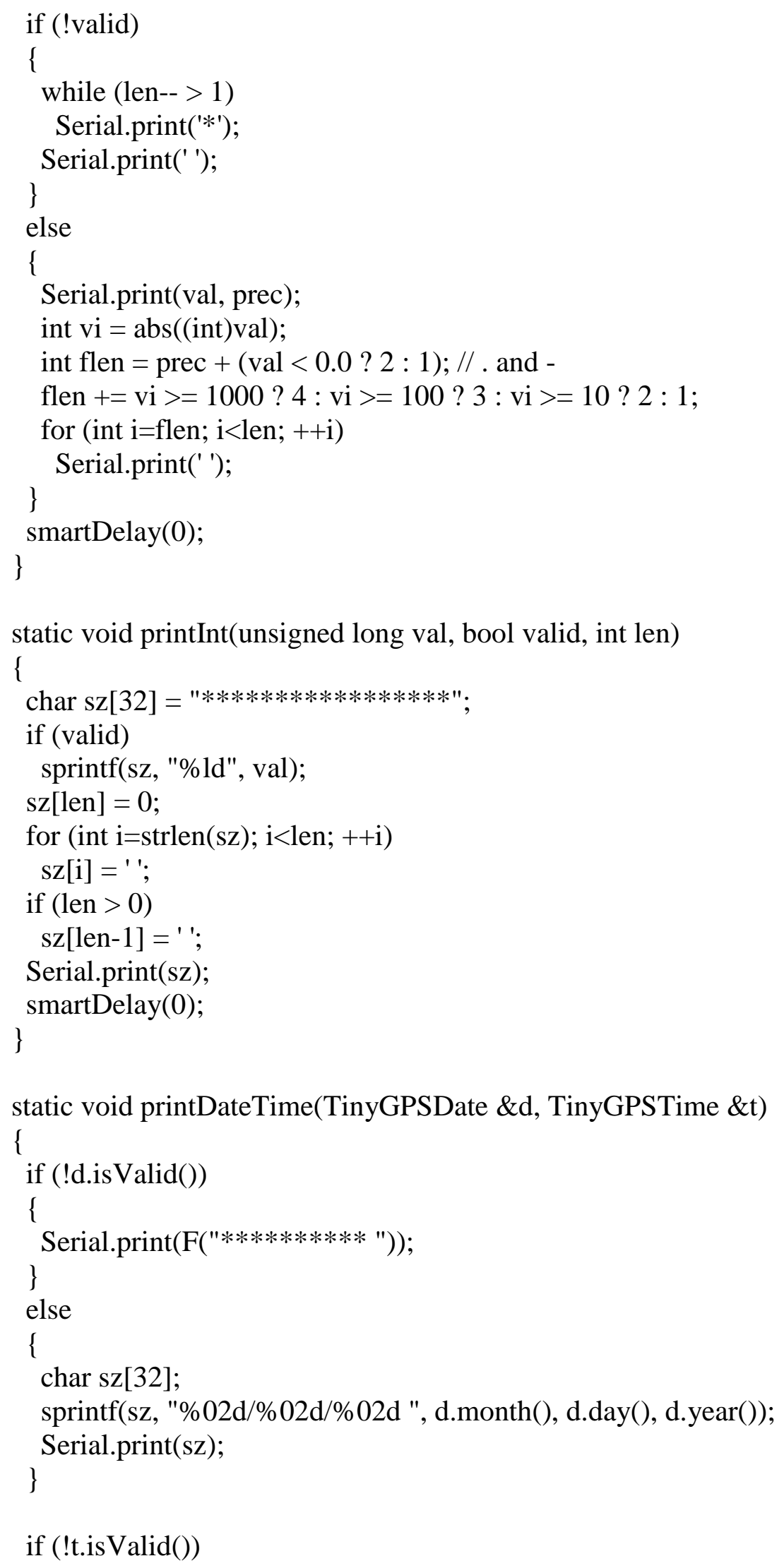




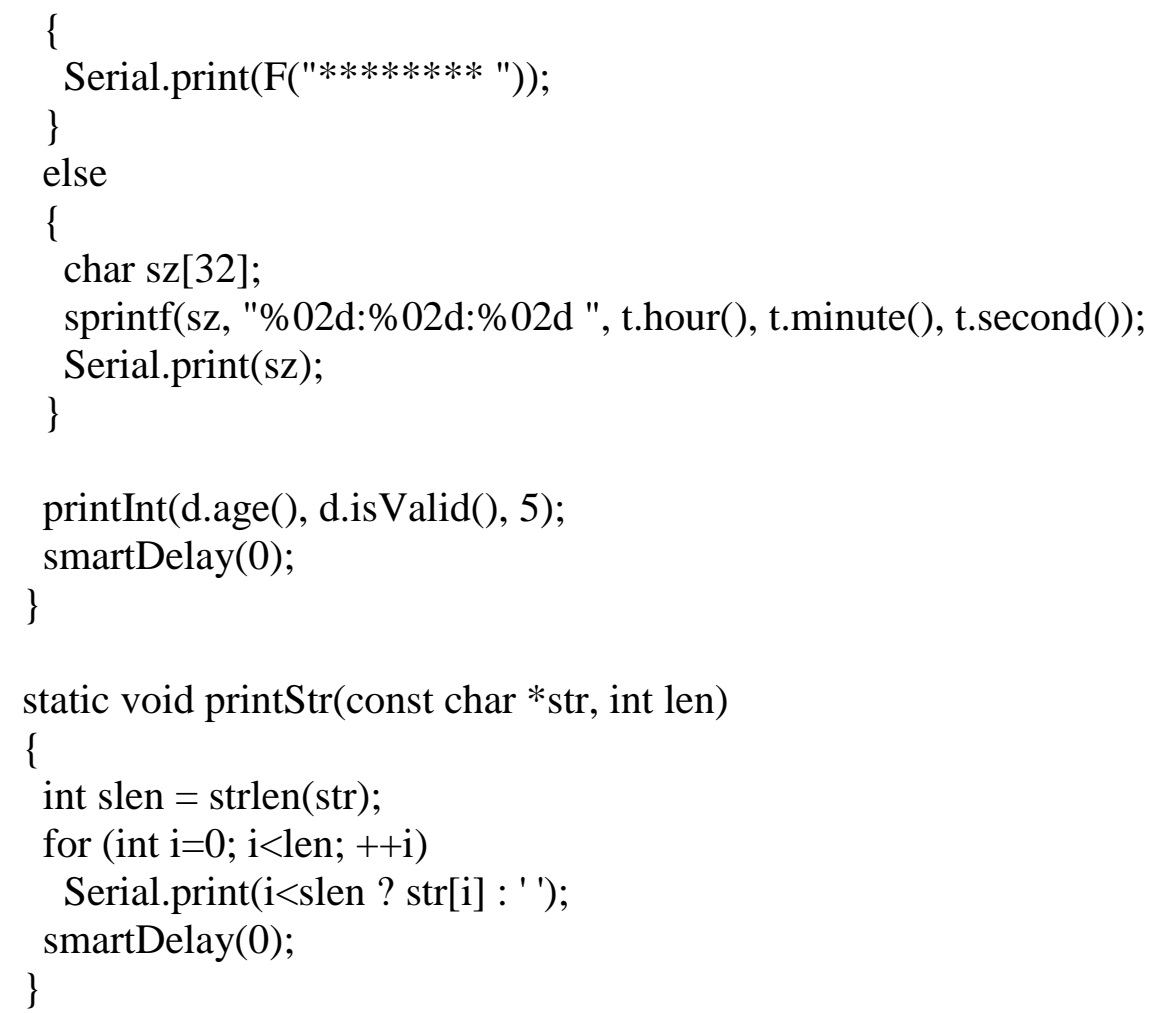

\section{Micro-SD card Module}

\#include $<$ SD.h $>$

\#include <SD.h>

\#include <SPI.h>

\#include <Wire.h>

\#include <Arduino.h>

\#include <BMx280I2C.h>

\#define I2C_ADDRESS 0x76

BMx280I2C bmx280(I2C_ADDRESS);

BMx280I2C mySensor; // create sensor object called mySensor while (!Serial);

Wire.begin();

//begin() checks the Interface, reads the sensor ID (to differentiate between BMP280 and BME280)

//and reads compensation parameters.

if $($ !bmx280.begin ()$)$

\{

Serial.println("begin() failed. check your BMx280 Interface and I2C Address."); while (1);

\} 


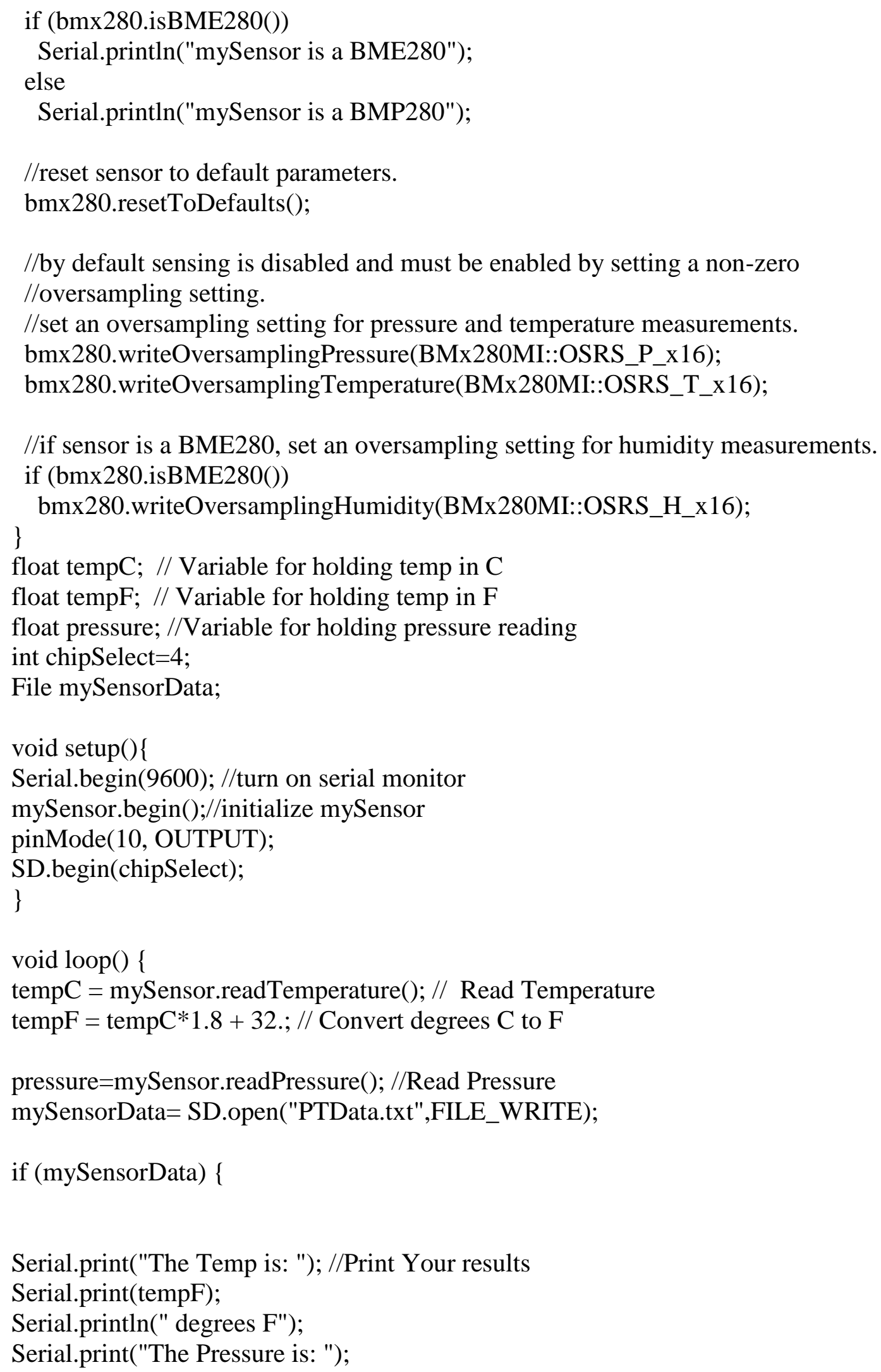




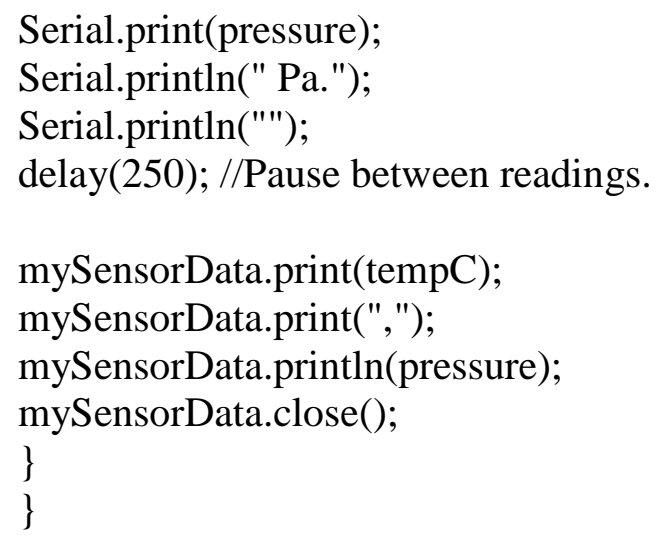

\section{$\underline{\text { Voltage Sensor }}$}

int offset $=35$;// set the correction offset value

void $\operatorname{setup}()\{$

Serial.begin(9600);

\}

void $\operatorname{loop}()\{$

int volt $=$ analogRead(A0);// read the input

double voltage $=\operatorname{map}($ volt $, 0,1023,0,2500)$ - offset;// map 0-1023 to 0-2500 and add correction offset

voltage / $=100 ; / /$ divide by 100 to get the decimal values

Serial.print("Voltage: ");

Serial.print(voltage);//print the voltge

Serial.println("V");

$\operatorname{delay}(500)$

\}

\section{Code used for the Ground Station}

\section{HC12 interfaced with BMP280 Sensor}

\#include <SoftwareSerial.h>

SoftwareSerial HC12(10, 11); // HC-12 TX Pin, HC-12 RX Pin

float rxInt[5];

void $\operatorname{setup}()\{$

Serial.begin(9600); // Serial port to computer 


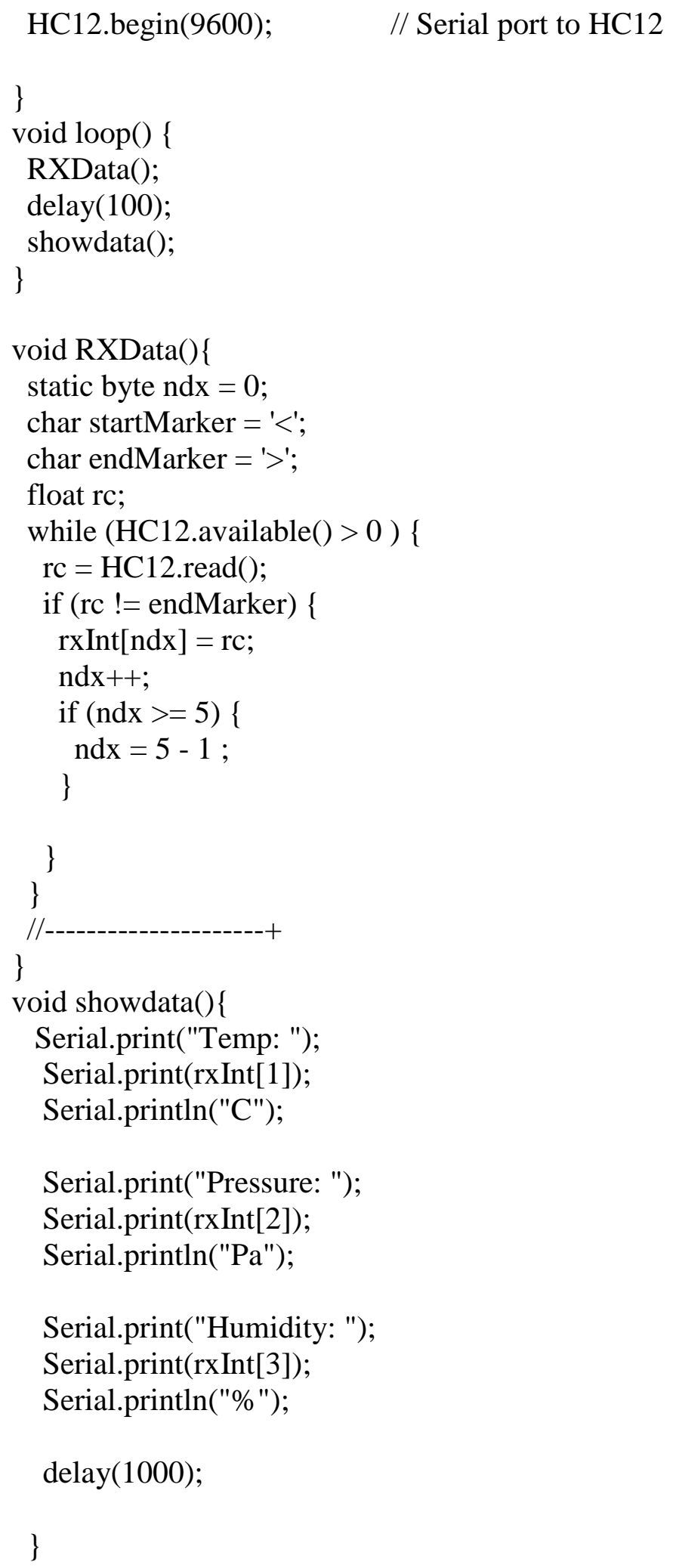

HC12 interfaced with IMU Sensor 
\#include <SoftwareSerial.h>

SoftwareSerial HC12(10, 11); // HC-12 TX Pin,

HC-12 RX Pin

float rxInt[14];

void $\operatorname{setup}()\{$

Serial.begin(9600); // Serial port to

computer

HC12.begin(9600); // Serial port to

$\mathrm{HC} 12$

\}

void $\operatorname{loop}()\{$

RXData();

delay(100);

showdata();

\}

void RXData()\{

static byte $n d x=0$;

char startMarker = '<';

char endMarker = '>';

char rc;

while (HC12.available()) \{

$\mathrm{rc}=\mathrm{HC} 12 \cdot \operatorname{read}()$;

if (rc != endMarker) \{

$\operatorname{rxInt}[\mathrm{ndx}]=\mathrm{rc}$;

$\mathrm{ndx}++$;

if (ndx > = 14) \{

$n d x=14-1$;

\}

\}

\}

//------------------------+

\}

void showdata( $)\{$

Serial.println("accelX: " +

String(float(rxInt[1])));

Serial.println("accelY: " +

String(float(rxInt[2])));

Serial.println("accelZ: " + String(float(rxInt[3])));

Serial.println("accelSqrt: " +

String(float(rxInt[4])));

Serial.println("gyroX: " +

String(float(rxInt[5]))); 
Serial.println("gyroY: " + String(float(rxInt[6])));

Serial.println("gyroZ: " + String(float(rxInt[7])));

Serial.println("magX: " + String(float(rxInt[8])));

Serial.println("magY: " + String(float(rxInt[9])));

Serial.println("magZ: " +

String(float(rxInt[10])));

// Serial.println("horizontal direction: " +

String(float(rxInt[11])));

//Serial.println("at " + String(float(rxInt[12]))

+ " ms");

//Serial.print);

Serial.println("');

delay(1000);

\} 